

TESIS DOCTORAL

Metodologías para la evaluación del contenido en polifenoles en tomate aplicadas al estudio del efecto del genotipo y de estrategias de cultivo respetuosas con el medio ambiente

\author{
Autor: \\ Raúl Martí Renau \\ Para optar al título de \\ DOCTOR EN CIENCIAS POR LA UNIVERSITAT JAUME I
}

\author{
Dirigida por: \\ Dr. Jaime Cebolla Cornejo \\ Dr. Salvador A. Roselló Ripollés
}

Castelló de la Plana, Enero de 2018 



\section{LOS DIRECTORES DE TESIS:}

Dr. Salvador A. Roselló Ripollés, Catedrático del Área de Producción vegetal del Departamento de Ciencias Agrarias y del Medio Natural de la Universitat Jaume I de Castelló, y Dr. Jaime Cebolla Cornejo, Profesor Contratado Doctor, en el Departamento de Biotecnología de la Universitat Politècnica de València.

\section{HACEN CONSTAR QUE:}

La presente memoria de Tesis Doctoral, presentada por Raúl Martí Renau, titulada "Metodologías para la evaluación del contenido en polifenoles en tomate aplicadas al estudio del efecto del genotipo y de estrategias de cultivo respetuosas con el medio ambiente" realizada en el Departamento de Ciencias Agrarias y del Medio Natural de la Universitat Jaume I de Castelló, reúne las condiciones necesarias para su defensa.

Fdo. Dr. Salvador Roselló Ripollés Fdo. Dr. Jaime Cebolla Cornejo 

"Cualquiera que hiciese nacer dos espigas de grano o dos briznas de hierba en el espacio de tierra en el que antes naciera una, merecía más de la Humanidad y hacía más esencial servicio a su país que toda la casta de políticos junta"

Los viajes de Gulliver

Jonathan Swift (1667 - 1745) 

El desarrollo de este trabajo ha sido en parte posible gracias a la financiación recibida por el Instituto Nacional de Investigación y Tecnología Agraria y Alimentaria (INIA), proyecto RTA2011-00062C04, al plan de promoción de la investigación de la Universitat Jaume I, proyecto P1-1B2011-41, a los proyectos CTQ2010-15335 y CTQ2014-52765-R del MINECO y a fondos FEDER.

La publicación en la revista Cancers ha sido posible gracias a la exención de costes ofrecida por su oficina editorial. 



\section{Agraïments}

És dificil poder agrair en unes poques línies per tot $i$ a tots els que d'una manera o un altra han contribuit a fer realitat esta tesi doctoral.

En primer lloc voldria donar les gràcies als meus directors de tesi, Jaime i Salva. Sobra destacar la seua qualitat humana així que em centraré en la part laboral. Vull donar-los les gràcies perquè ells em van acollir al seu grup d'investigació quan sols era "l'espia de la maleta" $i$ des de entonces, i a vegades amb molta paciència, m'han ensenyat el que és ser un investigador. Espere poder-los demostrarque ho han aconseguit.

En segon lloc, volia agrair als meus pares. No sols per educar-me sinó també per ser el millor exemple a seguir.

També vull donar les gràcies al meu germà. Estic segur que ben prompte seràs ja el pròxim químic de la família.

No em puc oblidar de la meua "família política": els meus sogres, cunyats, cunyades, nebots $i$ nebodes. A ells vull agrair-los que m'hagen acollit com un més a la familia.

Vull agrair a tots els companys amb els quals he compartit laboratoriestos anys. Especialment, volia agrair a Merche, Jaime, Ana, Josevi, Miguel, Eva i Rosa de la UPV, a Ginés i Alejandro de I'UJI i a tots els altres amb els que he pogut compartir este temps que en sou molts. D'especial ajuda han sigut Danii Davide, sense els quals no haguera pogut analitzar totes les mostres que apareixen en esta tesi.

També voldria donar-li les gràcies al Dr. José Manuel Herrero per donar-me l'oportunitat de poder passar un temps al seu laboratori.

No m'oblide de les meues companyes de carrera, que em van adoptarcom si jo fora "una més" i especial a les ja doctores Montse, Clara, Inés i María. Hem compartit molt durant estos an ys $i$ espere que mantinguem l'amistat per molts més.

Per acabar, però no per això menys important, voldria agrair a les meues xiques. Merche i Gabi, és molt difícil agrair-vos tot el que feu per mí, aixíque gràcies per tot. Vos vull molt.

A tots vosaltres gràcies de tot cor.

Raúl 

A Gabi 



\section{RESUMEN}

En Europa, en general, y en España, en particular, el futuro de la agricultura tiende a una especialización creciente hacia productos de calidad, satisfaciendo las demandas de los consumidores. Una tendencia por otro lado inevitable, ya que sería imposible competir con otras zonas de cultivo con menores costes laborales y exigencias medioambien tal es. En este contexto, ya existen nichos de mercado en los que los consumidores han demostrado estar dispuestos a pagar un diferencial de precio por una producción respetuosa con el medio ambiente y sin residuos o por un mayor valor funcional, es decir por la acumulación de compuestos bioactivos que ayudan a prevenir el desarrollo de enfermedades. En tomate ya se dispone de variedades alto licopeno, que aumentan el contenido en carotenoides y en algunos casos de vitamina $\mathrm{C}$ y polifenoles, pero con efectos colaterales negativos basados en una importante pérdida de producción. Es necesario por tanto proseguir cribando material para identificar nuevas fuentes de mayor acumulación en compuestos funcionales, a la vez que es necesario identificar las condiciones que influyen en una mayor acumulación de compuestos funcionales. Esto es especialmente necesario en el caso de los polifenoles, sobre los que se dispone de menor información. Pero la consecución de estos objetivos se ve limitada por la necesidad de contar con técnicas analíticas que permitan cribar grandes cantidades de material en el menor tiempo y con el menor coste posible.

En este contexto, la presente tesis se ha dirigido a desarrollar metodologías de cuantificación conjunta de polifenoles en tomate y su aplicación al estudio de los efectos del genotipo, las condiciones climatológicas y las técnicas de cultivo respetuosas con el ambiente sobre la acumulación de polifenoles.

Respecto a la cuantificación de los polifenoles, en primer lugar se ha abordado la optimización de las condiciones de extracción, ya que estas suponen un paso limitante. En este sentido, se propone un protocolo de extracción asistida por ultrasonidos durante 177 minutos que utiliza una mezcla metanol/agua (48:52 v/v), desaconsejándose el uso de liofilización por los efectos negativos que puede tener en la extracción de naringenina.

A continuación, se han desarrollado dos métodos alternativos de cuantificación de los polifenoles, empleando el análisis de superficies de respuesta y funciones de deseabilidad. El primero se basa en la cromatografía liquida de alta resolución (HPLC) de fase reversa y es aplicable a varios tipos de frutas y hortalizas. Utiliza columnas de núcleo fundido junto con un gradiente segmentado y permite separar en menos de 18 minutos hasta 17 flavonoides y ácidos fenólicos con una buena capacidad de resolución. La reproducibilidad, en términos de área de pico (RSD $<2.9 \%$ ) y de tiempo de retención (RSD $<0.2 \%$ ), los límites de detección (entre 3 y $44 \mu \mathrm{g} \mathrm{kg}^{-1}$ peso fresco), asícomo las recuperaciones de los polifenoles observados en muestras de tomate (76-108\%) mejoran los descritos para métodos anteriores. Por otro lado, se ha desarrollado un método basado en cromatografía micelar electrocinética (MEKC) específico para tomate, que consigue una separación eficaz de los principales polifenoles en estas muestras (ácidos caféico, $p$-cumárico, trans-ferúlico y clorogénico, y los flavonoides kaempferol, quercetina, myricetina, naringenina y rutina) en 20 minutos. Se utiliza un tam pón de carrera con $11.3 \mathrm{mM}$ de borax y $11.2 \mathrm{mM}$ de SDS ajustado a $\mathrm{pH} 8.5$, siendo las condiciones de separación $15^{\circ} \mathrm{C}$ y $25 \mathrm{kV}$. Las repetibilidades (entre 0.1 y $4.4 \%$ para el área de pico y entre 0.2 y $4.0 \%$ para los tiempos de retención), límites de detección (entre 0.8 y $3.8 \mathrm{mg} \mathrm{kg}^{-1}$ peso 
fresco) y recuperaciones obtenidas en muestras de tomate (entre 77 y $106 \%$ ) son similares a las obtenidas por otros autores trabajando en condiciones similares o con técnicas más sensibles. Siendo una de las principales ventajas de este método su simplicidad y el escaso consumo de reactivos.

Una vez se disponía de la metodología adecuada, ésta se ha aplicado al estudio del efecto de I genotipo, empleando cultivares convencionales y alto licopeno, las condiciones ambientales de cultivo, estudiando el comportamiento en Navarra y Extremadura durante dos años y de estrategias de cultivo respetuosas con el ambiente, cultivo ecológico y riego deficitario controlado, sobre la acumulación de polifenoles y otros compuestos funcionales. De los resultados se desprende que el genotipo es el factor más determinante en la conse cución de los mayores niveles de polifenoles. Respecto a la estrategia de cultivo, es difícil dar una respuesta inequívoca sobre las bondades de las estrategias de cultivo respetuosas con el medioambiente sobre la acumulación de polifenoles. No parece que el cultivo ecológico realmente suponga una mejora en los niveles de acumulación de polifenoles. Es cierto que este sistema de cultivo aumentó significativamente el contenido de ácido cafe ico, pe ro tuvo efectos negativos sobre el contenido de ácido ferúlico y naringenina. No obstante, existe una importante interacción genotipo $x$ ambiente que condiciona los resultados. Tambié $n$ hay que tener en cuenta que, aunque el cultivo ecológico no tenga un efecto importante sobre la acumulación de polifenoles y de compuestos bioactivos en general, lo cierto es que puede contribuir a obtener un producto de al ta calidad global, por lo que para aquellos consumidores y productores que valoren la calidad medioambiental y la ausencia de trazas de fitosanitarios puede ser una opción, siempre que se combine con los genotipos más adecuad os y las zonas de producción más favorables. Por otro lado, parece claro que la selección de la zona de cultivo también puede ser importante, ya que las condiciones más suaves como las de Navarra parecen maximizar el potencial de los genotipos. El riego deficitario controlado, es decir, aplicado a partir de la fase de cuajado, también tuvo un efecto limitado sobre la acu mulación de polifenoles y otros compuestos funcionales. Concretamente, aumentó la acumulación de los ácidos hidroxicinámicos cl orogénico y ferúlico, el flavonol rutina y el ácido L-ascórbico, pero no afectó a la acumulación del resto de polifenoles ni de carotenoides. Al igual que pasa con la modalidad de cultivo, el uso de riego deficitario controlado también se observó una importante interacción genotipo $\mathrm{x}$ ambiente, altamente influenciado por el año y la zona de cultivo. No obstante, en zonas como Navarra, con condiciones algo más benignas, un riego deficitario controlado suave $\left(100-75 \% \mathrm{ET}_{\mathrm{c}}\right)$ podría aumentar todavía más los niveles de polifenoles, conllevando un importante ahorro de un recurso tan valioso como escaso: el agua. 


\section{ABSTRACT}

In Europe, in general, and in Spain, in particular, the future of agriculture tends to a growing specialization towards quality products, satisfying consumers' demands. This trend is otherwise inevitable, since it is impossible to compete with other growing areas with lower labour costs and environmental restrictions. In this context, there are already some of the markets in which consumers are willing to pay a price premium for a production that is respectful with the environment and free of phytosanitary traces or with a higher functional value, that is, accumulating bioactive compounds that help to prevent the development of diseases. In tomato, high lycopene varieties are available, which increase the content of carotenoids and in some cases of vitamin $\mathrm{C}$ and polyphenols, but with negative side effects based in a loss of production. It is therefore necessary to continue screening material to identify new sources of variation with higher accumulation of functional compounds, while it is necessary to identify the conditions that influence a greater accumulation of these functional compounds. This is especially necessary in the case of polyphenols, as, in this case, less information is available. However, the achievement of these objectives depends on the necessity to have analytical techniques that allow to screen large quantities of material in the shortest time and at the lowest cost possible.

In this context, the present thesis has been directed to develop methodologies of joint quantification of polyphenols in tomato and its application to the study of ge notype effects, weather conditions and environmentally-friendly cultivation techniques on the accumulation of polyphenols.

Regarding the quantification of polyphenols, the optimization of extraction conditions has been firstly addressed, since these suppose a limiting step. In this sense, an ultrasound assisted extraction for 177 minutes using a methanol/water mixture (48:52 v/v), dissuading the use of lyophilization because of the negative effects it can have on naringenin extraction.

Next, two alternative methods of quantifying polyphenols have been developed, using response surface analysis and desirability functions. The first one is based on reverse phase high performance liquid chromatography (HPLC) and is applicable to several types of fruits and vegetables. It uses fused core columns with a segmented gradient and allows the se paration, in less than 18 minutes, of up to 17 flavonoids and phenolic acids with a good resolution capacity. The reproducibility, in terms of peak area (RSD $<2.9 \%$ ) and retention time (RSD $<0.2 \%$ ), the limits of detection (between 3 and $44 \mu \mathrm{kg}^{-1}$ fresh weight), as well as the recoveries of the polyphenols observed in tomato samples (76-108\%) improve those described for previous methods. On the other hand, a method based on electrokinetic micellar chromatography (MEKC) specific for tomato has been developed, which achieves an effective separation of the main polyphenols in these samples (caffeic, $p$-coumaric, trans-ferulic and chlorogenicacids, and the flavonoids kaempferol, quercetin, myricetin, naringenin and rutin) in 20 minutes. A running buffer made of $11.3 \mathrm{mM}$ borax and $11.2 \mathrm{mM}$ SDS adjusted to $\mathrm{pH} 8.5$ was used, with the separation conditions $15^{\circ} \mathrm{C}$ and $25 \mathrm{kV}$. Repeatabilities (between 0.1 and $4.4 \%$ for the peak area, and between 0.2 and $4.0 \%$ for retention times), detection limits (between 0.8 and $3.8 \mathrm{mg} \mathrm{kg}^{-1}$ fresh weight) and recoveries in tomato samples (among $77 \%$ and $106 \%)$ are similar to the previous works. One of the main advantages of this method its simplicity and low consumption of reagents. 
Once the appropriate methodology was available, it has been applied to the study of the effect of the genotype, using conventional and high lycopene cultivars, the environmental conditions of cultivation, studying the performance in Navarra and Extremadura for two years, and cultivation strategies respectful with the environment, organicfarming and controlle d de ficit irrigation, on the accumulation of polyphenols and other functional compounds. From the results, it is clear that the genotype is the most determining factor in achieving the highest levels of polyphenols. Regarding the cultivation strategy, it is difficult to give an unambigu ous answer about the benefits of environmentally-friendly farming strategies on the accumulation of polyphenols. It does not seem that organic farming really results in an improvement in the levels of polyphenols accumulation. It is true that this culture system significantly increased the content of caffeic acid, but had negative effects on the content of ferulic acid and naringenin. However, there is an important genotype $x$ environment interaction that conditions the results. It should also be considered that, although organic farming does not have an important effect on the accumulation of polyphenols and bioactive compounds in general, it is certain that it can contribute to obtaining a product of high global quality. For those consumers and producers that value the environmental quality and the absence of phytosanitary traces this can be an option, as long as it is combined with the most suitable genotypes and the most favourable production areas. On the other hand, it seems clear that the selection of the cultivation area can al so be important, since milder conditions, like those of Navarra, seem to maximize the potential of the genotypes. Controlled deficit irrigation, applied after fruit set phase, also had a limited effect on the accumulation of polyphenols and other functional compounds. Specifically, the accumulation of the hydroxycinnamic acids chlorogenicand ferulic, the flavonol rutin and L-ascorbic acid increased, but did not affect the accumulation of other polyphenols or carotenoids. As in the case of organicfarming, the use of controlled deficit irrigation also showed an important genotype $x$ environment interaction, highly influenced by the year and the cultivation area. In areas such as Navarra, with somewhat more benign conditions, a soft controlled deficit irrigation (100-75\% $\mathrm{ET}_{\mathrm{c}}$ ) could increase polyphenol levels even more, leading to an important saving of a resource as valuable as scarce: water. 


\section{RESUM}

A Europa, en general, i a Espanya, en particular, el futur de l'agricultura tendeix cap a una especial ització creixent cap a productes de qualitat, satisfent les demandes dels consumid ors. Una tendència per un altra banda inevitable, ja que seria impossible competir amb altres zones de cultiu amb menors costos laborals i exigències mediambientals. En aquest context, ja existeixen nínxols de mercat en els que els consumidors han demostrat estar disposats a pagar un diferencial de preu per una producció respectuosa amb el medi ambient i sense residus o per un major valor funcional, és a dir per la acumulació de compostos bioactius que ajuden en la prevenció de malalties. En tomata ja es disposen de varietats alt licopè, que augmenten el contingut en carotenoids $\mathrm{i}$ en alguns casos de vitamina $\mathrm{C}$ i polifenols, però amb efectes colaterals negatius basats en la important pèrdua de producció. És necessari per tant prosseguir garbellant material per a identificar noves fonts de major acumulació de compostos funcionals. Açò és especialment necessari en el cas dels polifenols, sobre els que es disposa de menys informació. Però la consecució d'aquest objectius es veu limitada per la ne ce ssitat de comptar amb tècniques analítiques que permeten garbellar grans quantitats de material en el menor tempsiamb el menor cost possible.

En aquest context, la present tesi s'ha dirigit a desenvolupar metodologies de quantificació conjunta de polifenols en tomata i la seua aplicació al estudi dels efectes del genotip, les condicions climatològiques i les tècniques de cultiu respectuoses amb el medi ambient sobre I'acumulació de polifenols.

Respecte a la quantificació dels polifenols, en primer lloc s'ha abordat l'optimització de les condicions d'extracció, ja que aquestes suposen un pas limitant. En aquest sentit, es proposa un protocol d'extracció assistida per ultrasons durant 177 minuts que utilitza una mescla metanol/aigua (48:52 v/v), desaconsellant-sel'ús de la liofilització pels efecte s negatius que pot tenir en l'extracció de naringenina.

A continuació, s'han desenvolupat dos mètodes alternatius de quantificació del polifenols, emprant l'anàlisi de superfícies de resposta i funcions de desitjabilitat. El primer es base en la cromatografia líquida d'alta resolució (HPLC) de fase reversa i es aplicable a diversos tipus de fruites i hortalisses. Utilitza columnes de nucli fos junt amb un gradient segmentat i permet separar en menys de 18 minuts fins 17 flavonoids i àcids fenòlics amb una bona capacitat de resolució. La reproduïbilitat, en termes d'àrea de pic $(\mathrm{RSD}<2.9 \%)$ i de temps de retenció (RSD $<0.2 \%$ ), els límits de detecció (entre 3 i $44 \mu \mathrm{g} \mathrm{kg}^{-1}$ pes fresc), així com les recuperacions dels polifenols observats en mostres de tomata (76-108\%) milloren els descrits per a mètodes anteriors. Per un altra banda, s'ha desenvolupat un mètode basat en cromatografia micel·lar electrocinètica (MEKC) específic per a tomata, que aconsegueix una separació eficaç dels principals polifenols en aquestes mostres (àcids cafèic, $p$-coumàric, trans-ferúlic i clorogè nic, $i$ els flavonoids kaempferol, quercetina, myricetina, naringenina i rutina) en 20 minuts. S'utilitza un tampó de carreta amb $11.3 \mathrm{mM}$ de bòrax i $11.2 \mathrm{mM}$ de SDS ajustat a $\mathrm{pH} 8.5$, sent les condicions de separació $15^{\circ} \mathrm{C}$ i $25 \mathrm{kV}$. Les reproduïbilitats (entre 0.1 i $4.4 \%$ pera l'àrea de pic i entre 0.2 i $4.0 \%$ perals temps de retenció), límits de detecció (entre $0.8 \mathrm{i} 3.8 \mathrm{mg} \mathrm{kg}^{-1}$ pesfresc) i recuperacions obtingudes en mostres de tomata (entre 77 i 106\%) són similars a les obtingudes per al tres autors treballant en condicions similars o amb tècniques més sensibles. 
Sent una dels principals avantatges d'aquest mètode la seua simplicitat i l'escàs consum de reactius.

Una volta es disposava de la metodologia adequada, aquesta s'ha aplicat a l'estudi de l' e fecte del genotip, emprant cultivars convencionals i alt licopè, les condicions ambientals de cultiu, estudiant el comportament en Navarra i Extremadura durant dos anys i d'estratègies de cul tiu respectuoses amb el medi ambient, cultiu ecològic i reg deficitari controlat, sobre l'acumulació de polifenols i altres compostos funcionals. Dels resultats es desprèn que el genotip és el factor més determinat en la consecució dels majors nivells de polifenols. Respecte a l'estratègia de cultiu, és difícil donar una resposta inequívoca sobre les bondats de les estratègies de cultiu respectuoses amb el medi ambient sobre l'acumulació de polife nols. No pareix que el cultiu ecològic realment supose una millora en els nivells d'acumulació de polifenols. És cert que aquest sistema de cultiu va augmentar significativament el contingut d'àcid cafèic, però va tindre efectes negatius sobre el contingut d'àcid ferúlic i naringenina. No obstant això, existeix una important interacció genotip x ambient que condiciona els resultats. També hi ha que tenir en compte que, encara que el cultiu ecològic no tinga un efecte important sobre l'acumulació de polifenols i de compostos bioactius en general, el que és ben cert és que pot contribuir a obtenir un producte d'alta qualitat global, pel que per aquells consumidors i productors que valoren la qualitat mediambiental i l'absència de traces de fitosanitaris pot ser una opció, sempre que es combine amb els genotips més adequats i les zones de producció més favorables. Per un altra banda, pareix clar que la selecció de la zona de cultiu també pot ser important, ja que les condicions més suaus com les de Navarra pare ixen maximitzar el potencial dels genotips. El reg deficitari controlat, és a dir, aplicat a partir de la fase de quallat, també va obtindré un efecte limitat sobre l'acumulació de polifen ols i altres compostos funcionals. Concretament, va augmentar l'acumulació dels àcids hidroxicinàmics clorogènic i ferúlic, el flavonol rutina il'àcid L-ascòrbic, però no va afectar a l'acumulació de la resta de polifenols ni de carotenoids. Igual que passa amb la modalitat de cultiu, l'ús de reg deficitari controlat també es va observar una important interacció genotip x ambient, altament influenciat per l'any i la zona de cultiu. No obstant això, en zones com Navarra, amb condicions un poc més benignes, un reg deficitari controlat suau $\left(100-75 \% \mathrm{ET}_{\mathrm{c}}\right)$ podria augmentar encara més els nivells de polifenols, el que comporta un important estalvi d'un recurs tan valuós com escàs:I'aigua. 
ÍNDICE

I. INTRODUCCIÓN GENERAL____ 1

1. El mercado de calidad en horticultura: caso concreto del tomate __ 3

2. Importancia económica del tomate___ 6

3. Consumo de tomate y potencial como fuente de compuestos funcionales ___ 9

4. Los carotenoides: compuestos funcionales clave en el tomate _ 10

4.1. Acumulación de carotenoides en tomate _ 10

4.2. Mejora genética del contenido en carotenoides __ 11

5. Los polifenoles: compuestos funcionales de "última generación"___ 13

5.1. Acumulación de polifenoles en to mate __ 13

5.2. Mejora genética del contenido en polifenoles _ 14

6. Efecto del ambiente en la acumulación de carotenoides y polifenoles___ 17

6.1. Radiación solar _ 17

6.2. Temperatura__ 18

6.3. Abonado 19

6.4. Sistema de cultivo — 20

6.5. Riego_ 22

7. La cuantificación de polifenoles: una limitación en la evaluación de estrategias de mejora de su contenido __ 23

8. Bibliografía 30

II. OBJETIVOS_ 43

III. EL TOMATE COMO FUENTE DE CAROTENOIDES Y POLIFENOLES EN LA PREVENCIÓN DEL CÁNCER___ 47

1. Introduction $\longrightarrow 52$

2. Accumulation of Bioactive Compounds in Tomato

3. Chemoprotective Characteristics of Tomato Bioactive Compounds _ 56

3.1. Carotenoids

3.2. Polyphenols

4. Breeding Strategies for the Improvement of Carotenoid and Polyphenol Content in

Tomato__ 61

4.1. Carotenoids 61

4.2. Polyphenols 66

4.3. Joint Accumulation of Carotenoids and Polyphenols__ 73

5. Conclusions _ 74

References__ 75

IV. DETERMINACIÓN RÁPIDA Y SIMULTÁNEA DE LOS PRINCIPALES POLIFENOLES EN FRUTAS Y HORTALIZAS MEDIANTE CROMATOGRAFÍA LÍQUIDA DE FASE REVERSA USANDO UNA COLUMNA DE NÚCLEO FUNDIDO 
V. DETERMINACIÓN SIMULTÁNEA DE LOS PRINCIPALESÁCIDOS FENÓLICOSY FLAVONOIDES EN TOMATE POR CROMATOGRAFÍA MICELAR ELECTROCINÉTICA (MEKC)

VI. CONTENIDO EN POLIFENOLES Y ÁCIDO L-ASCÓRBICO EN TOMATE INFLUENCIADO POR GENOTIPOS DE ALTO LICOPENO Y AGRICULTURA ECOLÓGICA EN DIFERENTES AMBIENTES 99

VII. INFLUENCIA DEL DÉFICIT DE RIEGO CONTROLADO SOBRE LA CALIDAD FUNCIONAL DEL TOMATE 105

VIII. DISCUSIÓN GENERAL 111

IX. CONCLUSIONES 119

X. ANEXO 125 


\section{INTRODUCCIÓN GENERAL}




\section{El mercado de calidad en horticultura: caso concreto del tomate}

Los consumidores, especialmente en países desarrollados están cada vez más preocupados por la calidad y seguridad de los alimentos y por la forma en que han sido producidos (Dias y Ryder, 2011). Los reguladores no obvian estas tendencias, y en este sentido, la re forma de la Política Agraria Común (PAC) se ha orientado a modernizar del sector agrícola para hacerlo más competitivo, con métodos de producción respetuosos con el medio ambiente, contribuyendo al manteniendo la diversidad en las "formas" de la agricultura y conservando productos que satisfagan el requerimiento de calidad de los consumidores (Lacroix, 2004).

La mejora genética vegetal no escapa a esta tendencia. La elevada competitividad en el sector ha propiciado que, si bien la productividad siga manteniéndose como objetivo prioritario, aparezcan líneas de trabajo orientadas a satisfacer la demanda de calidad del consumidor.

En este sector, el concepto de calidad no es fácil de definirya que por un lado hace referencia a muchos parámetros externos e internos y por otro la valoración de los mismos depende de la subjetividad del individuo que los evalúa. Por ejemplo, en el caso del tomate, se podría hablar de una calidad organoléptica externa definida por el tamaño, uniformidad, coloración y ausencia de defectos estéticos. Así, la mayoría de consumidores verían como bu eno un fruto de tamaño medio redondo de coloración roja e intensa y sin cicatrices. Sin embargo, un consumidor de productos locales/tradicionales podría preferir frutos de mayor tamaño, típicamente tradicionales, con hombros verdes, gradación de color rojo-anaranjada y valoraría positivamente la falta de uniformidad considerando el atractivo de la diversidad. Incluso, la presencia de defectos estéticos que ni siquiera son apreciados por los consumidores ecológicos (Thompson y Kidwell, 1998), podría utilizarse por parte de un consumidor de productos tradicionales como una marca de identificación, ya que no suelen estar presentes en las variedades modernas (Cortés-Olmos et al., 2015).

La calidad organoléptica interna tampoco escapa de estas características de complejidad y subjetividad. De nuevo queda defina por múltiples parámetros que afectan a la textura (carnosidad, harinosidad, jugosidad...), el gusto (dulzor, acidez, intensidad de sabor, sabor umami...) y el aroma (floral, afrutado, verde, intenso...), que también se perciben positiva o negativamente, o a los que se da mayor o menor peso en la valoración global, en función del consumidor que los considera (Causse et al., 2010; Pagliarini et al., 2011; Oltman et al., 2014).

En el contexto de la mejora genética vegetal, y siguiendo con el caso del tomate, la calidad como objetivo en la producción, comercialización y en el desarrollo de nuevas varie dades ha chocado tradicionalmente con otros objetivos considerados prioritarios. Así, durante las décadas de 1970 y 1980, los aspectos visuales eran los que condicionaban las decisiones de compra de los consumidores ya que se tomaban como indicativos de la calidad esperada del producto (Eastwood et al., 1986). Este hecho contribuyó a que atributos externos como el color, la forma o la uniformidad de los frutos, junto con una elevada productividad, se convirtieran en los principales criterios de selección aplicados a los programas de mejora de la época. Además, la facilidad para cuantificar y por tanto seleccionar estos aspectos externos propició su inclusión en los programas de mejora. Lamentablemente, los esfuerzos de dicad os al incremento de la calidad externa acarrearon consigo indirectamente que otros atributos importantes como el sabor o el aroma, asociados con la calidad organoléptica interna, se dejasen de lado y fuesen perdiendo peso en las nuevas variedades desarrolladas. Por ejemplo, 
la demanda por parte de los comercializadores de frutos de un color rojo uniforme, que resultasen atractivos a la vista para el consumidor, se consiguió mediante el uso del gen uniform ripening, $u$. Este gen es responsable de la desaparición de los hombros verdes en los frutos de tomate (Fig. 1), dando como resultado unos frutos de color rojo uniforme en su estado maduro (Kinzer et al., 1990). Sin embargo, la desaparición de los hombros verdes, donde se concentran una gran cantidad de cloroplastos, conllevó una reducción de la capacidad fotosintética y de la acumulación de azúcares, resultando en una pérdi da de sabor (Powell et al., 2012).

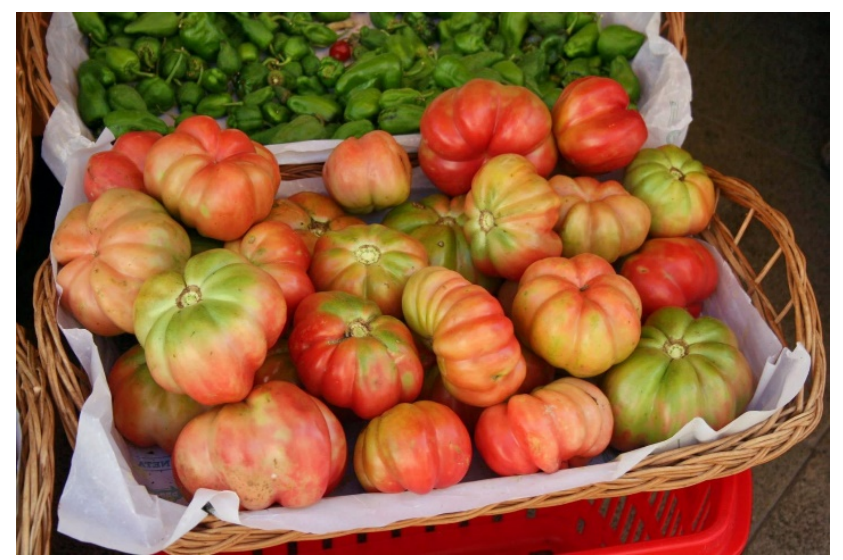

Fig. 1. Coloración verde en los hombros característica de algunas variedades tradicionales. Cortesía de J.V. Valcárcel.

En el mismo sentido, el peso de la opinión de los comercializadores en la priorización de objetivos de mejora impuso la rápida extensión de genes larga vida ripening inhibitor, rin, y non-ripening, nor, que afectan a la biosíntesis del etileno y retrasan la maduración alargando la vida post-cosecha, la firmeza y la resistencia al manipulado (revisado por Paran y van der Knaap, 2007), pero que interfieren en la síntesis de aromas y empeoran el sabor de los materiales que los Ilevan (McGlasson et al., 1987; Chalukova y Manuehyan, 1991).

Por otro lado, otra de las causas de la pérdida de sabor en las variedades modernas de tomate podría deberse a la fijación de alelos no deseados en genes involucrados en la ruta de biosíntesis de aromas, como consecuencia de no considerar el aroma como criterio de selección en programas de mejora (Tieman et al., 2017).

Por todo ello, en la década de 1990 se hicieron comunes las quejas por parte de los consumidores acerca de la falta de sabor del tomate (Bruhn et al., 1991). Al mismo tiempo, un segmento de consumidores apostó por reconocer el mejor sabor de las variedades tradicionales desarrollándose mercados de calidad, cuyos consumidores estaban dispuestos a pagar un mayor precio por un producto con un mejor sabor (Cebolla-Cornejo et al., 2007). El desarrollo de estos mercados, sin duda ha contribuido a poner la calidad en el punto de mira de los mejoradores, ya que en un mercado tan competitivo como el europeo es necesario destacar frente a la competencia y una forma clara de hacerlo es a través de la mejora de la calidad organoléptica.

Pero desde inicios del siglo XXI, los consumidores ya no solo se conforman con alimentos con una buena calidad organoléptica, sino que además también han empezado a valorar los beneficios de los compuestos bioactivos de los alimentos en la prevención de enfermedad es y 
el mantenimiento de una buena salud en general. Se trataría de una nueva perspectiva de la calidad: la calidad funcional, que va más allá de la calidad nutricional al considerar no sól o los nutrientes, sino cualquier compuesto que pueda ser beneficioso para la salud (SunWaterhouse, 2011).

Tradicionalmente la calidad funcional y su éxito como estrategia de comercialización se ha asociado al sector lácteo, gracias al éxito conseguido por una gran variedad de productos enriquecidos (Menrad, 2003). Sin embargo, existe un gran potencial en el sector de frutas y hortalizas. Sin duda, el éxito y reconocimiento por parte de los consumidores de los beneficios de una dieta sana como la dieta mediterránea tradicional puedeayudar al éxito de la calidad funcional entre los productos agrícolas. Esta dieta se caracteriza por un alto consumo de alimentos de origen vegetal, una ingesta moderada de carnes rojas y un elevado cons umo de aceite de oliva y conlleva una menor incidencia de cáncer (Trichopolou et al., 2000), enfermedades cardiovasculares y otras enfermedades crónicas relacionadas con la dieta (Willett et al., 1995).

El éxito de dietas como la mediterránea, ha favorecido que los compuestos funcionales presentes en frutas y hortalizas (como por ejemplo el licopeno) se hayan incluso comercializado en forma de suplementos alimenticios. No obstante, existen evidencias científicas de que su ingesta directa en el producto natural tiene mayores beneficios para la salud que su ingesta en forma de suplementos alimenticios (Vattem et al., 2005). Así, en el caso concreto del tomate, se comprobó que su consumo como tal es más efectivo que la ingesta de suplementos de licopeno en la prevención y desarrollo del cáncer de próstata en ratas (Boileau et al., 2003).

Por tanto, más allá de suplementos, una dieta rica en hortalizas sería la mejor forma de aprovechar los beneficios de compuestos funcionales (Liu, 2013), ya que los efectos sinérgicos de estos compuestos funcionales con otros presentes en frutas y hortalizas podrían incrementar los beneficios para la salud (Wang et al., 2003; Liu, 2004). Sirva como ejemplo el caso de los carotenoides y los lípidos. Dado que la mayoría de las frutas y verduras ricas en carotenoides son bajas en lípidos, se aconseja promover su ingesta conjunta con lípi dos para promover su absorción. Por ejemplo, se ha demostrado que la adición de aguacate a las ensaladas mejora la absorción de los carotenoides del tomate (Unlu et al., 2005); o en el caso del tomate cocinado, el uso de aceite de oliva durante la cocción es capaz de potenciar la absorción de licopeno (Fielding et al., 2005).

Más allá de promover dietas saludables como la Mediterránea, el gran auge de la calidad funcional como estrategia de comercialización en el sector agroalimentario (Bigliardi y Galati, 2013) establece el marco idóneo para potenciar el valor funcional de frutas y hortalizas. Se trataría, por tanto, de ofrecer al consumidor productos que maximicen el contenido en compuestos funcionales, bien a través de su potencial genético mediante la mejora genética vegetal, bien proveyendo las condiciones agronómicas que maximicen su acumulación. Dentro de esta estrategia, el tomate cobra gran importancia, ya que, sin ser especialmente rico en compuestos nutricionales o funcionales, su elevado consumo lo sitúa como una importante fuente de este tipo de compuestos y su gran valor económico favorece que las inversiones de desarrollo requeridas puedan recuperarse mediante una comercialización adecuada. 


\section{Importancia económica del tomate}

El tomate (Solanum lycopersicum L.) es una de las especies hortícolas más importantes a nivel mundial. En el año 2014 se obtuvo una producción de más de 170 millones de toneladas, representando el $15 \%$ de la producción mundial de hortalizas, sólo por detrás de la patata (FAO, 2017).

El principal productor mundial de tomate es China, con una producción que superó los 52 millones de toneladas en el año 2014. España ocupa una destacada octava posición en el ranking mundial de productores, con cerca de 5 millones de toneladas, tras la ya me ncionada China, India, Estados Unidos, Turquía, Egipto, Irán e Italia (Tabla 1).

La Unión Europea es responsable de un 10\% de la producción mundial de tomate según datos de 2014, concentrándose principalmente en los países del sur: Italia, España, Portugal y Gre cia (Fig. 2), entre los que suman el 77\% de dicha producción. Cabe destacar el importante papel de los dos principal es productores europeos, Italia y España, que concentran un 62\% del total de la producción de tomate de la UE (FAO, 2017).

Tabla 1. Principales productores mundiales de tomate (datos 2014; FAO 2017).

\begin{tabular}{llc}
\hline Ranking & Area & Producción $(\boldsymbol{t})$ \\
\hline 1 & China continental & 52.586 .860 \\
2 & India & 18.735 .910 \\
3 & Estados Unidos de América & 14.516 .060 \\
4 & Turquía & 11.850 .000 \\
5 & Egipto & 8.288 .043 \\
6 & República Islámica del Irán & 5.973 .275 \\
7 & Italia & 5.624 .245 \\
8 & España & 4.888 .880 \\
9 & Brasil & 4.302 .777 \\
10 & México & 3.536 .305 \\
11 & Federación de Rusia & 2.819 .193 \\
12 & Uzbekistán & 2.285 .801 \\
13 & Ucrania & 2.147 .880 \\
14 & Nigeria & 2.143 .500 \\
15 & Portugal & 1.399 .535 \\
16 & Túnez & 1.250 .000 \\
17 & Marruecos & 1.230 .953 \\
18 & Argelia & 1.065 .609 \\
19 & Grecia & 1.032 .220 \\
20 & Indonesia & 916.001 \\
21 & Chile & 909.025 \\
22 & Países Bajos & 900.000 \\
\hline & &
\end{tabular}




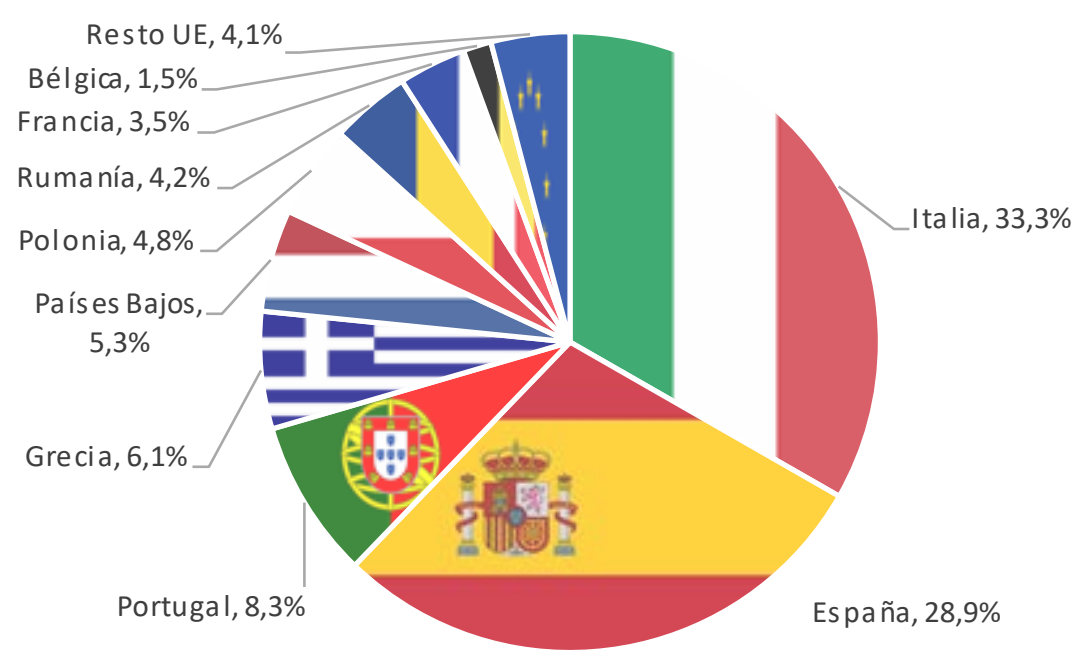

Fig. 2. Producción de tomate (\%) en la Unión Europea (datos 2014; FAO, 2017).

También dentro del sector hortícola español el tomate es de gran importancia, ya que es la principal hortal iza producida en España (excluyendo la patata), con un 34.5\% sobre el total de la producción, seguida de lejos por cebollas (9.6\%), pimientos verdes (8.0\%), lechuga y achicoria (6.4\%), sandías (6.1\%) y otras en menores porcentajes según datos de 2014 (Fig. 3).

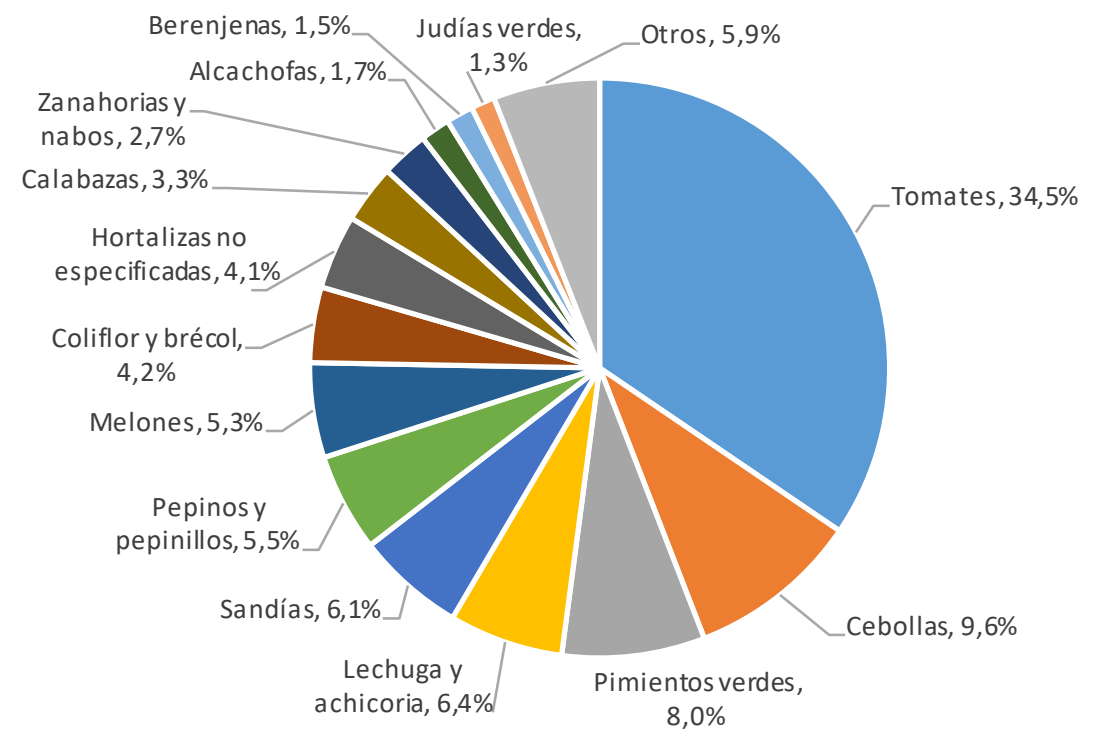

Fig. 3. Distribución de la producción de hortalizas en España en 2014, porcentaje sobre el total; FAO, 2017.

La producción española de tomate se concentra principalmente en las comunidades autónomas de Andalucía y Extremadura, aunque seguidas de cerca por la Región de Murcia y Navarra, según datos de 2015 (MAPAMA, 2017). Cabe destacar el papel predominante de las provincias de Badajoz, con 1.727.297 toneladas y Almería, con 984.757 toneladas en 2015 como las principales zonas de producción. 
Según datos del Ministerio de Agricultura y Pesca, Alimentación y Medio Ambiente (MAPAMA), un 60\% de la producción española de tomate se destina al consumo en fresco, y el resto para su procesado en industria (MAPAMA, 2017). En el caso del tomate de industria, Extremadura representa el $72 \%$ de la producción española, seguida a distancia de Andalucía, con el 17\%, y el valle del Ebro, con el 7\%. En Extremadura se elabora principalmente tomate concentrado y en menor medida tomate en polvo, tomate frito, salsas de tomate, kétchup, tomate triturado y cubeteado, mientras que en Navarra tradicionalmente se ha concentrado el procesado como tomate pelado entero, que en la actualidad va siendo sustituido por tomate troceado o cubeteado (Lahoz, 2015).

Además de ser la hortaliza más producida en España, el tomate es también un cultivo de vital importancia para la economía española. Tanto es así, que el tomate es el primer cultivo hortícola en cuanto a valor bruto de la producción con 2.856 millones de euros en 2014 (FAO, 2017), muy por encima del siguiente cultivo, el pimiento con un valor de 897 millones de euros (Fig. 4).

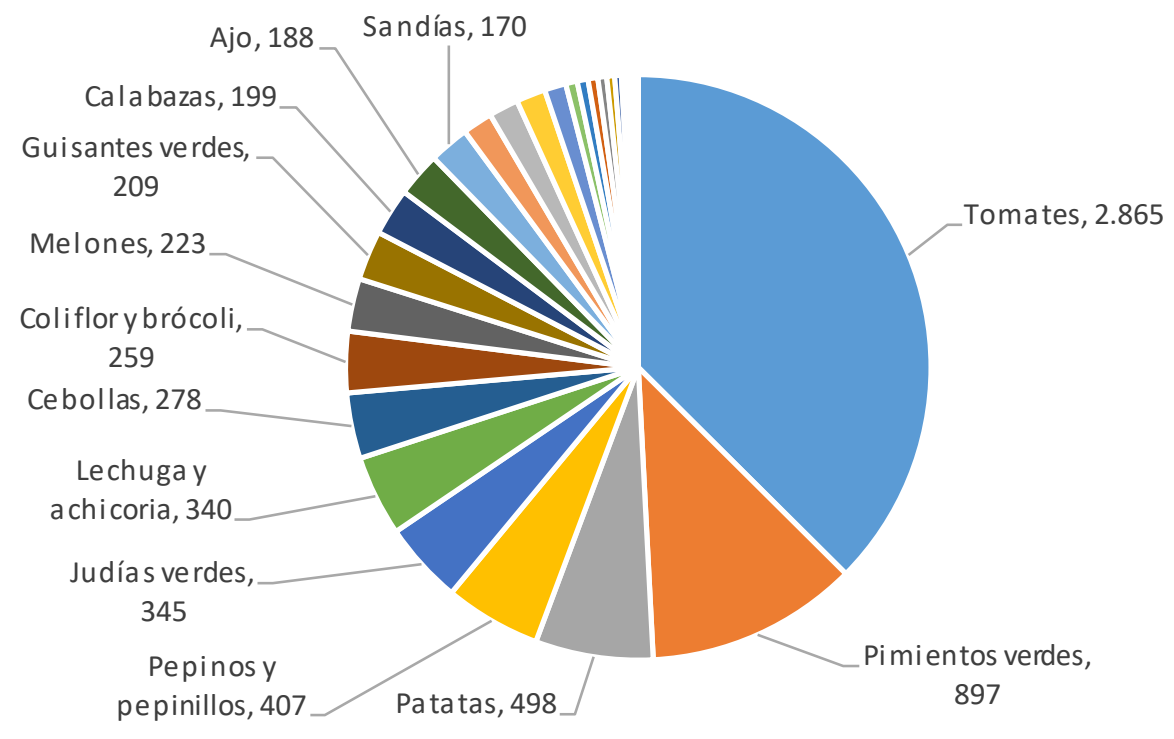

Fig. 4. Valor bruto (millones de euros) de la producción de hortalizas en España en 2014; FAO, 2017.

Las exportaciones de tomate son un importante motor para el sector hortícola español, alcanzando las 907.614 toneladas en el año 2016, según los datos de la Federación Española de Asociaciones de Productores Exportadores de Frutas, Hortalizas, Flores y Plantas vivas (FEPEX, 2017). De esta forma, el tomate sería la principal hortaliza exportada por España con un $17 \%$ del total, seguida por el pimiento, 14\%, la lechuga, 13\%, y el pepino, 12\% (FEPEX, 2017). Las exportaciones españolas de tomate son mayoritariamente como tomate en fresco, $73 \%$, seguido por la pasta de tomate, $16 \%$, tomate pelado, $11 \%$ y zumo de tomate, $0.5 \%$ (FAO, 2017). El destino de la mayor parte del tomate español son países de la Unión Europea, en tre los que destacan Alemania, Francia, Reino Unido y los Países Bajos (Fig. 5), con un valor total de las exportaciones que superó los 959 millones de euros en el año 2016 (FEPEX, 2017). 


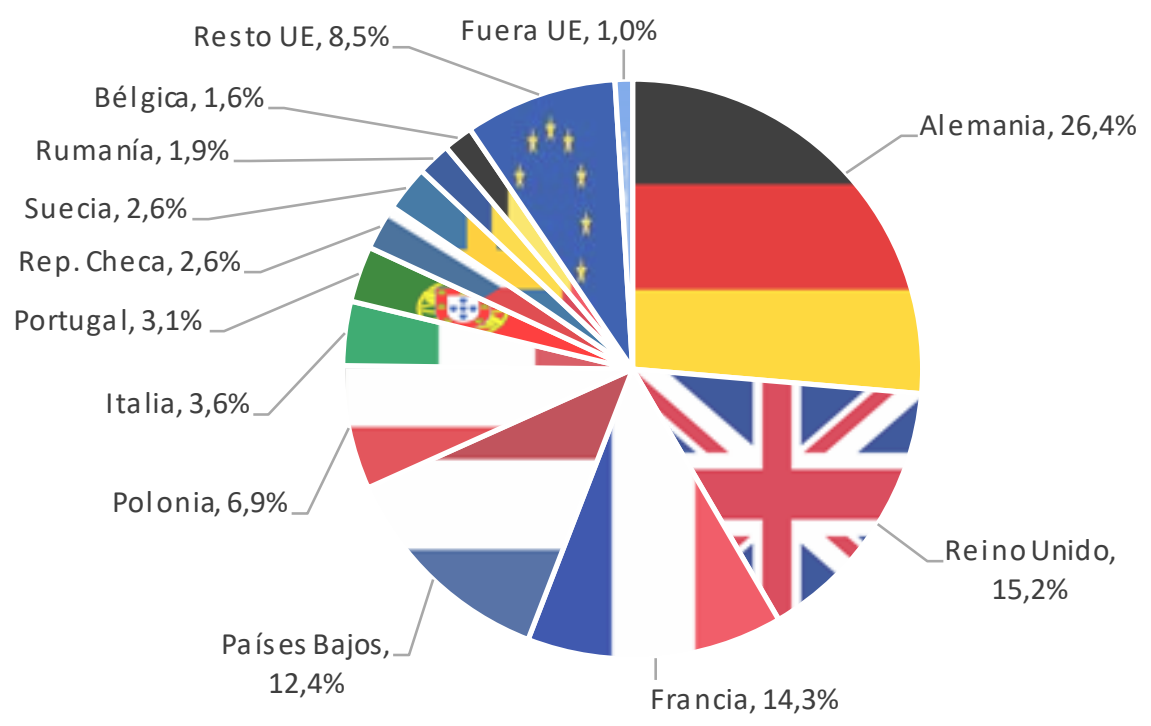

Fig. 5. Distribución del volumen de las exportaciones españolas de tomate en 2016; FEPEX, 2017.

\section{Consumo de tomate y potencial como fuente de compuestos funcionales}

El consumo de tomate, ya sea en fresco o en cualquiera de sus productos derivados, está ampliamente extendido en todo el mundo; siendo los países de América del Norte, con $35.8 \mathrm{~kg}$ persona $^{-1}$ año-1 $^{-1}$, los países del Sur de Europa con $34.8 \mathrm{~kg}_{\text {persona }}{ }^{-1}$ año $^{-1}$ y Oceanía con $26.7 \mathrm{~kg}$ persona $^{-1}$ año-1 donde se concentran las mayores ingestas de tomate según datos de 2013 (FAO, 2017). El gran consumo de esta hortaliza, la convierte en una de las principal es fuentes de compuestos bioactivos, pese a no destacar especialmente por su riqueza en este tipo de compuestos. Entre ellos, el valor funcional del tomate habitualmente se asocia a los contenidos en carotenoides, vitaminas, entre las que destaca el ácido L-ascórbico, y polifenoles (Martí et al., 2016).

De hecho, debido a sus altos niveles de consumo, al tomate se le considera la principal fuente de licopeno en la dieta, ya que sólo la ingesta de tomate fresco y la salsa de tomate representan el $95 \%$ de la ingesta diaria de este carotenoide. Además, el tomate es considerado como la segunda fuente de $\beta$-caroteno tras las zanahorias, la segunda fuente de vitamina $C$ tras las naranjas y la sexta fuente de polifenoles, tras las naranjas, manzanas, patatas, plátanos y pomelos (García-Closas et al., 2004; Chun et al., 2005).

El peso del tomate como fuente de compuestos bioactivos ha favorecido el desarrollo de programas de mejora genética encaminados a aumentar el potencial de acumulación de los mismos. Estos intentos se han ido desarrollando desde la década de 1970. Uno de los primeros cultivares desarrollados específicamente con este objetivo fue el cultivar 'Double-rich', empleando la especie silvestre Solanum peruvianum L. como fuente de variabilidad. Este cultivar se caracterizaba por sus al tas concentraciones en vitamina $C$, que oscilaban entre los $318 \mathrm{mg} \mathrm{kg}^{-1}$ (Watada et al., 1976) y $500 \mathrm{mg} \mathrm{kg}^{-1}$ (Stevens y Rick, 1986) según el ensayo, niveles que duplicaban los contenidos habituales en vitamina $C$ en tomate. Sin embargo, varios problemas limitaron el éxito de la comercialización de cultivares con al to nivel en vitamina $C$. En el caso 'Double-rich' pesó bastante el bajo peso de fruto que afectaba a la producción (Stevens y Rick, 1986). Por otro lado, el contenido en vitamina Ces muy inestable, debido a su 
fuerte dependencia de las condiciones ambientales (Hamner et al., 1945; Hanson et al., 2004), al notable efecto de la interacción genotipo x ambiente (Leiva-Brondo et al., 2012) y a su uso como factor de defensa frente a situaciones de estrés por parte de la planta (Davey et al., 2000; loannidi et al., 2009). Por ello, es difícil asegurar un nivel alto en el producto comercializado independientemente de las condiciones de cultivo. Por esta razón, y por la naturaleza termolábil de la vitamina $\mathrm{C}$ que dificulta su aprovechamiento industrial los esfuerzos actuales de mejora se centran sobre los otros dos grandes grupos de compuestos funcionales de tomate: los carotenoides y los polifenoles.

De hecho, los cultivares con elevados contenidos en carotenoides han obtenido mayores éxitos. Si bien su desarrollo fue también temprano, lo cierto es que los primeros intentos se enfocaban más a aumentar la coloración rojiza del fruto que a aumentar el valor funcional. Por ello, los logros en este ámbito se extendieron rápidamente dentro del tomate de industria en el que la coloración es un factor a tener muy en cuenta.

Más recientemente se han redirigido los esfuerzos a aumentar los contenidos en polife noles, según se han ido desarrollando estudios que ponen de relieve el papel de e stos compuestos sobre enfermedades como el cáncer. En este sentido, la importancia real de estos dos grupos de compuestos funcionales en la prevención de diversos tipos de cáncer se ha contrastado en el trabajo de revisión publicado en la revista Cancers (Martí et al., 2016) que se incluye como epígrafe 3 de esta tesis. En este trabajo también se incluye información amplia respecto a niveles habituales en tomate de estos dos grupos de compuestos (carotenoides y polifenoles), rutas biosintéticas, mutantes natural es y logros obtenidos hasta el momento mediante mejora genética, por lo que no se repetirán todos esos datos en esta introducción general. No obstante, a efectos de describir adecuadamente el contexto de trabajo en el que se enmarca la tesis, se incluye en los apartados 4 y 5 de esta introducción un resumen de los mismos.

\section{Los carotenoides: compuestos funcionales clave en el tomate}

\subsection{Acumulación de carotenoides en tomate}

En el tomate, la síntesis de carotenoides tiene lugar principalmente en las hojas, flores y frutos, siendo diferentes los carotenoides presentes en cada uno de estos tejidos. En los frutos maduros de tomate el licopeno es el principal carotenoide, siendo responsable de su coloración roja. Otros carotenoides destacados en frutos de tomate son el fitoeno y el fitoflueno, ambos precursores incoloros de la biosíntesis de licopoeno, y el $\beta$-caroteno, sintetizado porciclación de licopeno y que es el responsable de las coloraciones an aranjadas de los frutos de tomate, aunque en estado rojo maduro la concentración de estos carotenoides es bastante menor que la del licopeno. Por último, además de estos carotenoides más destacados, también se puede encontrar otros menos importantes y en cantidades menores tales como el $\gamma$-caroteno, $\delta$-caroteno, luteína, neurosporeno, $\alpha$-caroteno y otros.

La distribución de los carotenoides en los frutos de tomate no es regular. En ese sentido, el licopeno se acumula en mayores proporciones en el pericarpio comparado con los lóculos, mientras que en el caso del $\beta$-caroteno ocurre lo contrario, acumulándose en mayor medida en los lóculos comparado con el pericarpio (Davies et al., 1981). Además, durante los diferentes estados del proceso de maduración la concentración de licopeno va cambiando. 
Inicialmente, en los frutos en estado verde, no hay licopeno. Este comienza a apare cer en los lóculos en el estado pintón y a partir de ese momento su concentración va aumentando durante todo el proceso de maduración, llegando a su máxima concentración en el estado rojo maduro (Qin et al., 2011).

Además, el genotipo y el ambiente también condicionan la acumulación de carotenoides (Tiwari y Cummings 2013; Lahoz et al., 2016a). De hecho, ese es uno de los principales motivos por el que existe una alta variabilidad en las concentraciones de este tipo de compuestos.

\subsection{Mejora genética del contenido en carotenoides}

El colorfue uno de los primeros atributos a considerar en los programas de mejora de tomate, especial mente dentro de las líneas dedicadas a tomate de industria. Dado que los carotenoides son los responsables de la coloración del fruto, de forma indirecta la mejora del color en tomate conllevó una mejora del contenido en carotenoides. Por ese motivo, se ha avanzado mucho más en la mejora para incrementar el contenido en carotenoides que la de cualquier otro compuesto bioactivo.

La utilización de germoplasma, proveniente de la diversidad natural presente en el género Solanum sección Lycopersicum, permitió la identificación de variantes genéticas (mutantes naturales) con un elevado potencial para acumular carotenoides. Algunos de estos mutantes se han utilizado para desarrollar variedades de tomate con niveles al terados de caroten oi des. Entre ellos destacan mutantes del gen Beta, $B$, implicado en la regulación de la biosín te sis de $\beta$-caroteno a partir de licopeno (Ronen et al., 2000). Este gen tiene tres alelos, $B$, old gold (og), $y$ old gold crimson $\left(o g^{c}\right)$. El alelo $B$ afecta al promotor del gen de la enzima licopeno $\beta$-ciclasa LCY-B y produce una mayor síntesis de $\beta$-caroteno al sobrexpresarlo, confiriendo al fruto una tonalidad anaranjada (Ronen et al., 2000; Zhang y Stommel, 2000). Sin embargo, hay que tener en cuenta que, en este tipo de mutantes, el aumento en la concentración de $\beta$-caroteno se produce a costa del licopeno, con lo que la concentración global de carotenoides permanece constante. El gen $B$ tiene un modificador, el Beta-modifier $(m o B)$ que todavía inclina más la balanza a favor del $\beta$-caroteno a expensas del licopeno (Ronen et al., 2000).

Utilizando el gen $B$ y su modificador $m o B$ se han desarrollado cultivares naranjas como el 'Caro Red' (Tomes y Quackenbush, 1958), 'Caro Rich' (Tigchelaar y Tomes, 1974) y 'Caro beta' (Georgiev et al., 1981). Estos cultivares pueden llegar a contener casi 10 veces más que el contenido normal en los cultivares rojos. Desafortunadamente, esta coloración anaranjada ha hecho que esos cultivares de frutos con altos contenidos de $\beta$-caroteno no hayan tenido éxito desde el punto de vista comercial, ya que los consumidores prefieren tomates rojos.

Los otros dos alelos mutantes, og y og ${ }^{c}$, se han utilizado en el desarrollo de cultivares rojos con mayores contenidos de licopeno. Estas mutaciones representan deleciones en el gen que dan lugar a enzimas LCY-B no funcionales, con lo que se bloquea la ruta de síntesis y por tanto la acumulación de $\beta$-caroteno (Ronen et al., 2000). Como consecuencia, se produce una mayor acumulación de licopeno, lo que produce que los frutos sean de un color rojo intenso. El uso de mutantesog y $\mathrm{og}^{c}$, ha permitido obtener cultivares con contenidos en licopeno que pueden llegar a ser de hasta un $30 \%$ mayores que el contenido normal, pero con menores acumulaciones de $\beta$-caroteno (Vogel et al., 2010). En este caso, los mutantes $\mathrm{og}^{c}$ han sido los 
que se han comercializado con mayor éxito debido a su intensa pigmentación roja incluso cuando los frutos no están completamente maduros.

A pesar del éxito de algunos mutantes que afectan a puntos concretos de la ruta ha sido exitosa, lo cierto que estas al teraciones tienen un escaso efecto sobre el contenido total de carotenoides, ya que el incremento en la concentración de un carotenoide se obtiene a expensas del otro. En ese sentido, sería de esperar que los mutantes que sean capaces de afectar a la regulación global de la ruta produzcan un mayor efecto sobre el contenido total de carotenoides.

Otra posibilidad es actuar sobre la regulación hormonal del proceso de maduración del fruto que también desempeña un papel importante en el control de la ruta biosintética de los carotenoides. Durante el proceso de maduración, el etileno tiene un fuerte control sobre el incremento de los niveles de mRNA de las enzimas productoras de licopeno, al mismo tie mpo que, los niveles de mRNA de las enzimas que lo utilizan como sustrato para ciclarlo y obte ner otros carotenoides disminuyen hasta desaparecer completamente (Klee y Giovannoni, 2011). Este hecho explica que las mutaciones que afectan a la síntesis o la percepción de etileno, como son las mutaciones de larga vida rin, nor, alç no solo retrasan el proceso normal de maduración, sino que también afectan al contenido en carotenoides (Cebolla-Cornejo et al., 2013).

Por último, también es posible actuar sobre los fitocromos de los frutos, ya que éstos son capaces de regular la acumulación de carotenoides (Alba et al., 2000). La respuesta de los fitocromos a la luz permite la biosíntesis de carotenoides, que no es posible en la oscuridad. Este hecho condiciona la biosíntesis de carotenoides a períodos de biosíntesis diurnos (regulación dependiente de la luz). En ese sentido, las mutaciones high pigment ( $h p$ ) han sido las que más se han utilizado en los cultivares de al to licopeno, también llamados high pigment, ya que presentan al teraciones en la regulación normal del fitocromo lo que se traduce en un contenido global de carotenoides aumentado. Estas mutaciones high pigment comprenden los genes high pigment-1 (hp-1), high pigment-2 (hp-2) e Intense pigmentation (Ip). La mutación $h p-1$, y su alelo el $h p-1^{w}$ actúan sobre la planta para que ésta responda como si percibie ra luz continuamente (Liu et al., 2004). La mutación $h p-2$ y sus alelos $h p-2^{j}$ y $h p-2^{d g}$ (Bino et al., 2005), afectan a genes regulatorios de la fotomorfogénesis, y a la maquinaria de transducción de señales lumínicas (Mustili et al., 1999). El mutante Ip presenta una amplificación de la señal del fitocromo (Kendrick et al., 1997; Lavi et al., 2009).

Siguiendo esta estrategia se han obtenido algunos cultivares de tomate que portan tanto los genes crimson como los high pigment (alelos $h p-1$ o $h p-2$ ) con lo que se obtienen contenidos de licopeno hasta 3 o 4 veces mayores que en los cultivares estándar (Stommel, 2007). Sin embargo, se ha comprobado que existen algunos efectos colaterales perjudiciales asociad os a estos mutantes high pigment en la germinación de semillas, vigor de las plantas y producción. Para remediarlo, se ha propuesto usar el gen $I p$, permitiendo llegar a acumulaciones de carotenoides similares a la de los genes $h p$, pero sin esos efectos colaterales indeseables. Además, el Ip es dominante, lo que permite un desarrollo de cultivares comerciales más interesante comparado con los genes recesivos como los $h p$ (Rick, 1974).

Otro punto de vista diferente es el uso de biotecnología avanzada que permita transferirgenes foráneos (ingeniería genética) para producir una al teración beneficiosa en la biosíntesis de los 
carotenoides. Los avances en el conocimiento de la ruta metabólica de estos compue stos, de sus precursores y mecanismos de regulación ha permitido el uso de esta información para obtener líneas transgénicas experimentales con genes modificados que controlen algunos pasos en la biosíntesis. En ese sentido, algunos trabajos tratan de emular el rendimiento en la biosíntesis de carotenoides de algunos mutantes naturales, tratando de evitar los efectos colaterales indeseables de estos mutantes naturales (Fray et al., 1995; Römer et al, 2000; Ronen et al., 2000; Rosati et al., 2000; Fraser et al., 2002; D’Ambrosio et al., 2004; Enfissi et al., 2005; Apel y Bock, 2009; Ma et al., 2011; Guo et al., 2012). Otros trabajos tratan la modificación de algunos mecanismos regulatorios de la ruta biosintética. En ese sentido, algunas líneas experimental es han tratado de emular el rendimiento de los mutantes hp-1 (Liu et al., 2004) y $h p-2$ (Davuluri et al., 2005). En este último caso, la estrategia usada implicó la supresión del gen regulador de la fotomorfogénesis TDET1 sólo en frutos, con el fin de re ducir los efectos colaterales negativos de los $h p$ en el desarrollo vegetativo.

Hay que destacar que ambas estrategias pueden ser complementarias, de hecho, la ingeniería genética puede ser usada para evitar algunos efectos colaterales negativos de al gu nos genes cambiando su promotor (revisado por Cebolla-Cornejo et al. 2013). No obstante, el nivel de escepticismo público en algunas regiones como Europa, dificulta la comercialización de variedades transgénicas (Goldman, 2011) y los enfoques comerciales se centran en programas de mejora convencionales.

\section{Los polifenoles: compuestos funcionales de "última generación"}

\subsection{Acumulación de polifenoles en tomate}

Los polifenoles son metabolitos secundarios de la ruta del ácido shikímico y en tomate se encuentran en menores concentraciones que los carotenoides. Estos compuestos son potentes antioxidantes y se pueden dividir en diferentes familias en función de su estructura principal. Entre los principales compuestos fenólicos del tomate podemos encontrar ácidos hidroxicinámicos, flavanonas, flavonoles y antocianinas. Además, es muy común encontrar los polifenoles formando parte de glicósidos formados por un polifenol, que actúa como esqueleto central, al que se le unen una o varias moléculas de azúcar a través de enlaces $O$ glicosídicos o C-glicosídicos. En los frutos de tomate los glicósidos más importantes son los de los flavonoles quercetina y kaempferol que generan rutina y el kaempferol-3-rutinosido respectivamente.

El principal compuesto fenólico que se encuentra en tomate es la naringenin chalcona, con

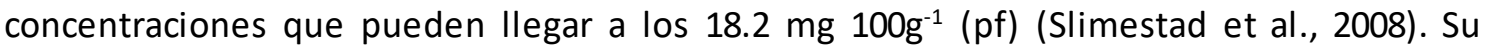
acumulación en la epidermis de tomate da a la piel el típico color amarillo (Ballester et al., 2010). La quercetina es el principal compuesto de la familia de los flavonoles y es, además, uno de los flavonoides más importantes del tomate. Sus contenidos varían desde 0.7 hasta $4.4 \mathrm{mg}$ $100 \mathrm{~g}^{-1}$ (pf) en función de la variedad (Martínez-Valverde et al., 2002). Es común en tomate encontrar la quercetina en forma de glicósido formando rutina, con contenidos que pueden

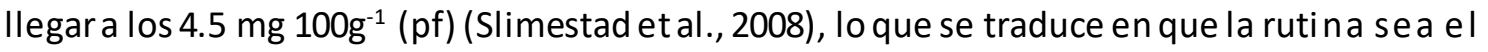
segundo polifenol más presente en tomate tras la naringenin chalcona. El ácido clorogénico es el principal polifenol de la familia de los ácidos hidroxicinámicos y su concentración oscila

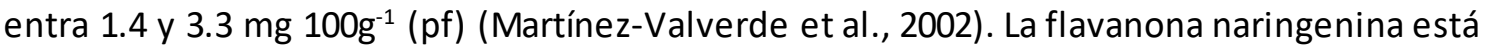


presente en menores concentraciones (hasta 1,3 mg 100 ${ }^{-1} \mathrm{pf}$ ) (Martínez-Valverde et al., 2002). A todos estos, hay que añadir otros flavonoles como el kaempferol y myricetina que se encuentran en pequeñas cantidades en tomate cultivado (Martínez-Valverde et al., 2002; Shen et al., 2007).

La acumulación de flavonoides en tomate es dependiente del tejido y se desarrolla en etapas específicas. Por ejemplo, la naringenin chalcona se acumula casi exclusivamenteen la piel de forma simultánea con la acumulación de carotenoides y degradación de clorofilas, al canzan do los mayores niveles en pieles sobre-maduras (Muir et al., 2001). De hecho, la ruta biosintética de los flavonoides no está activa en la pulpa debido a la falta de expresión de los genes que codifican las enzimas correspondientes (Colliver et al., 2002). En este sentido, la acumulación de flavonoles, principalmente glicosidos de quercetina y kaempferol, está restringida casi en su totalidad a la piel del fruto (Stewart et al., 2000), aunque algunos estudios muestran ciertos niveles de acumulación en la pulpa, pero unas seis veces inferiores a los de la piel (Ballester et al., 2010).

Generalmente, en tomate la producción de antocianinas está restringida a los tejidos vegetativos, como el hipocotilo. Sin embargo, en algunas condiciones como altas radiaciones y bajas temperaturas, se pueden acumular en el tallo y las hojas. Las principales antocianinas que encontramos en el tomate derivan de la delfinidina, malvidina y petunidina (Mes et al., 2008; Sapir et al., 2008).

\subsection{Mejora genética del contenido en polifenoles}

Pese a que el estudio de la acumulación de polifenoles en los frutos de tomate ha ganado en importancia durante la última década, los logros de mejora alcanzados siguen yendo por detrás de los obtenidos para los carotenoides. En la actualidad, existe bastante información sobre la ruta biosintética de los polifenoles en tomate y se han identificado varios factores de transcripción relacionados con la regulación de su biosíntesis (revisado por Martí et al., 2016). Sin embargo, todavía se requiere trabajo para recabar más información sobre cómo se acumulan estos compuestos en el fruto y cómo se puede actuar para modificar su contenido.

Como se ha comentado en el punto anterior, es extraño encontrar antocianinas en los frutos de las especies cultivadas de tomate. Sin embargo, se han identificado varias mutaciones en especies silvestres que permiten la acumulación de antocianinas en la parte exterior del fruto. En ese sentido, las mutaciones más utilizadas han sido Anthocyanin fruit (Aft) y Aubergine $(A b g)$, que son capaces de incrementar la acumulación de antocianinas en la piel delfruto.

El alelo mutante Anthocyanin fruit procede de Solanum chilense Dunal y se encuentra en el cromosoma 10. La presencia de la mutación Aft produce un incremento en los niveles de las antocianinas delfinidina, malvidina y petunidina en la piel y el pericarpio externo del fruto. Además, también produce un aumento en los niveles de los flavonoles quercetina y kaempferol, con contenidos incrementados 3,6 y 2,7 veces respectivamente (Sapir et al., 2008).

El alelo mutante Aubergine procede de Solanum lycopersicoides Dunal (Rick et al., 1994). Este gen también se encuentra localizado en el cromosoma 10 y es muy posible que se trate de un alelo del Aft (Canady et al., 2006). 
A estos hay que añadir otro mutante, el atroviolacea (atv), que procede de Solanum cheesmaniae (L. Riley) Fosberg y se encuentra en el cromosoma 7 (Rick et al., 1968). Normalmente, este mutante tiende a acumular antocianinas en los tejidos vegetativos co mo las hojas, pero tiene un escaso efecto en la acumulación de estos compuestos en el fruto. No obstante, se ha demostrado que existe un efecto sinérgico con otros genes como en los mutantes homocigotos dobles Abg Abg atv atv y Aft Aft atv atv y permite obtener mayores contenidos en antocianinas en estos mutantes que en los mutantes individuales (Mes et al., 2008; Povero et al., 2011).

Ninguno de esos mutantes es capaz de inducir la acumulación de antocianinas en la carne del fruto. En este sentido, los tomates con carne morada sólo se han obtenido medianteingeniería genética (Butelli et al., 2008).

Los niveles de polifenoles en tomate dependen de la expresión de los genes responsables de la ruta de síntesis. Durante el proceso de desarrollo del fruto, cuando empieza la maduración, uno de los enzimas que se sobrexpresan es la chalcona sintasa (CHS). Este enzima es el responsable de la biosíntesis de naringenin chalcona. El enzima $\mathrm{CHI}$ se encarga de la biosíntesis de naringenina a partir de naringenin chalcona, y juega un papel fundamental en la tasa de producción de flavonoles (Bovy et al., 2002). Durante la maduración del tomate, se produce un aumento en la expresión del enzima CHS junto con la desregulación de $\mathrm{CHI}$ en la piel del fruto produce una acumulación de naringenin chalcona y limita la acumulación de naringenina (Ballester et al., 2010). Willits et al. (2005) sugirió que los al tos niveles de naringenin chal cona en la piel del fruto podrían explicarse por la falta de expresión de $\mathrm{CH}$ en este tejido. Ade más, estos autores también sugieren que es posible que el tomate cultivado haya perdido la expresión de $\mathrm{CHI}$ en la piel en un paso temprano del proceso de domesticación.

Como se ha comentado, la acumulación de naringenin chalcona en la piel del tomate confiere la característica coloración amarilla que, junto con la pulpa roja, produce el color exterior rojo del fruto. De hecho, existen algunas variedades tradicionales de tomate que se caracterizan por una coloración externa rosa, que se debe a la presencia de piel transparente por la falta de acumulación de naringenin chal cona. En este sentido, la evaluación de líneas de in trogresión de Solanum chmielewskii Spooner, Anderson y Jansen en tomate permitió la identificación del gen responsable de esta mutación (yellow, y), descrito inicialmente en 1925 (Lindstrom, 1925).

Las posibilidades de mejora del contenido en polifenoles empleando materiales de la propia especie cultivada son limitadas. Así, el análisis de diferentes germoplasmas de tomate para la acumulación de flavonoles no muestra niveles muy altos de variación. En ese sentido, los contenidos de quercetina en los extractos de piel hidrolizados más al tos sólo representaron un aumento de 2,5 veces en comparación con una variedad comercial estándar (Colliver et al., 2002). Otros autores encontraron niveles similares de variación, con niveles más altos en los frutos de tomate 'Cherry' más pequeños procedentes de climas soleados (Stewart et al., 2000). Por otro lado, en una amplia evaluación de variedades tradicionales españolas de tomate se registraron contenidos en polifenoles totales interesantes $y$, por lo que sería posible seleccionar poblaciones con mayor valor funcional (Cortés-Olmos et al., 2014).

Mayores éxitos se han logrado mediante la utilización de la riqueza genética de especies silvestres del género Solanum sección Lycopersicum, que ha permitido la identificación y uso de materiales como fuente de variación para mejorar el contenido en polifenol es. Sigui endo 
esta aproximación, se ha conseguido aumentar el contenido en flavonoides del tomate usando especies silvestres como Solanum pennellii Correl, de frutos verdes y pequeños, para restaurar la ruta de los flavonoides en la pulpa del fruto. Mediante el cruzamiento y selección por la expresión de $\mathrm{CHI}$ en la pulpa, se ha llegado a desarrollar nuevas variedades hibridas con especies cultivadas con mayores acumulaciones de diglicósido de quercetina (Willits et al., 2005).

Por otro lado, también se ha estudiado la regulación lumínica de la ruta de síntesis de los polifenoles. En ese sentido, Giuntini et al. (2008) mostró que la radiación UV-B afecta diferencialmentela expresión de los genes de la ruta de los flavonoides y da como resul tado un contenido alterado de flavonoides y ácidos hidroxicinámicos. Por ejemplo, en el cultivar convencional 'Esperanza' se encontraron mayores niveles de naringenin chal cona, quercetina y rutina y de los ácidos sinápico, caféico, ferúl ico y $p$-coumárico en la pulpa de frutos protegidos de la radiación UV-B en el estado rojo maduro, mientras el efecto fue limitado en el cultivar de alto licopeno DRW5981, especialmente para el contenido en flavonoides. La expresión de genes que codifican la expresión de los enzimas CHS y CHI fue mayor en el cultivar 'Esperanza' y la correspondiente a los enzimas flavanona 3-hidroxilasa (F3H) y flavonoide 3'-hidroxilasa $\left(F^{\prime} H\right)$ se redujo en los frutos protegidos de UV-B. En ambos cultivares, la acumulación de carotenoides siguió la misma respuesta que la acumulación de flavonoides. En el genotipo con alto contenido en licopeno DRW5981 en la pul pa del fruto se sobrexpresaron varios ge nes de la ruta de los flavonoides con la excepción de $\mathrm{CHI}$. Como resultado, se observó un aumento espectacular de la acumulación de naringenin chal cona y un modesto aumento del con ten ido en quercetina.

Al igual que ocurre con los carotenoides, los mutantes high pigment también afectan a la regulación de la luz de la síntesis de los flavonoides en tomate. La consecuencia es una sobreproducción de compuestos bioactivos que se acompaña con un aumento de la biogénesis de los plastidios y, por tanto de los metabolitos acumulados en los mismos (revisado por Azari et al., 2010).

La utilización conjunta de los genes high pigment en combinación con los relacion ad os con la síntesis de antocianinas se está revelando como la mejor estrategia para desarrollar variedades de elevado valor funcional Así, los dobles homocigotos para Aft y $h p$ - 1 muestran un efecto sinérgico, mayor que simplemente aditivo, con aumentos de 5,19 y 33 veces en el contenido de petunidina, malvidina y delfinidina respectivamente (Sapir et al., 2008). Mes et al. (2008) también obtuvieron niveles elevados con esta combinación de genes, aunque todavía menores a los obtenidos con la combinación de Aft y atv. Siguiendo con la piramidalización de genes, Sestari et al. (2014) acumularon en una variedad tipo 'Cherry' los genes $h p-2$, Aft y atv obteniendo niveles muy elevados de polifenoles. Hay que destacar la importancia que puede tener el uso de variedades 'Cherry' en esta estrategia, ya que al presentar una mayor relación superficie volumen los niveles de carotenoides y polifenoles tienden a ser superiores, ya que ambos se acumulan preferentemente en la parte exterior del fruto.

Cualquiera de las estrategieas mencionadas puede contribuir a desarrollar nuevos mate riales con mayor potencial de acumulación de compuestos funcionales. Sin embargo, la re al ización de dicho potencial depende en gran medida de que las condiciones ambientales, ya sean 
climáticas o de manejo de cultivo, permitan la mayor acumulación posible de este tipo de compuestos o, por el contrario, que la acaben limitando.

\section{Efecto del ambiente en la acumulación de carotenoides y polifenoles}

Las condiciones ambientales influyen en la acumulación final de compuestos funcionales como los carotenoides y los polifenoles en tomate (revisado por Dumas et al., 2003). Dentro del ambiente ejercen un papel destacado las condiciones climáticas, por ejemplo, a través del efecto de la radiación solar o la temperatura, pero también el manejo del cultivo, incluyen do aspectos como el abonado, el riego o el propio sistema de cultivo, por lo que todos estos aspectos deben ser tenidos en cuenta a la hora de evaluar las características de calidad funcional en tomate. A continuación, se revisa el efecto de cada factor sobre la acumulación de estos compuestos.

\subsection{Radiación solar}

La radiación solar efectiva que llega a las plantas puede verse afectada por cubiertas de invernaderos, mallas de sombreo, densidad de plantas y estructura de la cubierta vegetal (Yahia et al., 2005). Aunque actúa a distintos niveles, uno de sus efectos más importantes viene condicionado por su papel en la fotosíntesis. En tomate, como en cualquier otro cultivo, la composición del fruto está influida por la capacidad de atraer fotoasimilados procedentesen gran medida de la hoja, aunque hasta un $15 \%$ pueden proceder del propio fruto (Hetherington et al., 1998). Estos fotoasimilados representarán en gran medida azúcares, determinantes a la hora de establecer el dulzor del fruto y por tanto su calidad organoléptica (Baldwin et al., 1998). Pero, por otro lado, de la capacidad del fruto para ser sumidero de fotoasimilados también dependerá la acumulación de metabolitos secundarios derivados de los mismos, como por ejemplo los terpenos, entre los que se encuentran los carotenoides, y los polifenoles.

Por otro lado, el efecto de la radiación no se restringe a su papel a la hora de determinar la capacidad fotosintética. Por ejemplo, la biosíntesis de carotenoides en tomate está controlada por el fitocromo y se ve favorecida por la luz roja, mientras que longitudes de onda más cercanas al infrarrojo la inhiben, por lo que la calidad e intensidad de la luz determinarán el contenido de carotenoides sintetizados (Thomas y Jen, 1975). En este sentido, McCollum (1954) encontró que los frutos de tomate expuestos a la radiación solar directa durante su desarrollo presentaron mayores niveles de carotenoides que los frutos protegidos de la radiación. Por ese motivo, es de esperar que una alta radiación solar produzca una al ta tasa de biosíntesis de carotenoides.

Un exceso de radiación también puede influir negativamente en la acumulación de algunos de estos compuestos. Este sería el caso del licopeno, cuya acumulación se ve severamente afectada por la exposición a una radiación solar intensa (Dumas et al., 2003). La acumulación de este carotenoide se ve inhibida en los frutos expuestos directamente a una radiación de $650 \mathrm{~W} \mathrm{~m}^{-2}$ en periodos de 1,5 a 4 horas (Adegoroye y Jolliffe, 1987; Brandt et al., 2006). Dumas et al. (2003) sugirieron como explicación que este daño podría deberse al sobrecalentamiento que produce esta radiación en los tejidos del fruto de tomate irradiados, por lo que la 
temperatura de estos podría fácilmente llegar a sobrepasar los $32^{\circ} \mathrm{C}$, nivel a partir de la cual se inhibe la biosíntesis de licopeno.

En condiciones de radiación excesiva, el uso de mallas de sombreo puedeayudar a disminuir la cantidad de radiación que reciben las plantas y frutos. En estas condiciones, las mallas de sombre o fotoselectivas son la mejor manera de proteger el fruto de la exposición directa al sol (Ilić et al., 2014), presentando distintos porcentajes de transmisión, absorción y reflexión de la luz. No obstante, en los periodos en los que la radiación solar no es excesiva pueden pro ducir una menor acumulación de licopeno y $\beta$-caroteno (Gautier et al., 2005) por lo que es aconsejable programar su uso en función de las condiciones de radiación existente.

La luz recibida también afecta al contenido en polifenoles de los frutos de tomate, produciendo una mayor acumulación en condiciones de alta luminosidad. En ese sentido, Wilkens et al. (1996) encontraron contenidos de rutina y ácido clorogénico en tomates 'Cherry' cultivados en condiciones de mayor luminosidad que casi duplicaban a los de las plantas cultivadas en con menos luz. De nuevo, no solo la cantidad de luz recibida es importante en la acumulación de compuestos fenólicos por su efecto sobre la acumulación de fotoasi milados. Así, la longitud de onda de la luz recibida también influye en su contenido. Luthria et al. (2006) obtuvieron contenidos de polifenoles un 10-16\% mayores en aquellos tomates cultivados bajo una cubierta que bloquee la transmisión de la radiación de longitud de onda menor a $380 \mathrm{~nm}$. De hecho, al igual que pasa con los carotenoides, la luz roja favorece la biosíntesis de polifenoles como la naringenin chalcona (Dumas et al., 2003).

\subsection{Temperatura}

La temperatura tiene un efecto sobre el crecimiento general de las plantas, asícomo sobre su floración, cuajado, crecimiento y maduración de frutos. Durante la maduración, el contenido de carotenoides, principalmente licopeno, aumenta significativamente en el fruto de tomate (Carrillo-López y Yahia, 2010). El contenido en polifenoles también se ve afectado por el proceso de maduración, ya que los contenidos de rutina y ácido clorogénico aumentan durante este proceso (Carrillo-López y Yahia, 2010).

Como ya se ha comentado, es un hecho que la síntesis de licopeno depende de la temperatura. Se sabe que temperaturas entre los 12 y los $32^{\circ} \mathrm{C}$ permiten su biosíntesis (Leoni, 1992), aunque el rango óptimo para su síntesis va de los 22 a los $25^{\circ} \mathrm{C}$ (Lumpkin, 2005). En los frutos de tomate sometidos a temperaturas mayores a $32^{\circ} \mathrm{C}$ se inhibe la biosíntesis de licopeno (Tomes, 1963), pero no así la de $\beta$-caroteno (Baqar y Lee, 1978). En este sentido, Baqar y Lee (1978) encontraron un menor contenido total de carotenoides en frutos expuestos a $30^{\circ} \mathrm{C}$, comparados con frutos a $20^{\circ} \mathrm{C}$. Especialmente dramático es el descenso en el contenido en licopeno, que pasa de $40.5 \mathrm{mg} \mathrm{kg}^{-1}$ (pf) a $20^{\circ} \mathrm{C}$ a $1.1 \mathrm{mg} \mathrm{kg}^{-1}$ (pf) a $30^{\circ} \mathrm{C}$, lo que supone prácticamente su inhibición total. También muy importante son los descensos en los contenidos de fitoeno y fitoflueno, que pasan de 18.4 y $10.5 \mathrm{mg} \mathrm{kg}^{-1}$ (pf) a 5.6 y $0.5 \mathrm{mg} \mathrm{kg}^{-1}$ (pf) respectivamente al pasar de 20 a $30^{\circ} \mathrm{C}$. El único carotenoide que no ve afectada su acumulación por la temperatura es el $\beta$-caroteno, cuyo contenido permanece prácticamente constante al pasar de 20 a $30^{\circ} \mathrm{C}$. Una posible explicación a este hecho es que las temperaturas altas $\left(35^{\circ} \mathrm{C}\right)$ inhiben la acumulación de licopeno porque favorecen la conversión de licopeno en $\beta$-caroteno (Dumas et al., 2003). 
Las bajas temperaturas también afectan a la biosíntesis de carotenoides. Temperaturas inferiores a $12^{\circ} \mathrm{C}$ inhiben completamente la síntesis de licopeno (Dumas et al., 2003), mientras que temperaturas no tan bajas, entorno a los $18^{\circ} \mathrm{C}$, dan lugar a menores concentraciones de licopeno, asícomo a mayores ratios entre $\beta$-caroteno y licopeno, ya que, si bien el licopeno ve ralentizada su síntesis, el $\beta$-caroteno se ve menos afectado (Koskitalo y Ormrod, 1972).

En cuanto al contenido en polifenoles, la temperatura también tiene un efecto sobre su concentración. Gautier et al. (2008) encontraron mayores acumulaciones del flavonol rutina en tomates expuestos $a 32^{\circ} \mathrm{C}$, aunque solo en condiciones de al ta radiación, pero no encontra ron diferencias en los contenidos de ácido clorogénico. Rivero et al. (2001) encontraron distintas acumulaciones de compuestos fenólicos en función de la temperatura aplicada. A bajas temperaturas $\left(15^{\circ} \mathrm{C}\right)$ la acumulación de polifenoles se ve potenciada, al igual que ocurre a altas temperaturas $\left(35^{\circ} \mathrm{C}\right)$. Según estos autores, parece ser que esta mayor acumulación de polifenoles podría formar parte del sistema de defensa de la planta al estrés térmico. En este mismo trabajo, Rivero et al. (2001) encontraron que la actividad del enzima fenilalanina amonio liasa (PAL) también se ve potenciada a bajasy altas temperaturas. Como este e nzima es el responsable de catalizar el primer paso en la ruta de los fenilpropanoides, esta mayor actividad explicaría la mayor acumulación de polifenoles.

\subsection{Abonado}

El buen desarrollo de la planta, asícomo su rendimiento y la calidad de los frutos pasan por un aporte adecuado y equilibrado de nutrientes. El exceso o defecto de algunos de estos elementos químicos puede provocar alteraciones en el crecimiento y estado fisiológico de los frutos (Romojaro et al., 2007). La nutrición de las plantas, por tanto, va a ser un factor condicionante en la composición de los frutos, entre ellos la acumulación de carotenoides y compuestos fenólicos.

El aporte de nitrógeno ( $N$ ) puede condicionar el contenido de algunos de estos compuestos en los frutos de tomate. Así, Benard et al. (2009) encontraron mayores contenidos de rutina y derivados del ácido caféico en tomates cultivados con aportes más bajos de $\mathrm{N}$, aunque en la mayoría estas diferencias no llegaron a ser significativas. Estos autores sugirieron como explicación a este hecho que la respuesta específica de estos compuestos a los bajos contenidos en $\mathrm{N}$, junto con un menor desarrollo vegetativo que favorecería la llegada de radiación a los frutos podría ser la responsable.

En la misma línea, Toor et al. (2006) observaron que los tomates cultivados usando gallinaza y abono orgánico como fuente de $\mathrm{N}$ presentaban contenidos de flavonoides totales un $17.6 \%$ mayores que los cultivados usando fertilizantes minerales, aunque estas diferencias no fueron significativas. Mitchell et al. (2007) encontraron mayores niveles de flavonoides en tomates cultivados con un aporte limitado de N, como ocurre, por ejemplo, en tomates provenientes de cultivo ecológico. Por el contrario, otros estudios no pudieron establecer una clara relación entre la acumulación de estos compuestos en frutos de tomate y la reducción del aporte de $\mathrm{N}$ (Stewart et al., 2001; Benard et al., 2009)

En el caso de los carotenoides, Kuscu et al. (2014) observaron un aumento progresivo en el contenido de licopeno y $\beta$-caroteno a medida que la dosis de $\mathrm{N}$ se iba incrementando de $0 \mathrm{a}$ 
$120 \mathrm{~kg} \mathrm{~N} \mathrm{ha}^{-1}$, aunque dicho contenido se vio disminuido con dosis de $180 \mathrm{~kg} \mathrm{~N} \mathrm{ha}^{-1}$. Sin embargo, en su estudio, Benard et al. (2009) no pudieron encontrar una relación tan clara del efecto del $\mathrm{N}$ en la acumulación de carotenoides.

También se ha estudiado el efecto de la nutrición potásica en la acumulación de carotenoides y polifenoles. En ese sentido, Trudel y Ozbun $(1970,1971)$ encontraron que, al aumentar el aporte de $K$, se aumenta también el contenido en carotenoides de los frutos de tomate, con la única excepción del $\beta$-caroteno. Además, estos autores encontraron que el contenido en licopeno aumentaba rápidamente al aumentar el nivel de $\mathrm{K}$, llegando a su máximo con un aporte de $8 \mathrm{meq} \mathrm{I}^{-1}$. En la misma línea, Oded y Uzi (2003) también encontraron mayores acumulaciones de licopeno en tomates cultivados con la misma concentración de solución potásica.

Taber et al. (2008) determinaron que esa mayor acumulación de licopeno en respuesta a la dosis de K administrada depende del cultivar. Combinando ambos efectos, Serio et al. (2007) estudiaron el efecto del aporte de $\mathrm{K}$ en cultivares de tomate high pigment y estándar obteniendo mayores contenidos de licopeno al aumentar el contenido de $\mathrm{K}$ de la solución nutritiva. Estos autores sugirieron que este efecto del K podría deberse a la estimulación de algunos enzimas específicos que participan en la ruta biosintética de los carotenoides.

En lo que respecta al fósforo (P), Saito y Kano (1970) encontraron mayores contenidos en licopeno al aumentar el aporte de $\mathrm{P}$ desde 0 hasta $100 \mathrm{mg} \mathrm{l}^{-1}$ en cultivo hidropónico. En esa línea Zelená et al. (2009) observaron un incremento significativo en la acumulación de este carotenoide en tomates para procesado obtenidos de plantas que habían sido sometidas a distintas formas de fertilizantes azufrados. Sin embargo, otros autores no encontraron grandes diferencias en el contenido de licopeno en un estudio del zumo de tomate obtenido a partir de frutos sometidos a diferentes dosis de dicho elemento mineral (Oke et al., 2005). Por otro lado, Stewart et al. (2001) encontraron que una deficiencia de $\mathrm{P}$ provoca un aumento en el contenido de flavonoles en tomate al inicio del proceso de maduración.

\subsection{Sistema de cultivo}

Muy relacionado con el abonado, el sistema de cultivo es otro factor que puede tener un efecto sobre el contenido en carotenoides y polifenoles de los frutos de tomate. En ese sentido, se ha propuesto al modo de cultivo ecológico como una alternativa para conseguir mejorar los contenidos de estos compuestos a la vez que se emplea una práctica agronómica más respetuosa con el medio ambiente.

Se han llevado a cabo varios estudios acerca de cómo afecta el cultivo ecológico a la acumulación de estos compuestos, aunque los resul tados obtenidos son en al gunas ocasi on es contradictorios. Según Caris-Veyrat et al. (2004), los tomates cultivados en condiciones de cultivo ecológico presentaban mayores acumulaciones de los carotenoides licopeno y $\beta$ caroteno. Estos autores también encontraron mayores acumulaciones para los polifenoles, rutina y naringenina en tomates ecológicos, pero no así para el ácido clorogénico, que estuvo presente a mayores concentraciones en los tomates del cultivo convencional. Sin embargo, estas diferencias fueron menos evidentes si se tiene en cuenta el peso seco. En esas condiciones, el cultivo ecológico solo favorecería la acumulación de rutina y $\beta$-caroteno. 
Vinha et al. (2014) encontraron mayores contenidos de licopeno, polifenoles totales y flavonoides en tomates provenientes de cultivo ecológico. En ese sentido, los tomates ecológicos tenían un $20 \%$ más de licopeno, un $24 \%$ más de polifenoles totales y un $21 \%$ más de flavonoides. De forma similar, Hallmann (2012) encontró mayores contenidos de algunos polifenoles en tomates ecológicos. En un estudio posterior, Hallman et al. (2013) encontraron contenidos de $\beta$-caroteno y flavonoides totales significativamente mayores en tomates ecológicos. Además, los tomates producidos con agricultura ecológica destacaron por sus acumulaciones significativamente mayores de los flavonoides quercetina y rutina.

En la misma línea, Mitchell et al. (2007), encontraron mayores acumulaciones de flavonoles en tomates provenientes de cultivo ecológico. En ese sentido, los contenidos de quercetina y kaempferol encontrados por estos autores en los tomates ecológicos fueron un $79 \%$ y un $97 \%$ mayores respectivamente a los contenidos de los tomates cultivados en condiciones convencionales. Además, estos autores también destacaron que el cultivo ecológico es capaz de aumentar la acumulación de flavonoides con el paso de las campañas, posiblemente al debido a la limitación en el aporte de $\mathrm{N}$ en las plantas cultivadas en condiciones ecológicas, lo que favorecería la acumulación de flavonoides.

Otros autores encontraron aumentos espectaculares en la acumulación de polifenoles en tomates ecológicos, que llegan a ser un $139 \%$ mayores que los tomates cultivados siguiendo las prácticas convencionales (Oliveira et al., 2013). Además, estos autores destacaron que los tomates provenientes del cultivo ecológico experimentan unas condiciones estresantes que resultan en un estrés oxidativo y la acumulación de mayores concentraciones de polifenoles entre otros compuestos.

No obstante, existe controversia acerca de los beneficios del cultivo ecológico en la acumulación de este tipo de compuestos, ya que en otras ocasiones sus beneficios no están tan claros. En ese sentido, Riahi et al. (2009), no encontraron diferencias para los contenidos de licopeno y polifenoles totales, al comparar sistema de producción convencional y ecológico en un estudio con distintos cultivares de tomate para consumo en fresco y procesado. En la misma línea, Rossi et al. (2008) no encontraron diferencias para la acumulación de $\beta$-carote no en tomate, comparando tres modos de cultivo: convencional, manejo integrado de plagas y ecológico. Estos autores encontraron que los modos de cultivo ecológico e integrado influyen negativamente en la acumulación de licopeno, siendo el convencional el más favorable para su acumulación. Por otro lado, Hallmann et al. (2013) no encontraron diferencias en los contenidos de ácidos fenólicos comparando zumos hechos tomates ecológicos y con tomates cultivados convencionalmente, con la única excepción del ácido clorogénico, presente en mayores concentraciones en los tomates ecológicos. Estos autores encontraron que los contenidos de licopeno en los zumos hechos con tomates provenientes de la agricultura ecológica presentaban acumulaciones de licopeno significativamente menores.

En la misma línea, Anton et al. (2014) encontraron un efecto limitado del sistema de cultivo en la acumulación de polifenoles. Estos autores destacaron que el cultivo ecológico solo es capaz de aumentar los contenidos de unos pocos compuestos y que el contenido en polife noles de los tomates es más dependiente de los efectos del año y del genotipo.

Nuestro grupo ya estudió previamente el efecto del cultivo ecológico sobre el contenido en carotenoides, no observándose diferencias para el contenido en licopeno y pequeños 
aumentos (16\%) en el caso del $\beta$-caroteno (Lahoz et al., 2016a). En aquel momento quedó por estudiar el posible efecto sobre la acumulación del resto de principales compuestos funcionales: Ios polifenoles y el ácido L-ascórbico.

\subsection{Riego}

La dosis de riego puede alterar la acumulación de compuestos en los frutos de tomate y por tanto influir en su calidad. Este efecto puedeestar relacionado con una menor acumulación de agua y por tanto por un efecto de concentración, aunque no es necesariamente el único efecto (Mitchell et al., 1991). En este sentido, el riego deficitario se ha propuesto como estrategia para aumentar la calidad organoléptica de los frutos, ya que daría lugar a una mayor acumulación de solutos relacionados con el sabor. A pesar de que una de las principales pegas de esta estrategia reside en la disminución del tamaño del fruto y un consiguiente menor rendimiento, lo cierto es que un buen manejo podría minimizar dichas pérdidas (Mitchell et al., 1991; Veit-Köhler et al., 1999). No obstante, estudios recientes abordando el efecto del ri ego deficitario prolongado ponen de manifiesto que la perdida de productividad puede llegar a ser importante $y$, aunque pueda tener efectos positivos al aumentar la acumulación de compuestos volátiles relacionados con el aroma (Lahoz et al., 2016b), es un efecto muy restrictivo para el productor.

Siguiendo las mismas premisas, se ha estudiado el efecto que podría tener una reducción de la aportación de agua al cultivo sobre la acumulación de compuestos funcionales. Algunos de los estudios se han elaborado restringiendo completamente el riego o aplicando un riego deficitario. Respecto a la primera estrategia, Pernice et al. (2010) encontraron mayores contenidos de carotenoides totales en tomates que solo obtuvieron agua de la almacenada por el suelo en las precipitaciones comparados con los regados normalmente. Este efecto también fue extensible a los flavonoides totales, pero solo en uno de los dos genotipos estudiados. Pék et al., (2014), también con reducciones severas de la dosis de riego, encontraron mayores contenidos de carotenoides y flavonoides en tomates a los que solo se les proporcionaba el agua proveniente de la lluvia frente a tomates regados normalmente. Este efecto fue especialmente significativo para la rutina, uno de los principal es compuestos fenólicos del tomate, aunque la respuesta del resto de compuestos fenólicos fue dependiente de la fecha de cosecha. Esos autores atribuyeron la menor concentración de este tipo de compuestos a un efecto de dilución en los frutos con mayores dosis de riego. En el mismo sentido, Barbagallo et al. (2013) encontraron que la ausencia de riego tras el trasplante produce un aumento del $13 \%$ en el contenido total de polifenoles, comparado con el riego completo. Estos resultados fueron opuestos a los obtenidos para los carotenoides, donde la concentración de licopeno fue ligeramente menor en los tomates cultivados bajo estés hídrico (110.7 $\mathrm{mg} \mathrm{kg}^{-1}$ ) comparado con los tomates cultivados en condiciones no estresantes (126.3 $\left.\mathrm{mg} \mathrm{kg}^{-1}\right)$.

En nuestro propio grupo, el estudio de un riego deficitario continuado puso de manifiesto que los efectos sobre la acumulación de carotenoides son muy limitados con dosis del $75 \%$ de la $\mathrm{ET}_{\mathrm{c}}$, de hecho, la acumulación de licopeno no cambia, mientras que la pérdida de producción media alcanzaría el 16\% (Lahoz et al., 2016b). Por el contrario, en dicho estudio sí que se 
observó que un exceso de irrigación provocaría un efecto de dilución sobre la acumulación de licopeno.

Dado que los efectos de un riego deficitario continuado pueden ser demasiado severos, se han propuesto estrategias de déficit de riego controlado, en las que se aplica una dosis de riego reducida tras el cuajado de fruto (Pernice et al., 2010). Siguiendo esta estrategia, Pernice et al. (2010) no encontraron diferencias para la acumulación de carotenoides totales con un riego reducido $\left(200 \mathrm{~m}^{3} \mathrm{ha}^{-1}\right.$ ) aplicado 40 días tras el trasplante. Por otro lado, el contenido en polifenoles totales si que se vio incrementado en los frutos expuestos a un riego reducido,

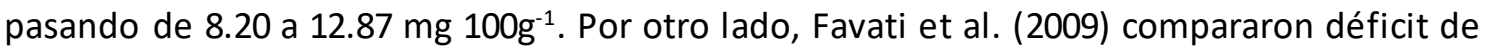
riego continuo o controlado, encontrando que un riego restrictivo durante todo el ciclo de cultivo (50-50\% $\mathrm{ET}_{\mathrm{c}}$ ) o en la última parte del ciclo de cultivo (100-50\% $\mathrm{ET}_{\mathrm{c}}$ ) favoreció la acumulación de licopeno y $\beta$-caroteno, especialmente con los regimenes más restrictivos.

De esta forma, se postula el riego deficitario controlado como una posible medida encaminada a obtener los beneficios del riego deficitario, pero con un impacto reducido sobre la producción.

\section{La cuantificación de polifenoles: una limitación en la evaluación de estrategias de mejora de su contenido}

Una de las mayores limitaciones a la hora de abordar el incremento en la acumulación de compuestos bioactivos reside en la posibilidad de disponer de metodologías de análisis lo más precisas rápidas y baratas que se pueda. Esto es así, por un lado, porque el cribado de germoplasma destinado a la identificación de fuentes de variación y el desarrollo de programas de retrocruce requieren la evaluación de grandes cantidades de muestras. Por otro lado, la evaluación del efecto del ambiente y de distintas estrategias de cultivo también requiere analizar cantidades importantes de individuos. Estas metodologías serán además básicas para establecer controles de calidad en el caso de que se consiguieran comercializar materiales de alto valor añadido.

En el caso del ácido L-ascórbico, se dispone de metodológia eficiente desarrollada por el grupo en el que se enmarca la presente tesis (Galiana-Balaguer et al., 2001). Para el análisis de carotenoides se ha estado empleando rutinariamente la medodología basada en cromatografía líquida de alta resolución (HPLC) de fase reversa descrita por García-Plazaola y Becerril (1999), además de disponer de alternativas en electroforesis capilar desarrolladas por el grupo (Adalid et al., 2007).

Sin embargo, no se disponía de métodos lo suficientemente adaptados a las necesidades de programas de mejora de evaluación agronómica del contenido en polifenoles. Por lo que se contempló la necesidad de desarrollar metodologías propias. A continuación, se describe el estado de la metodología al inicio de la presente tesis.

\subsection{Métodos para la cuantificación de polifenoles}

Tradicionalmente, la cuantificación de polifenoles se basa en la determinación de su contenido total mediante el método Folin-Ciocalteu (Singleton y Rossi, 1965; Singleton et al., 1999; 
Georgé et al., 2005). Este método se basa en la reacción de los compuestos fenólicos presentes en la muestra con el reactivo de Folin-Ciocalteu. Este reactivo se compone de una mezcla de los ácidos fosfowolfrámico $\left(\mathrm{H}_{3} \mathrm{PW}_{12} \mathrm{O}_{40}\right)$ y fosfomolíbdico $\left(\mathrm{H}_{3} \mathrm{PMo}_{12} \mathrm{O}_{40}\right)$, que son reducidos, en condiciones alcalinas, por los polifenoles presentes en la muestra a los óxidos de wolframio $\left(\mathrm{W}_{8} \mathrm{O}_{23}\right)$ y molibdeno $\left(\mathrm{Mo}_{8} \mathrm{O}_{23}\right)$ de color azul. Esta coloración resultante se mide a $760 \mathrm{~nm}$ y proporciona una determinación indirecta de la concentración total de polifenoles, que normalmente se expresa como equivalentes de ácido gálico (GAE) o equivalentes de catequina (Georgé et al., 2005). Si bien esta metodología es sencilla y no requiere de instrumentación compleja, sólo permite obtener información sobre los polifenoles totales y no da información sobre qué compuestos fenólicos están presentes en la muestra. Este hecho puede ser un inconveniente para programas de mejora o en controles de calidad, donde se requiere la cuantificación individual de los polifenoles de la muestra. Otro inconveniente de esta metodología es que, el reactivo de Folin-Ciocalteu, no es del todo específico ya que también reacciona con algunas sustancias no fenólicas, produciendo una sobrestimación del conten ido en polifenoles (Georgé et al., 2005). Pese a estas limitaciones, el método Folin-Ciocalteu se sigue utilizando actualmente para cuantificar el contenido total de polifenoles en muestras de hortalizas y sus productos derivados (Luthria et al., 2006; Fu et al., 2011; Wootton-Beard et al., 2011; Rizzo et al., 2016).

Para llevar a cabo programas de mejora del contenido de polifenoles, o bien para realizar controles de calidad, es necesario contar con metodologías analíticas rápidas, económicas, que permitan cuantificar de forma individual los compuestos fenólicos y que hagan posible analizar un gran número de muestras en poco tiempo. En ese sentido, la HPLCy la electroforesis capilar (CE) son técnicas instrumentales más utilizadas para abordar esta tarea.

Muchos de estos métodos cromatográficos que evalúan de forma individual los polifenoles en muestras de frutas y hortalizas se fundamentan en una hidrólisis de los glicósidos como paso previo a la determinación de las agliconas resultante por HPLC (Hertog et al., 1992; Crozie r et al., 1997; Torres et al., 2005). En el caso concreto del tomate, Crozier et al. (1997) no encontraron flavonoides libres en los extractos crudos, pero sí encontraron niveles detectables de quercetina tras una hidrólisis ácida a altas temperaturas con ácido clorhídrico diluido en metanol. En la misma línea, Matinez-Valverde et al. (2002) encontraron los flavonoides quercetina, kaempferol y naringenina tras una hidrólisis ácida de los extractos de tomate. Además, se han usado también otros tipos de hidrólisis para liberar las agliconas como la hidrólisis básica o la enzimática. En ese sentido, Giuntini et al. (2008) aplicaron una hid rólisis básica con hidróxido sódico diluido como paso previo a la extracción de los ácidos hidroxicinámicos de dos híbridos de tomate. Por otro lado, Torres et al. (2005) utilizaron una hidrólisis enzimática con HP-2 $\beta$-glucosidasa para detectar cantidades variables de quercetina, kaempferol y naringenina en diferentes partes del tomate. Además, estos autores destacaron la mayor eficiencia de la hidrólisis enzimática comparada con la hidrólisis ácida, posiblemente debido a la mayor especificidad de la HP-2 $\beta$-glucosidasa en el proceso de desglicolización. Según estos autores, esta mayor especificidad permitiría hidrolizar un mayor número de glicósidos para liberar un mayor número de flavonoides comparado con la hidrólisis ácida combinada o no con altas temperaturas.

Uno de los principales inconvenientes de la hidrólisis es que se trata de un paso que re quiere mucho tiempo, y que además puede producir la degradación de algunos polifenoles como los 
flavonoles y flavanonas presentes en la muestra (Merken et al., 2001), entre los que se encuentran la quercetina y la naringenina respectivamente, dos de los principales poli fenoles del tomate. Una alternativa para solventar este inconveniente es la cuantificación di recta de los polifenoles en la muestra, ya sea en forma de glicósidos o agliconas. En ese sentido, Moco et al. (2006) encontraron una gran variedad de glicósidos de los ácidos hidroxicinámicos caféico, coumárico y de los flavonoles quercetina y kaempferol en muestras de piel de tomate sin hidrolizar, mientras que en tras hidrólisis ácida se detectaron sus correspondientes agliconas.

En las últimas décadas se han publicado multitud de métodos analíticos para la determinación de polifenoles en tomate y sus productos derivados. La mayoría de ellos, emplean HPLC de fase reversa (RP-HPLC) utilizando columnas de C18y acoplando distintos detectores, a un que los más comunes son el detector de ultravioleta-visible (UV-vis), detector de diodo (DAD), de masas (MS) o masas en tándem (MS/MS), pero en muchos casos las condiciones para el análisis de ácidos fenólicos y de flavonoides cambian (Martínez-Valverde et al., 2002; Mattila y Kumpulainen, 2002; Helmja et al., 2008; Barros et al., 2012; Vallverdú-Queralt et a., 2012).

Una evaluación eficiente de polifenoles en tomate requiere un único análisis para la determinación de ácidos fenólicos y flavonoides, ahorrando tiempo y costes. Sin embargo, la mayoría de métodos cromatográficos que permiten la determinación simultánea de ambos grupos de compuestos requieren tiempos de análisis muy largos, del orden de 1 hora o más por cada muestra (Sakakibara et al., 2003; Gautier et al., 2008). Estos largos periodos de análisis dificultan la evaluación rápida de materiales haciendo que su uso en programas de mejora sea muy limitado. Existen métodos más cortos, aunque no permiten la cuantificación de forma simultánea de ambos grupos (Mattila y Kumpulainen, 2002; Repollés et al., 2006; Biesagra et al., 2009; Dall'Asta et al., 2009).

Con infraestructura más cara, sí que es posible aplicar procedimientos capaces de determin ar flavonoides y ácidos fenólicos al mismo tiempo en tomate. En este caso, se requiere el uso de espectrometría de masas como detector (Helmja et al., 2008; Vallverdú-Queralt et al., 2010; Barros et al., 2012). Estas metodologías consiguen bajar los límites de detección y además permiten detectar una gran variedad de glicósidos, permitiendo ampliar el estu dio a no solo los más representativos. En ese sentido, Barros et al. (2012) consiguieron la identificación tentativa de 20 glicósidos y derivados de compuestos fenólicos en muestras de tomate en poco más de 20 minutos. En la misma línea Vallverdú-Queralt et al. (2010) consiguieron la identificación de 38 compuestos en muestras de tomate usando OrbiTrap, tres de ellos descritos por primera vez en tomate por estos autores. No obstante, el uso de esta instrumentación más sofisticada y cara limita la posibilidad de acceso a muchos laboratorios de mejora o control de calidad, por lo que los detectores de absorbancia, UV-vis y DAD, se postulan como las mejores opciones para abordar este problema.

En los últimos años, la utilización de detectores de masas junto con la popularización de las columnas de tamaño de partícula menores de $2 \mu \mathrm{m}$ han permitido mejorar la cuantificación de polifenoles en matrices complejas como alimentos, posibilitando separaciones eficaces, sensibles y selectivas (Motilva et al., 2013). Cuando se trabaja con columnas de tamaño de partícula sub- $2 \mu \mathrm{m}$, la presión del sistema se dispara por encima de los $400 \mathrm{bar}$, por lo que se requiere trabajar con equipos específicos de cromatografía líquida de ultra alta resolución 
(UHPLC). Este tipo de columnas se han aplicado con éxito en los últimos años para el desarrollo de metodologías para la determinación de ácidos hidroxicinámicos, flavonoles y flavanonas en muestras de tomate y sus productos derivados (Ribas-Agustí et al., 2012; Di Lecce et al., 2013). Sin embargo, la posibilidad de transferencia de estos métodos de UHPLC a otras plataformas más económicas como el HPLC acoplado a DAD han permitido un importante ahorro en equipamiento (Ribas-Agustí et al., 2012).

Existen alternativas para conseguir separaciones casi tan eficaces como con las columnas sub$2 \mu \mathrm{m}$, pero usando equipos de HPLC convencionales. En este sentido se han desarrollado diversas estrategias analíticas relacionadas con la tecnología de la columna en HPLC para el análisis de polifenoles en muestras de alimentos, entre las que se incluyen columnas monolíticas (Chinnici et al., 2004; Biesagra et al., 2009) y las columnas de núcleo fundido o fused core (Rostagno et al., 2011; Manns y Mansfield, 2012; Natale et al., 2015). En el caso concreto del tomate, Biesagra et al. (2009) utilizaron columnas monolíticas para conseguir la separación de los polifenoles rutina, quercetina, naringenina y los ácidos $p$-coumárico/ferúlico en menos de 14 minutos estudiando el proceso de maduración del tomate. Por otro lado, las columnas de núcleo fundido se han aplicado a la determinación de polifenoles en distintas matrices de alimentos, como por ejemplo infusiones y refrescos (Rostagno et al., 2011), en mostos y vinos (Manns y Mansfield, 2012) o en matrices con bajos contenidos de polifenoles como brácteas de alcachofa y aguas residuales de molino de aceite junto con detección amperométrica (Natale et al., 2015). Sin embargo, existe muy poca información acerca de la aplicación de este tipo de columnas en el análisis de polifenoles en tomate, por lo que resultaría interesante estudiar su aplicabilidad al análisis de polifenoles en esta matriz.

Como alternativa al HPLC, las técnicas electroquímicas como la CE están cobrando una mayor importancia en el análisis de polifenoles en frutas, hortalizas y derivados. Las principales ventajas de la CE se deben sobre todo a sus al tas eficiencias de separación, tiempos de análisis cortos, pequeñas cantidades de muestra, bajo consumo en disolventes y posibilidad de variar la selectividad con la adición de modificadores. Debido a su sencillez y amplia disponibilidad en multitud de laboratorios, uno de los detectores más ampliamente utilizados en CE para la detección de polifenoles en este tipo de matrices es el detector UV o de diodo (DAD) (Ehal a et al., 2005; Herrero-Martínez, et al., 2007; Helmja et al., 2007; Helmja et al., 2008; Zhang et al., 2008; Fukuji et al., 2010; Lee et al., 2012; Navarro et al., 2014). No obstante, el uso de estos detectores de absorbancia es responsable de uno de los principales inconvenientes de la CE frente a HPLC: los peores límites de detección. Esto se debe a que en el detector de UV, la detección se lleva a cabo directamente en el capilar donde se produce la separación, de un tamaño muy pequeño $(50 \mu \mathrm{m})$, por lo que el camino óptico es también muy corto, lo que se traduce en unos peores límites de detección comparado con las celdas de detección de los detectores UV de HPLC. Para evitar esta problemática se han desarrollado diseños de capilar alternativos que consiguen ampliar la zona de detección como los capilares en forma de Z o los de burbuja. Otra alternativa para mejorar los límites de detección es mediante el uso de detectores más sensibles como los de masas (Gómez-Caravaca et al., 2008) o electroquímicos (Peng et al., 2008), o bien usando técnicas de pre concentración en columna como el stacking (Zhang et al., 2008; Honegr et al., 2010; Lee et al., 2012). En ese sentido, Honegr et al. (2010) consiguieron aumentar la absorbancia hasta 90 veces usando large volumen sample stacking (LVSS) analizando polifenoles en extractos de plantas. 
Los dos modos de trabajo más usados en CE para el análisis de polifenoles en frutas y hortalizas son la electroforesis capilar zonal (CZE) (Ehala et al., 2005; Helmja et al., 2008; Peng et al., 2008; Fukuji et al., 2010; Lee et al., 2012; Navarro et al., 2014) y la cromatografía micelar electrocinética (MEKC) (Herrero-Martínez et al., 2007), empleando tampones fosfato, tetraborato o borato a pH básico. Además, en MEKC al tampón de carrera se añade un surfactante como por ejemplo el dodecilsulfato sódico, colato sódico..., para formar una pseudofase estacionaria que ayude en la separación de los analitos. Gracias a esto, a diferencia de lo que ocurre con CZE donde los analitos cargados se separan en función de su movilidad electroforética, en MEKC es posible separar analitos cargados junto a neutros, debido a los diferentes coeficientes de partición de estos entre la fase acuosa y micelar. Pese a estas ventajas de la MEKC, la cantidad de artículos que trabajan con este modo para el análisis de polifenoles en frutas y verduras es muy limitado, y se centran más en polifenoles en infusiones como el té (Liu et al., 2014; Ye et al., 2014) o en raíces de plantas (Xiao et al., 2015).

Otros autores también tratan de mejorar las separaciones añadiendo al tampón de carrera disolventes orgánicos como metanol o acetonitrilo en proporciones que van desde el $1 \%$ hasta el 20\% (Ehala et al., 2005; Herrero-Martínez et al., 2007; Fukuji et al., 2010). En ese sentido, Herrero-Martínez et al. (2007) encontró que la presencia de metanol en el tampón de carrera era capaz de disminuir las movilidades electroforéticas de los analitos, pero no la de los interferentes de la matriz, lo que permitió la separación y cuantificación todos los compuestos estudiados.

Pese a estas ventajas, existen muy pocos trabajos sobre la determinación de polifenoles en tomate (Helmja et al., 2007; Helmja et al., 2008; Peng et al., 2008), por lo que sería interesante aprovechar las ventajas de la electroforesis capilar frente a la cromatografía empleando métodos específicamente diseñados para muestras de tomate.

Existen otras técnicas instrumentales para la determinación de polifenoles, como por eje mplo la cromatografía de gases (GC) (Zafra et al., 2006; Viñas et al., 2009; Viñas et al., 2011). No obstante, para conseguir analizar analitos polares no volátiles como los polifenoles por GC, es necesario un paso previo de derivatización para obtener sus derivados volátiles. En este sentido Viñas et al. (2009), utilizó bis(trimetilsilil)trifluoroacetamida (BSTFA) como agente derivatizante para el análisis de polifenoles en vino y uvas, previo a su análisis por GC-MS. Sin embargo, la necesidad este paso previo de derivatización hace que su aplicabilidad al anál isis de en programas de mejora de tomate sea poco viable.

Además de disponer de un método de análisis lo suficientemente corto, otra limitación en la determinación de los principales polifenoles en tomate reside en la extracción previa al análisis. De hecho, este paso es incluso más limitante, por el tiempo requerido para la extracción. Por esta razón, en este tipo de programas es necesario contar con métodos eficientes de extracción que aseguren la máxima recuperación de polifenoles en el menor tiempo posible.

\subsection{Métodos para la extracción de polifenoles}

Generalmente, la extracción de los polifenoles de la matriz vegetal se lleva a cabo con disolventes orgánicos en disolución acuosa. En el caso del tomate la extracción se suele llevara 
cabo con mezclas metanol-agua en proporciones variables que van desde $20 \%$ hasta $90 \%$ de metanol (Crozier et al., 1997; Mattila y Kumpulainen, 2002; Martínez-Valverde et al., 2002; Sakakibara et al., 2003; Torres et al., 2005; Moco et al., 2006; Helmja et al., 2008; Peng et al., 2008; Biesagra et al., 2009; Dall'Asta et al., 2009; Barros et al., 2012; Vallverdú-Queralt et al., 2012). Para ayudar en la extracción, algunos autores añaden pequeñas proporciones de hexano (Torres et al., 2005) o ácido, como por ejemplo ácido acético (Mattila y Kumpulainen, 2002; Sakakibara et al., 2003) o ácido fórmico (Vallverdú-Queralt et al., 2010; Di Lecce et al., 2013).

En algunos trabajos en tomate, también se han usado otros solventes para la extracción de polifenoles, como por ejemplo mezclas acuosas de etanol (Di Lecce et al., 2013), acetona (Simonetti et al., 2005) o mezclas de hexano/acetona/etanol (Motilva et al., 2014). Sin embargo, estos autores encontraron recuperaciones bajas de quercetina usando una mezcla de hexano/acetona/etanol, lo que podría ser un inconveniente en la extracción de este tipo de compuestos.

Tradicionalmente, la extracción de polifenoles se realizado mediante reflujo a altas temperaturas con metanol acuoso en presencia de ácido clorhídrico (Hertog et al., 1992; Crozier et al., 1997; Martínez-Valverde et al., 2002). Con este tipo de extracción se obtienen unas buenas recuperaciones de los polifenoles, pero tiene algunas desventajas como el gran consumo de solventes y los largos tiempos de extracción. Además, existe la posibilidad degradación de algunos de los polifenoles durante la extracción si no se ajustan bien los tiempos y concentración de ácido (Hertog et al., 1992). En ese sentido, Hertog et al. (1992) encontraron que periodos de extracción mayores de 4 horas pueden producir la pérdida de flavonoles, hecho que se acentúa si se aumenta la concentración de ácido. Además, otro inconveniente de este tipo de extracción es que la infraestructura requerida limita el nú mero de muestras que se pueden extraer al mismo tiempo, lo que dificulta su aplicabilidad a programas de mejora.

Estas dificultades operativas han hecho que durante las últimas décadas se hayan popularizado otros métodos de extracción capaces de reducir el consumo de disolventes de forma considerable y aumentar la velocidad del proceso de extracción, a la vez que lo simplifican. En ese sentido, una de las técnicas más utilizadas para la extracción de polifenoles en muestras vegetales ha sido la extracción asistida por ultrasonidos (Mattila y Kumpulainen, 2002; Hel mja et al., 2008; Peng et al., 2008; Jerman et al., 2010; Vallverdú-Queralt et al., 2012; Di Lecce et al., 2013). También se han desarrollado otras técnicas como la extracción con fluidos supercríticos (Adil et al., 2007; Helmja et al., 2008), la extracción asistida por microondas (Li et al., 2012; Pinela et al., 2016) o la extracción con líquidos presurizados (Alonso-Salces et al., 2001; Howard y Pandjaitan, 2008). De entre todas ellas, la extracción asistida por ultrasoni dos es una alternativa barata, simple y eficiente que puede ser de gran utilidad en la extracción de compuestos fenólicos en tomate como al ternativa a las técnicas de extracción convencionales.

Otro factor a tener en cuenta en el proceso de extracción es la naturaleza de la muestra. Existen numerosos trabajos que se centran en la extracción de polifenoles en muestras liofilizadas de tomate (Crozier et al., 1997; Martínez-Valverde et al., 2002; Sakakibara et al., 2003; Torres et al., 2005; Peng et al., 2008). Sin embargo, la liofilización requiere de equipamiento específico, que puede no estar disponible en todos los laboratorios, y ad emás 
alarga el tiempo total de extracción al añadir un paso extra de pre-tratamiento de muestra, lo que puede ser un inconveniente a la hora de analizar grandes cantidades de muestra. Otro inconveniente de la liofilización es que puede producir la pérdida de algunos polifenoles importantes en tomate. En ese sentido, Martí et al. (2015) comprobaron que el proceso de liofilización puede producir menores recuperaciones de naringenina en tomate.

Una alternativa rápida es la extracción de los polifenoles directamente en la muestra en fresco. Algunos autores utilizan muestra en fresco para extraer los polifenoles trabajando tanto en tomate como en algunos productos derivados (Simonetti et al., 2005; Dall'Asta et al., 2009; Vallverdú-Queralt et al., 2010; Di Lecce et al., 2013; Motilva et al., 2014). Este menor tratamiento previo puede ser de utilidad en programas de mejora, ya que simplifica y acorta el proceso de análisis. 


\section{Bibliografía}

Adalid, A. M., Herrero-Martínez, J. M., Roselló, S., Maquieira, A., \& Nuez, F. (2007). Fast determination of prominent carotenoids in tomato fruits by CEC using methacrylate ester-based monolithic columns. Electrophoresis, 28(22), 4120-4127.

Adegoroye, A. S., \& Jolliffe, P. A. (1987). Some inhibitory effects of radiation stress on tomato fruit ripening. Journal of the Science of Food and Agriculture, 39(4), 297-302.

Adil, I. H., Cetin, H. I., Yener, M. E., \& Bayındırlı, A. (2007). Subcritical (carbon dioxide+ ethanol) extraction of polyphenols from apple and peach pomaces, and determination of the antioxidant activities of the extracts. The journal of supercritical fluids, 43(1), 55-63.

Alba, R., Cordonnier-Pratt, M. M., \& Pratt, L. H. (2000). Fruit-localized phytochromes regulate Iycopene accumulation independently of ethylene production in tomato. Plant physiology, 123(1), 363370.

Alonso-Salces, R. M., Korta, E., Barranco, A., Berrueta, L. A., Gallo, B., \& Vicente, F. (2001). Pressurized liquid extraction for the determination of polyphenols in apple. Journal of chromatography A, 933(1), 37-43.

Anton, D., Matt, D., Pedastsaar, P., Bender, I., Kazimierczak, R., Roasto, M., ... \& Püssa, T. (2014). Three-year comparative study of polyphenol contents and antioxidant capacities in fruits of tomato (Lycopersicon esculentum Mill.) cultivars grown under organic and conventional conditions. Journal of agricultural and food chemistry, 62(22),5173-518

Apel, W., \& Bock, R. (2009). Enhancement of carotenoid biosynthesis in transplastomic tomatoes by induced lycopene-to-provitamin A conversion. Plant Physiology, 151(1), 59-66.

Azari, R., Tadmor, Y., Meir, A., Reuveni, M., Evenor, D., Nahon, S., ... \& Levin, I. (2010). Light signaling genes and their manipulation towards modulation of phytonutrient content in tomato fruits. Biotechnology advances, 28(1), 108-118.

Baldwin, E. A., Scott, J. W., Einstein, M. A., Malundo, T. M. M., Carr, B. T., Shewfelt, R. L., \& Tandon, K. S. (1998). Relationship between sensory and instrumental analysis for tomato flavor. Jo urnal of the American Society for Horticultural Science, 123(5), 906-915.

Ballester, A. R., Molthoff, J., de Vos, R., te Lintel Hekkert, B., Orzaez, D., Fernández-Moreno, J. P., ... \& Ykema, M. (2010). Biochemical and molecular analysis of pink tomatoes: deregulated expression of the gene encoding transcription factor SIMYB12 leads to pink tomato fruit color. Plant physiology, 152(1), 71-84.

Baqar, M. R., \& Lee, T. H. (1978). Interaction of CPTA and high temperature on carotenoid synthesis in tomato fruit. Zeitschrift für Pflanzenphysiologie, 88(5), 431-435.

Barbagallo, R. N., Di Silvestro, I., \& Patanè, C. (2013). Yield, physicochemical traits, antioxidant pattern, polyphenol oxidase activity and total visual quality of field-grown processing tomato cv. Brigade as affected by water stress in Mediterranean climate.Journal of the Science of Food and Agriculture, 93(6), 1449-1457.

Barros, L., Dueñas, M., Pinela, J., Carvalho, A. M., Buelga, C. S., \& Ferreira, I. C. (2012). Characterization and quantification of phenolic compounds in four tomato (Lycopersicon esculentum L.) farmers' varieties in northeastern Portugal homegardens. Plant foods for human nutrition, 67(3), 229234.

Bénard, C., Gautier, H., Bourgaud, F., Grasselly, D., Navez, B., Caris-Veyrat, C., ... \& Génard, M. (2009). Effects of low nitrogen supply on tomato (Solanum lycopersicum) fruit yield and quality with 
special emphasis on sugars, acids, ascorbate, carotenoids, and phenolic compounds. Journal of agricultural and food chemistry, 57(10), 4112-4123.

Biesaga, M., Ochnik, U., \& Pyrzynska, K. (2009). Fast analysis of prominent flavonoids in tomato using a monolithic column and isocratic HPLC. Journal of separation science, 32(15-16), 2835-2840.

Bigliardi, B., \& Galati, F. (2013). Innovation trends in the food industry: the case of functional foods. Trends in Food Science \& Technology, 31(2), 118-129.

Bino, R. J., De Vos, C. H., Lieberman, M., Hall, R. D., Bovy, A., Jonker, H. H., ... \& Levin, I. (2005). The light-hyperresponsive high pigment-2dg mutation of tomato: alterations in the fruit metabolome. New Phytologist, 166(2), 427-438.

Boileau, T. W. M., Liao, Z., Kim, S., Lemeshow, S., Erdman, Jr, J. W., \& Clinton, S. K. (2003). Prostate carcinogenesis in $\mathrm{N}$-methyl-N-nitrosourea (NMU)-testosterone-treated rats fed tomato powder, Iycopene, or energy-restricted diets. Journal of the National Cancer Institute, 95(21), 15781586.

Bovy, A., de Vos, R., Kemper, M., Schijlen, E., Pertejo, M. A., Muir, S., ... \& Santos-Buelga, C. (2002). High-flavonol tomatoes resulting from the heterologous expression of the maize transcription factor genes LC and C1. The Plant Cell, 14(10), 2509-2526.

Brandt, S., Pék, Z., Barna, É., Lugasi, A., \& Helyes, L. (2006). Lycopene content and colour of ripening tomatoes as affected by environmental conditions.Journal of the Science of Food and Agriculture, 86(4), 568-572.

Bruhn, C. M., Feldman, N., Garlitz, C., Harwood, J., Ivans, E., Marshall, M., ... \& Williamson, E. (1991). Consumer perceptions of quality: apricots, cantaloupes, peaches, pears, strawberries, and tomatoes. Journal of Food Quality, 14(3), 187-195.

Butelli, E., Titta, L., Giorgio, M., Mock, H. P., Matros, A., Peterek, S., ... \& Martin, C. (2008). Enrichment of tomato fruit with health-promoting anthocyanins by expression of select transcription factors. Nature biotechnology, 26(11), 1301-1308.

Canady, M. A., Ji, Y., \& Chetelat, R. T. (2006). Homeologous recombination in Solanum Iycopersicoides introgression lines of cultivated tomato. Genetics, 174(4), 1775-1788.

Caris-Veyrat, C., Amiot, M. J., Tyssandier, V., Grasselly, D., Buret, M., Mikolajczak, M., ... \& Borel, P. (2004). Influence of organic versus conventional agricultural practice on the antioxidant microconstituent content of tomatoes and derived purees; consequences on antioxidant plasma status in humans. Journal of agricultural and food chemistry, 52(21), 6503-6509.

Carrillo-Lopez, A., \& Yahia,E. M. (2010). Qualitative and quantitativechanges in carotenoids and phenolic compounds in tomato fruit during ripening. Acta Horticulturae, 877, 1303-1308.

Causse, M., Friguet, C., Coiret, C., Lépicier, M., Navez, B., Lee, M., ... \& Grandillo, S. (2010). Consumer preferences for fresh tomato at the European scale: a common segmentation on taste and firmness. Journal of food science, 75(9).

Cebolla-Cornejo, J., Soler, S., \& Nuez, F. (2007). Genetic erosion of traditional varieties of vegetable crops in Europe: tomato cultivation in Valencia (Spain) as a case study. International Journal of Plant Production, 1(2), 113-128.

Cebolla-Cornejo, J., Roselló, S., \& Nuez, F. (2013). Selection of tomato rich in nutritional terpenes. In Ramawat, K. \& Mérillon, J. (eds.), Natural products Springer (pp. 2853-2881). Berlin Heidelberg.

Chalukova, M., \& Manuehyan, H. (1991). Breeding for carotenoid pigments in tomato. In Kalloo, G. (ed.), Genetic improvement of tomato. (pp. 179-195). Springer-Verlag, Berlin. 
Chinnici, F., Gaiani, A., Natali, N., Riponi, C., \& Galassi, S. (2004). Improved HPLC determination of phenolic compounds in cv. Golden Delicious apples using a monolithic column. Journal of agricultural and food chemistry, 52(1), 3-7.

Chun, O. K., Kim, D. O., Smith, N., Schroeder, D., Han, J. T., \& Lee, C. Y. (2005). Daily consumption of phenolics and total antioxidant capacity from fruit and vegetables in the American diet. Journal of the Science of Food and Agriculture, 85(10), 1715-1724.

Colliver, S., Bovy, A., Collins, G., Muir, S., Robinson, S., De Vos, C. H. R., \& Verhoeyen, M. E. (2002). Improving the nutritional content of tomatoes through reprogramming their flavonoid biosynthetic pathway. Phytochemistry Reviews, 1(1), 113-123.

Cortés-Olmos, C., Leiva-Brondo, M., Roselló, J., Raigón, M. D., \& Cebolla-Cornejo, J. (2014). The role of traditional varieties of tomato as sources of functional compounds. Journal of the Science of Food and Agriculture, 94(14), 2888-2904.

Cortés-Olmos, C., Vilanova, S., Pascual, L., Roselló, J., \& Cebolla-Cornejo, J. (2015). SNP markers applied to the characterization of Spanish tomato (Solanum Iycopersicum L.) landraces. Scientia Horticulturae, 194, 100-110.

Crozier, A., Lean, M. E., McDonald, M. S., \& Black, C. (1997). Quantitative analysis of the flavonoid content of commercial tomatoes, onions, lettuce, and celery. Journal of Agricultural and Food Chemistry, 45(3), 590-595.

Dall'Asta, C., Falavigna, C., Galaverna, G., Sforza, S., Dossena, A., \& Marchelli, R. (2009). A multiresidual method for the simultaneous determination of the main glycoalkaloids and flavonoids in fresh and processed tomato (Solanum Iycopersicum L.) by LC-DAD-MS/MS. Journal of separation science, 32(21), 3664-3671.

D’Ambrosio, C., Giorio, G., Marino, I., Merendino, A., Petrozza, A., Salfi, L., ... \& Cellini, F. (2004). Virtually complete conversion of lycopene into $\beta$-carotene in fruits of tomato plants transformed with the tomato lycopene $\beta$-cyclase (tlcy-b) cDNA. Plant Science, 166(1), 207-214.

Davey, M. W., Montagu, M. V., Inzé, D., Sanmartin, M., Kanellis, A., Smirnoff, N., ... \& Fletcher, J. (2000). Plant L-ascorbic acid: chemistry, function, metabolism, bioavailability and effects of processing. Journal of the Science of Food and Agriculture, 80(7), 825-860.

Davies, J. N., Hobson, G. E., \& McGlasson, W. B. (1981). The constituents of tomato fruit-the influence of environment, nutrition, and genotype. Critical Reviews in Food Science \& Nutrition, 15(3), 205-280.

Davuluri, G. R., Van Tuinen, A., Fraser, P. D., Manfredonia, A., Newman, R., Burgess, D., ... \& Bramley, P. M. (2005). Fruit-specific RNAi-mediated suppression of DET1 enhances carotenoid and flavonoid content in tomatoes. Nature biotechnology, 23(7), 890-895.

Dias, J. S. \& Ryder, E. (2011). World vegetable industry: production, breeding, trends. Horticultural Reviews, 38, 299.

Di Lecce, G., Martínez-Huélamo, M., Tulipani, S., Vallverdú-Queralt, A., \& Lamuela-Raventós, R. M. (2013). Setup of a UHPLC-QqQ-MS Method for the analysis of phenolic compounds in cherry tomatoes, tomato sauce, and tomato juice. Journal of agricultural and food chemistry, 61(35), 83738380 .

Dumas, Y., Dadomo, M., Di Lucca, G., \& Grolier, P. (2003). Effects of environmental factors and agricultural techniques on antioxidantcontent of tomatoes.Journal of the Science of Food and Agriculture, 83(5), 369-382. 
Eastwood, D. B., Orr, R. H., \& Brooker, J. R. (1986). Consumer stated preferences for fresh fruits and vegetables.

Ehala, S., Vaher, M., \& Kaljurand, M. (2005). Characterization of phenolic profiles of Northern European berries by capillary electrophoresis and determination of their antioxidant activity. Journal of agricultural and food chemistry, 53(16), 6484-6490.

Enfissi, E., Fraser, P. D., Lois, L. M., Boronat, A., Schuch, W., \& Bramley, P. M. (2005). Metabolic engineering of the mevalonate and non-mevalonate isopentenyl diphosphate-forming pathways for the production of health-promoting isoprenoids in tomato. Plant Biotechnology Journal, 3(1), 17-27.

FAO (2017). FAOSTAT. http://www.fao.org/faostat/en/\#data/QC (accedido el 18/09/2017).

Favati, F., Lovelli, S., Galgano, F., Miccolis, V., Di Tommaso, T., \& Candido, V. (2009). Processing tomato quality as affected by irrigation scheduling. Scientia Horticulturae, 122(4), 562-571.

FEPEX (2017). Federación Española de Asociaciones de Productores Exportadores de Frutas, Hortalizas, Flores y Plantas vivas. http://www.fepex.es/datos-del-sector/exportacion-importacionespa\%C3\%B1ola-frutas-hortalizas (accedido el 28/09/2017).

Fielding, J. M., Rowley, K. G., Cooper, P., \& O'Dea, K. (2005). Increases in plasma Iycopene concentration after consumption of tomatoes cooked with olive oil. Asia Pacific journal of clinical nutrition, 14(2), 131.

Fraser, P. D., Romer, S., Shipton, C. A., Mills, P. B., Kiano, J. W., Misawa, N., ... \& Bramley, P. M. (2002). Evaluation of transgenic tomato plants expressing an additional phytoene synthase in a fruitspecific manner. Proceedings of the National Academy of sciences, 99(2), 1092-1097.

Fray, R. G., Wallace, A., Fraser, P. D., Valero, D., Hedden, P., Bramley, P. M., \& Grierson, D. (1995). Constitutive expression of a fruit phytoene synthase gene in transgenic tomatoes causes dwarfism by redirecting metabolites from the gibberellin pathway. The Plant Journal, 8(5), 693-701.

Fu, L., Xu, B. T., Xu, X. R., Gan, R. Y., Zhang, Y., Xia, E. Q., \& Li, H. B. (2011). Antioxidant capacities and total phenolic contents of 62 fruits. Food Chemistry, 129(2), 345-350.

Fukuji, T. S., Tonin, F. G., \& Tavares, M. F. (2010). Optimization of a method for determination of phenolic acids in exotic fruits by capillary electrophoresis. Journal of pharmaceutical and biomedical analysis, 51(2), 430-438.

Galiana-Balaguer, L., Roselló, S., Herrero-Martınez, J. M., Maquieira, A., \& Nuez, F. (2001). Determination of L-ascorbic acid in Lycopersicon fruits by capillary zone electrophoresis. Analytical biochemistry, 296(2), 218-224.

García-Closas, R., Berenguer, A., Tormo, M. J., Sánchez, M. J., Quiros, J. R., Navarro, C., ... \& Ardanaz, E. (2004). Dietary sources of vitamin C, vitamin E and specific carotenoids in Spain. British Journal of Nutrition, 91(6), 1005-1011.

García-Plazaola, J. I., \& Becerril, J. M. (1999). A rapid high-performance liquid chromatography method to measure lipophilic antioxidants in stressed plants: simultaneous determination of carotenoids and tocopherols. Phytochemical Analysis, 10(6), 307-313.

Gautier, H., Rocci, A., Buret, M., Grasselly, D., Dumas, Y., \& Causse, M. (2005). Effect of photoselective filters on the physical and chemical traits of vine-ripened tomato fruits. Canadian Journal of Plant Science, 85(2), 439-446.

Gautier, H., Diakou-Verdin, V., Bénard, C., Reich, M., Buret, M., Bourgaud, F., ... \& Génard, M. (2008). How does tomato quality (sugar, acid, and nutritional quality) vary with ripening stage, temperature, and irradiance?. Journal of agricultural and food chemistry, 56(4), 1241-1250. 
Georgé, S., Brat, P., Alter, P., \& Amiot, M. J. (2005). Rapid determination of polyphenols and vitamin C in plant-derived products. Journal of Agricultural and Food Chemistry, 53(5), 1370-1373.

Georgiev, H., Vulkova-Atchkova, Z., Vladimirov, B. G., \& Baralieva, D. (1981). Breeding determinate tomatoes with higt Beta-carotene content. Gr. Lozar. Nauk, 18, 28-31.

Giuntini, D., Lazzeri, V., Calvenzani, V., Dall'Asta, C., Galaverna, G., Tonelli, C., ... \& Ranieri, A. (2008). Flavonoid profiling and biosynthetic gene expression in flesh and peel of two tomato genotypes grown under UV-B-depleted conditions during ripening.Journal of agricultural and food chemistry, 56(14), 5905-5915.

Goldman, I. L. (2011). Molecular breeding of healthy vegetables. EMBO reports, 12(2), 96-102.

Gómez-Caravaca, A. M., Verardo, V., Segura-Carretero, A., Caboni, M. F., \& Fernández-Gutiérrez, A. (2008). Development of a rapid method to determine phenolic and other polar compounds in walnut by capillary electrophoresis-electrospray ionization time-of-flight mass spectrometry. Journal of Chromatography A, 1209(1), 238-245.

Guo, F., Zhou, W., Zhang, J., Xu, Q., \& Deng, X. (2012). Effect of the citrus Iycopene $\beta$-cyclase transgene on carotenoid metabolism in transgenic tomato fruits. PloS one, 7(2), e32221.

Hallmann, E. (2012). The influence of organic and conventional cultivation systems on the nutritional value and content of bioactive compounds in selected tomato types. Journal of the Science of Food and Agriculture, 92(14), 2840-2848.

Hallmann, E., Lipowski, J., Marszałek, K., \& Rembiałkowska, E. (2013). The seasonal variation in bioactive compounds content in juice from organic and non-organic tomatoes. Plant foods for human nutrition, 68(2), 171-176.

Hamner, K. C., Bernstein, L., \& Maynard, L. A. (1945). Effects of light intensity, day length, temperature, and other environmental factors on the ascorbic acid content of tomatoes. Journal of Nutrition, 29, 85-97.

Hanson, P. M., Yang, R. Y., Wu, J., Chen, J. T., Ledesma, D., Tsou, S. C., \& Lee, T. C. (2004). Variation for antioxidant activity and antioxidants in tomato. Journal of the American Society for Horticultural Science, 129(5), 704-711.

Helmja, K., Vaher, M., Gorbatšova, J., \& Kaljurand, M. (2007, December). Characterization of bioactive compounds contained in vegetables of the Solanaceae family by capillary electrophoresis. In Proceedings of the Estonian Academy of Sciences, Chemistry (Vol. 56, No. 4).

Helmja, K., Vaher, M., Püssa, T., Raudsepp, P., \& Kaljurand, M. (2008). Evaluation of antioxidative capability of the tomato (Solanum Iycopersicum) skin constituents by capillary electrophoresis and highperformance liquid chromatography. Electrophoresis, 29(19), 3980-3988.

Herrero-Martínez, J. M., Oumada, F. Z., Rosés, M., Bosch, E., \& Ràfols, C. (2007). Determination of flavonoid aglycones in several food samples by mixed micellar el ectrokinetic chromatogra phy. Journal of separation science, 30(15), 2493-2500.

Hertog, M. G., Hollman, P. C., \& Venema, D. P. (1992). Optimization of a quantitative HPLC determination of potentially anticarcinogenic flavonoids in vegetables and fruits. Journal of Agricultural and Food Chemistry, 40(9), 1591-1598.

Hetherington, S. E., Smillie, R. M., \& Davies, W. J. (1998). Photosynthetic activities of vegetative and fruiting tissues of tomato. Journal of experimental botany, 49(324), 1173-1181. 
Honegr, J., Šafra, J., Polášek, M., \& Pospíšilová, M. (2010). Large-volume sample stacking with polarity switching in CE for determination of natural polyphenols in plant extracts. Chromatographia, 72(9-10), 885-891.

Howard, L., \& Pandjaitan, N. (2008). Pressurized liquid extraction of flavonoids from spinach. Journal of food science, 73(3).

Ilić S. Z., Kapoulas N., \& Šunić L. (2014). Tomato fruit quality from organic and conventional production. In Pilipavicius V. (ed.) Organic Agriculture Towards Sustainability. InTech. DOI: $10.5772 / 58239$.

Ioannidi, E., Kalamaki, M. S., Engineer, C., Pateraki, I., Alexandrou, D., Mellidou, I., ... \& Kanellis, A. K. (2009). Expression profiling of ascorbic acid-related genes during tomato fruit development and ripening and in response to stress conditions. Journal of Experimental Botany, 60(2), 663-678.

Jerman, T., Trebše, P., \& Vodopivec, B. M. (2010). Ultrasound-assisted solid liquid extraction (USLE) of olive fruit (Olea europaea) phenolic compounds. Food Chemistry, 123(1), 175-182.

Kendrick, R. E., Kerckhoffs, L. H. J., Tuinen, A. V., \& Koornneef, M. (1997). Photomorphogenic mutants of tomato. Plant, Cell \& Environment, 20(6), 746-751.

Kinzer, S. M., Schwager, S. J., \& Mutschler, M. A. (1990). Mapping of ripening-related or-specific cDNA clones of tomato (Lycopersicon esculentum). Theoretical and applied genetics, 79(4), 489-496.

Klee, H. J., \& Giovannoni, J. J. (2011). Genetics and control of tomato fruit ripening and quality attributes. Annual review of genetics, 45, 41-59.

Koskitalo, L. N., \& Ormrod, D. P. (1972). Effects of sub-optimal ripening temperatures on the color quality and pigment composition of tomato fruit. Journal of Food Science, 37(1), 56-59.

Kuscu, H., Turhan, A., Ozmen, N., Aydinol, P., \& Demir, A. O. (2014). Optimizing levels of water and nitrogen applied through drip irrigation for yield, quality, and water productivity of processing tomato (Lycopersicon esculentum Mill.). Horticulture, Environment, and Biotechnology, 55(2), 103-114.

Lacroix, E.L. (2004). The Common Agricultural Policy explained. European Communities. Bruselas, Francia.34pp

Lahoz, I. 2015. Influencia del Genotipo, el Ambiente de Cultivo y el Uso de Riegos Deficitarios en la Calidad Organoléptica y Funcional del Tomate de Industria. Tesis doctoral. Universitat Jaume I, Castelló, España. 279 pp.

Lahoz, I., Leiva-Brondo, M., Martí, R., Macua, J. I., Campillo, C., Roselló, S., \& Cebolla-Cornejo, J. (2016a). Influence of high Iycopene varieties and organic farming on the production and quality of processing tomato. Scientia Horticulturae, 204, 128-137.

Lahoz, I., Pérez-de-Castro, A., Valcárcel, M., Macua, J. I., Beltrán, J., Roselló, S., \& Cebolla-Cornejo, J. (2016b). Effect of water deficit on the agronomical performance and quality of processing tomato. Scientia Horticulturae, 200, 55-65.

Lavi, N., Tadmor, Y., Meir, A., Bechar, A., Oren-Shamir, M., Ovadia, R., ... \& Levin, I. (2009). Characterization of the intense pigment tomato genotype emphasizing targeted fruit metabolites and chloroplast biogenesis. Journal of agricultural and food chemistry, 57(11), 4818-4826.

Lee, I. S., Boyce, M. C., \& Breadmore, M. C. (2012). Extraction and on-line concentration of flavonoids in Brassica oleracea by capillary electrophoresis using large volume sample stacking. Food chemistry, 133(1), 205-211. 
Leiva-Brondo, M., Valcárcel, M., Cortés-Olmos, C., Roselló, S., Cebolla-Cornejo, J., \& Nuez, F. (2012). Exploring alternative germplasm for the development of stable high vitamin $\mathrm{C}$ content in tomato varieties. Scientia horticulturae, 133, 84-88.

Leoni, C. (1992). Industrial quality as influenced by crop management. Acta Horticulturae, 301, 177-184.

Li, H., Deng, Z., Wu, T., Liu, R., Loewen, S., \& Tsao, R. (2012). Microwave-assisted extraction of phenolics with maximal antioxidant activities in tomatoes. Food Chemistry, 130(4), 928-936.

Lindstrom, E. W. (1925). Inheritance in tomatoes. Genetics, 10(4), 305.

Liu, R. H. (2004). Potential synergy of phytochemicals in cancer prevention: mechanism of action. The Journal of nutrition, 134(12), 3479S-3485S.

Liu, Y., Roof, S., Ye, Z., Barry, C., Van Tuinen, A., Vrebalov, J., ... \& Giovannoni, J. (2004). Manipulation of light signal transduction as a means of modifying fruit nutritional quality in tomato. Proceedings of the National Academy of Sciences of the United States of America, 101(26), 9897-9902.

Liu, R. H. (2013). Dietary bioactive compounds and their health implications. Journal of food science, $78(\mathrm{~s} 1)$.

Liu, C. M., Chen, C. Y., \& Lin, Y. W. (2014). Estimation of tea catechin levels using micellar electrokinetic chromatography: A quantitative approach. Food chemistry, 150, 145-150.

Lumpkin, H. M. (2005). A comparison of lycopene and other phytochemicals in tomatoes grown under conventional and organic management systems. Technical bulletin, 34 .

Luthria, D. L., Mukhopadhyay, S., \& Krizek, D. T. (2006). Content of total phenolics and phenolic acids in tomato (Lycopersicon esculentum Mill.) fruits as influenced by cultivar and solar UV radiation. Journal of Food Composition and Analysis, 19(8), 771-777.

Ma, C., Ma, B., He, J., Hao, Q., Lu, X., \& Wang, L. (2011). Regulation of carotenoid content in tomato by silencing of lycopene $\beta / \varepsilon$-cyclase genes. Plant molecular biology reporter, 29(1), 117-124.

Manns, D. C., \& Mansfield, A. K. (2012). A core-shell column approach to a comprehensive highperformance liquid chromatography phenolic analysis of Vitis vinifera L. and interspecific hybrid grape juices, wines, and other matrices following either solid phase extraction or direct injection. Journal of Chromatography A, 1251,111-121.

MAPAMA (2017). Ministerio de Agricultura y pesca, alimentación y medio ambiente. http://www.mapama.gob.es/app/MaterialVegetal/fichaMaterialVegetal.aspx?idFicha=2193 (accedido el 25/09/2017).

Martí, R., Valcárcel, M., Herrero-Martínez, J. M., Cebolla-Cornejo, J., \& Roselló, S. (2015). Fast simultaneous determination of prominent polyphenols in vegetables and fruits by reversed phaseliquid chromatography using a fused-core column. Food chemistry, 169, 169-179.

Martí, R., Roselló, S., \& Cebolla-Cornejo, J. (2016). Tomato as a source of carotenoids and polyphenols targeted to cancer prevention. Cancers, 8(6), 58.

Martínez-Valverde, I., Periago, M. J., Provan, G., \& Chesson, A. (2002). Phenolic compounds, Iycopene and antioxidant activity in commercial varieties of tomato (Lycopersicum esculentum). Journal of the Science of Food and Agriculture, 82(3), 323-330.

Mattila, P., \& Kumpulainen, J. (2002). Determination of free and total phenolic acids in plantderived foods by HPLC with diode-array detection. Journal of Agricultural and Food Chemistry, 50(13), 3660-3667. 
McCollum, J. P. (1954). Effects of light on the formation of carotenoids in tomato fruits. Journal of Food Science, 19(1-6), 182-189.

McGlasson, W. B., Last, J. H., Shaw, K. J., \& Meldrum, S. K. (1987). Influence of the non-ripening mutants rin and nor on the aroma of tomato fruit. HortScience (USA), 22, 632-634.

Menrad, K. (2003). Market and marketing of functional food in Europe.Journal of food engineering, 56(2), 181-188.

Merken, H. M., Merken, C. D., \& Beecher, G. R. (2001). Kinetics method for the quantitation of anthocyanidins, flavonols, and flavones in foods. Journal of Agricultural and Food Chemistry, 49(6), 2727-2732.

Mes, P. J., Boches, P., Myers, J. R., \& Durst, R. (2008). Characterization of tomatoes expressing anthocyanin in the fruit. Journal of the American Society for Horticultural Science, 133(2), 262-269.

Mitchell, J. P., Shennan, C., Grattan, S. R., \& May, D. M. (1991). Tomato fruit yields and quality under water deficit and salinity. Journal of the American Society for Horticultural Science, 116(2), 215221.

Mitchell, A. E., Hong, Y. J., Koh, E., Barrett, D. M., Bryant, D. E., Denison, R. F., \& Kaffka, S. (2007). Ten-year comparison of the influence of organic and conventional crop management practices on the content of flavonoids in tomatoes. Journal of agricultural and food chemistry, 55(15), 6154-6159.

Moco, S., Bino, R. J., Vorst, O., Verhoeven, H. A., de Groot, J., van Beek, T. A.,... \& De Vos, C. R. (2006). A liquid chromatography-mass spectrometry-based metabolome database for tomato. Plant Physiology, 141(4), 1205-1218.

Motilva, M. J., Serra, A., \& Macià, A. (2013). Analysis of food polyphenols by ultra highperformance liquid chromatography coupled to mass spectrometry: an overview. Journal of Chromatography A, 1292,66-82.

Motilva, M. J., Macià, A., Romero, M. P., Labrador, A., Domínguez, A., \& Peiró, L. (2014). Optimisation and validation of analytical methods for the simultaneous extraction of antioxidants: Application to the analysis of tomato sauces. Food chemistry, 163, 234-243.

Muir, S. R., Collins, G. J., Robinson, S., Hughes, S., Bovy, A., De Vos, C. R., ... \& Verhoeyen, M. E. (2001). Overexpression of petunia chalcone isomerase in tomato results in fruit containing increased levels of flavonols. Nature biotechnology, 19(5), 470-474.

Mustilli, A. C., Fenzi, F., Ciliento, R., Alfano, F., \& Bowler, C. (1999). Phenotype of the tomato high pigment-2 mutant is caused by a mutation in the tomato homolog of DEETIOLATED1. The Plant Cell, 11(2), 145-157.

Natale, A., Nardiello, D., Palermo, C., Muscarella, M., Quinto, M., \& Centonze, D. (2015). Development of an analytical method for the determination of polyphenolic compounds in vegetable origin samples by liquid chromatography and pulsed amperometric detection at a glassy carbon el ectrode. Journal of Chromatography A, 1420, 66-73.

Navarro, M., Núñez, O., Saurina, J., Hernández-Cassou, S., \& Puignou, L. (2014). Characterization of fruit products by capillary zone electrophoresis and liquid chromatography using the compositional profiles of polyphenols: application to a uthentication of natural extracts. Journal of agricultural and food chemistry, 62(5), 1038-1046.

Oded, A., \& Uzi, K. (2003). Enhanced performance of processing tomatoes by potassium nitrate based nutrition. Acta Horticulturae, 613, 81-87. 
Oke, M., Ahn, T., Schofield, A., \& Paliyath, G. (2005). Effects of phosphorus fertilizer supplementation on processing quality and functional food ingredients in tomato. Journal of agricultural and food chemistry, 53(5), 1531-1538.

Oliveira, A. B., Moura, C. F., Gomes-Filho, E., Marco, C. A., Urban, L., \& Miranda, M. R. A. (2013). The impact of organic farming on quality of tomatoes is associated to increased oxidativestress during fruit development. PLoS One, 8(2), e56354.

Oltman, A. E., Jervis, S. M., \& Drake, M. A. (2014). Consumer attitudes and preferences for fresh market tomatoes. Journal of food science, 79(10), S2091-S2097.

Pagliarini, E., Monteleone, E., \& Ratti, S. (2001). Sensory profile of eight tomato cultivars (Lycopersicon esculentum) and its relationship to consumer preference. Italian journal of food science, 13(3), 285-296.

Paran, I., \& van der Knaap, E. (2007). Genetic and molecular regulation of fruit and plant domestication traits in tomato and pepper. Journal of Experimental Botany, 58(14), 3841-3852.

Pék, Z., Szuvandzsiev, P., Daood, H., Neményi, A., \& Helyes, L. (2014). Effect of irrigation on yield parameters and antioxidant profiles of processing cherry tomato. Open Life Sciences, 9(4), 383-395.

Peng, Y., Zhang, Y., \& Ye, J. (2008). Determination of phenolic compounds and ascorbic acid in different fractions of tomato by capillary electrophoresis with electrochemical detection. Journal of agricultural and food chemistry, 56(6), 1838-1844.

Pernice, R., Parisi, M., Giordano, I., Pentangelo, A., Graziani, G., Gallo, M., ... \& Ritieni, A. (2010). Antioxidants profile of small tomato fruits: Effect of irrigation and industrial process. Scientia horticulturae, 126(2), 156-163.

Pinela, J., Prieto, M. A., Carvalho, A. M., Barreiro, M. F., Oliveira, M. B. P., Barros, L., \& Ferreira, I. C. (2016). Microwave-assisted extraction of phenolic acids and flavonoids and production of antioxidant ingredients from tomato: A nutraceutical-oriented optimization study. Separation and Purification Technology, 164, 114-124.

Povero, G., Gonzali, S., Bassolino, L., Mazzucato, A., \& Perata, P. (2011). Transcriptional analysis in high-anthocyanin tomatoes reveals synergistic effect of Aft and atv genes.Journal of plant physiology, 168(3), 270-279.

Powell, A. L., Nguyen, C. V., Hill, T., Cheng, K. L., Figueroa-Balderas, R., Aktas, H., ... \& LopezBaltazar, J. (2012). Uniform ripening encodes a Golden 2-like transcription factor regulating tomato fruit chloroplast development. Science, 336(6089), 1711-1715.

Qin, J., Chao, K., \& Kim, M. S. (2011). Investigation of Raman chemical imaging for detection of lycopene changes in tomatoes during postharvest ripening. Journal of food engineering, 107(3), 277288.

Repollés, C., Herrero-Martínez, J. M., \& Ràfols, C. (2006). Analysis of prominent flavonoid aglycones by high-performance liquid chromatography using a monolithic type column. Journal of chromatography A, 1131(1), 51-57.

Riahi, A., Hdider, C., Sanaa, M., Tarchoun, N., Ben Kheder, M., \& Guezal, I. (2009). Effect of conventional and organic production systems on the yield and quality of field tomato cultivars grown in Tunisia. Journal of the Science of Food and Agriculture, 89(13), 2275-2282.

Ribas-Agustí, A., Cáceres, R., Gratacós-Cubarsí, M., Sárraga, C., \& Castellari, M. (2012). A validated HPLC-DAD method for routine determination of ten phenolic compounds in tomato fruits. Food Analytical Methods, 5(5), 1137-1144. 
Rick, C. M., Reeves, A. F., \& Zobel, R. W. (1968). Inheritance and linkage relations of four new mutants. Tomato Genet Coop Rep, 18, 34-35.

Rick, C. (1974). High soluble-solids content in large-fruited tomato lines derived from a wild green-fruited species. Hilgaldia, 42(15), 493-510.

Rick, C. M., Cisneros, P., Chetelat, R. T., \& DeVerna, J. W. (1994). Abg-a gene on chromosome 10 for purple fruit derived from S. Iycopersicoides. Rep. Tomato Genet. Coop, 44, 29-30.

Rivero, R. M., Ruiz, J. M., Garcia, P. C., Lopez-Lefebre, L. R., Sánchez, E., \& Romero, L. (2001). Resistance to cold and heat stress: accumulation of phenolic compounds in tomato and watermelon plants. Plant Science, 160(2), 315-321.

Rizzo, V., Clifford, M. N., Brown, J. E., Siracusa, L., \& Muratore, G. (2016). Effects of processing on the polyphenol and phenolic acid content and antioxidant capacity of semi-dried cherry tomatoes (Lycopersicon esculentum M.). Journal of the Science of Food and Agriculture, 96(6), 2040-2046.

Römer, S., Fraser, P. D., Kiano, J. W., Shipton, C. A., Misawa, N., Schuch, W., \& Bramley, P. M. (2000). Elevation of the provitamin A content of transgenic tomato plants. Nature biotechnology, 18(6), 666-669.

Romojaro, F., Madrid, M. M., \& Pretil, M. T. (2007). Factores precosecha determinantes de la calidad y conservación en poscosecha de productos agrarios. En www.hoticom.com/pd/imagenes/65/906/65906.pdf (accedido el 10/10/2017)

Rossi, F., Godani, F., Bertuzzi, T., Trevisan, M., Ferrari, F., \& Gatti, S. (2008). Health-promoting substances and heavy metal content in tomatoes grown with different farming techniques. European journal of nutrition, 47(5), 266.

Rostagno, M. A., Manchón, N., D’Arrigo, M., Guillamón, E., Villares, A., García-Lafuente, A., ... \& Martínez, J. A. (2011). Fast and simultaneous determination of phenolic compounds and caffeine in teas, mate, instant coffee, soft drink and energetic drink by high-performance liquid chromatography using a fused-core column. Analytica chimica acta, 685(2), 204-211.

Ronen, G., Carmel-Goren, L., Zamir, D., \& Hirschberg, J. (2000). An alternative pathway to $\beta$ carotene formation in plant chromoplasts discovered by map-based cloning of Beta and old-gold color mutations in tomato. Proceedings of the National Academy of Sciences, 97(20), 11102-11107.

Rosati, C., Aquilani, R., Dharmapuri, S., Pallara, P., Marusic, C., Tavazza, R., ... \& Giuliano, G. (2000). Metabolic engineering of beta-carotene and lycopene content in tomato fruit. The Plant Journal, 24(3), 413-420.

Saito, S., \& Kano, F. (1970). Influence of nutrients on the growth of solanaceous vegetable plants, their quality and the chemical composition of their fruits. Part 1 . The effect of different phosphatelevels on the Iycopene content of tomatoes. Agric. Sci., 14, 233-8.

Sakakibara, H., Honda, Y., Nakagawa, S., Ashida, H., \& Kanazawa, K. (2003). Simultaneous determination of all polyphenols in vegetables, fruits, and teas. Journal of Agricultural and Food Chemistry, 51(3), 571-581.

Sapir, M., Oren-Shamir, M., Ovadia, R., Reuveni, M., Evenor, D., Tadmor, Y., ... \& Levin, I. (2008). Molecular aspects of Anthocyanin fruit tomato in relation to high pigment-1. Journal of Heredity, 99(3), 292-303.

Sestari, I., Zsögön, A., Rehder, G. G., de Lira Teixeira, L., Hassimotto, N. M. A., Purgatto, E., ... \& Peres, L. E. P. (2014). Near-isogenic lines enhancing ascorbic acid, anthocyanin and carotenoid content in tomato (Solanum Iycopersicum L. cv Micro-Tom) as a tool to produce nutrient-rich fruits. Scientia Horticulturae, 175, 111-120. 
Shen, Y. C., Chen, S. L., \& Wang, C. K. (2007). Contribution of tomato phenolics to antioxidation and down-regulation of blood lipids. Journal of agricultural and food chemistry, 55(16), 6475-6481.

Simonetti, P., Gardana, C., Riso, P., Mauri, P., Pietta, P., \& Porrini, M. (2005). Glycosylated flavonoids from tomato puree are bioavailable in humans. Nutrition Research, 25(8), 717-726.

Singleton, V. L., \& Rossi, J. A. (1965). Colorimetry of total phenolics with phosphomolybdicphosphotungstic acid reagents. American journal of Enology and Viticulture, 16(3), 144-158.

Singleton, V. L., Orthofer, R., \& Lamuela-Raventós, R. M. (1999). Analysis of total phenols and other oxidation substrates and antioxidants by means of folin-ciocalteu reagent. Methods in enzymology, 299, 152-178.

Slimestad, R., Fossen, T., \& Verheul, M. J. (2008). The flavonoids of tomatoes. Journal of Agricultural and Food Chemistry, 56(7), 2436-2441.

Stevens, M. A., \& Rick, C. M. (1986). Genetics and breeding. In Atherton, J. G. \& Rudich, J. (eds.), The tomato crop (pp. 35-109). Springer Netherlands.

Stewart, A. J., Bozonnet, S., Mullen, W., Jenkins, G. I., Lean, M. E., \& Crozier, A. (2000). Occurrence of flavonols in tomatoes and tomato-based products. Journal of agricultural and food chemistry, 48(7), 2663-2669.

Stewart, A. J., Chapman, W., Jenkins, G. I., Graham, I., Martin, T., \& Crozier, A. (2001). The effect of nitrogen and phosphorus deficiency on flavonol accumulation in plant tissues. Plant, Cell \& Environment, 24(11), 1189-1197.

Stommel, J. R. (2007). Genetic enhancement of tomato fruit nutritive value. In Razdan, M. \& Matoo, A. (eds.) Genetic improvement of Solanaceous crops, volume 2, (pp. 193-238). CRC Press: Boca Raton, FL, USA.

Sun-Waterhouse, D. (2011). The development of fruit-based functional foods targeting the health and well ness market: a review. International Journal of Food Science \& Technology, 46(5), 899-920.

Taber, H., Perkins-Veazie, P., Li, S., White, W., Rodermel, S., \& Xu, Y. (2008). Enhancement of tomato fruitlycopene by potassium is cultivar dependent. HortScience, 43(1), 159-165.

Thomas, R. L., \& Jen, J. J. (1975). Red light intensity and carotenoid biosynthesis in ripening tomatoes. Journal of Food Science, 40(3), 566-568.

Thompson, G. D., \& Kidwell, J. (1998). Explaining the choice of organic produce: cosmetic defects, prices, and consumer preferences. American journal of agricultural economics, 80(2), 277-287.

Tieman, D., Zhu, G., Resende, M. F., Lin, T., Nguyen, C., Bies, D., ... \& Ikeda, H. (2017). A chemical genetic roadmap to improved tomato flavor. Science, 355(6323), 391-394.

Tigchelaar, C. C., \& Tomes, M. L. (1974). Caro-Rich. Tomato. Available online: http://hortsci. ashspublications. org/content/by/year (accedido 1/5/2016).

Tiwari, U., \& Cummins, E. (2013). Factors influencing levels of phytochemicals in selected fruit and vegetables during pre-and post-harvest food processing operations. Food Research International, 50(2), 497-506.

Tomes, M. L., \& Quackenbush, F. W. (1958). Caro-red, a new provitamin a rich tomato. Economic Botany, 12(3), 256-260.

Tomes, M. L. (1963). Temperature inhibition of carotene synthesis in tomato. Botanical Gazette, 124(3), 180-185. 
Toor, R. K., Savage, G. P., \& Heeb, A. (2006). Influence of different types of fertilisers on the major antioxidant components of tomatoes. Journal of Food Composition and Analysis, 19(1), 20-27.

Torres, C. A., Davies, N. M., Yanez, J. A., \& Andrews, P. K. (2005). Disposition of selected flavonoids in fruit tissues of various tomato (Lycopersicon esculentum Mill.) genotypes. Journal of agricultural and food chemistry, 53(24), 9536-9543.

Trichopoulou, A., Lagiou, P., Kuper, H., \& Trichopoulos, D. (2000). Cancer and Mediterranean dietary traditions. Cancer Epidemiology and Prevention Biomarkers, 9(9), 869-873.

Trudel, M. J., \& Ozbun, J. L. (1970). Relationship between chlorophylls and carotenoids of ripening tomato fruit as influenced by potassium nutrition. Journal of Experimental Botany, 21(4), 881886.

Trudel, M. J., \& Ozbun, J. L. (1971). Influence of potassium carotenoid content of tomato fruit. Amererican Society Horticultural Science Journal, 96, 763-765.

Unlu, N. Z., Bohn, T., Clinton, S. K., \& Schwartz, S. J. (2005). Carotenoid absorption from salad and salsa by humans is enhanced by the addition of avocado or avocado oil. The Journal of nutrition, 135(3), 431-436.

Vallverdú-Queralt, A., Jauregui, O., Medina-Remón, A., Andrés-Lacueva, C., \& Lamuela-Raventós, R. M. (2010). Improved characterization of tomato polyphenols using liquid chromatography/electrospray ionization linear ion trap quadrupole Orbitrap mass spectrometry and liquid chromatography/electrospray ionization tandem mass spectrometry. Rapid Communications in Mass Spectrometry, 24(20), 2986-2992.

Vallverdú-Queralt, A., Medina-Remón, A., Casals-Ribes, I., \& Lamuela-Raventos, R. M. (2012). Is there any difference between the phenolic content of organic and conventional tomato juices?. Food Chemistry, 130(1), 222-227.

Vattem, D. A., Ghaedian, R., \& Shetty, K. (2005). Enhancing health benefits of berries through phenolic antioxidant enrichment: focus on cranberry. Asia Pacific journal of clinical nutrition, 14(2), 120.

Veit-Köhler, U., Krumbein, A., \& Kosegarten, H. (1999). Effect of different water supply on plant growth and fruit quality of Lycopersicon esculentum. Journal of Plant Nutrition and Soil Science, 162(6), 583-588.

Vinha, A. F., Barreira, S. V., Costa, A. S., Alves, R. C., \& Oliveira, M. B. P. (2014). Organic versus conventional tomatoes: Influence on physicochemical parameters, bioactive compounds and sensorial attributes. Food and chemical toxicology, 67, 139-144.

Viñas, P., Campillo, N., Martínez-Castillo, N., \& Hernández-Córdoba, M. (2009). Solid-phase microextraction on-fiber derivatization for the analysis of some polyphenols in wine and grapes using gas chromatography-mass spectrometry. Journal of Chromatography A, 1216(9), 1279-1284.

Viñas, P., Martínez-Castillo, N., Campillo, N., \& Hernández-Córdoba, M. (2011). Directly suspended droplet microextraction with in injection-port derivatization coupled to gas chromatography-mass spectrometry for the analysis of polyphenols in herbal infusions, fruits and functional foods. Journal of Chromatography A, 1218(5), 639-646.

Vogel, J. T., Tieman, D. M., Sims, C. A., Odabasi, A. Z., Clark, D. G., \& Klee, H. J. (2010). Carotenoid content impacts flavor acceptability in tomato (Solanum lycopersicum). Journal of the Science of Food and Agriculture, 90(13), 2233-2240.

Wang, S., DeGroff, V. L., \& Clinton, S. K. (2003). Tomato and soy polyphenols reduce insulin-like growth factor-I-stimulated rat prostate cancer cell proliferation and apoptotic resistance in vitro via 
inhibition of intracellular signaling pathways involving tyrosine kinase. The Journal of nutrition, 133(7), 2367-2376.

Watada, A. E., Aulenbach, B. B., \& Worthington, J. T. (1976). Vitamins A and C in ripe tomatoes as affected by stage of ripeness at harvest and by supplementary ethylene. Journal of Food Science, 41(4), 856-858.

Wilkens, R. T., Spoerke, J. M., \& Stamp, N. E. (1996). Differential responses of growth and two soluble phenolics of tomato to resource availability. Ecology, 77(1), 247-258.

Willett, W. C., Sacks, F., Trichopoulou, A., Drescher, G., Ferro-Luzzi, A., Helsing, E., \& Trichopoulos, D. (1995). Mediterranean diet pyramid: a cultural model for healthy eating. The American journal of clinical nutrition, 61(6), 1402S-1406S.

Willits, M. G., Kramer, C. M., Prata, R. T., De Luca, V., Potter, B. G., Steffens, J. C., \& Graser, G. (2005). Utilization of the genetic resources of wild species to create a nontransgenic high flavonoid tomato. Journal of agricultural and food chemistry, 53(4), 1231-1236.

Wootton-Beard, P. C., Moran, A., \& Ryan, L. (2011). Stability of the total antioxidant capacity and total polyphenol content of 23 commercially available vegetable juices before and after in vitro digestion measured by FRAP, DPPH, ABTS and Folin-Ciocalteu methods. Food Research International, 44(1), 217-224.

Xiao, W., Chen, C., Zhang, Q., Zhang, Q. H., Hu, Y. J., Xia, Z. N., \& Yang, F. Q. (2015). Separation Study of Eight Isoflavones by MEKC with Different Surfactants. Chromatographia, 78(21-22), 1385-1393.

Yahia, E.M., Hao, X., \& Papadopoulos, A.P. (2005). Influence of crop management decisions on postharvest quality of greenhouse tomatoes. In Ramdane D. (ed.), Crops: Quality, Growth and Biotechnology (pp. 379-405). WFL Publisher: Helsinki, Finland.

Ye, N., Li, J., Wang, Y., \& Ma, J. (2014). Determination of Catechins in Tea by Micellar Electrokinetic Chromatography with a Graphene Oxide-Coated Capillary. Instrumentation Science \& Technology, 42(6), 605-617.

Zafra, A., Juárez, M. J. B., Blanc, R., Navalón, A., González, J., \& Vílchez, J. L. (2006). Determination of polyphenolic compounds in wastewater olive oil by gas chromatography-mass spectrometry. Talanta, 70(1), 213-218.

Zelená, E., Holasová, M., Zelený, F., Fiedlerová, V., Novotná, P., Landfeld, A., \& Houška, M. (2009). Effect of sulphur fertilisation on Iycopene content and colour of tomato fruits. Czech Journal of Food Science, 27,80 .

Zhang, Y., \& Stommel, J. R. (2000). RAPD and AFLP tagging and mapping of Beta (B) and Beta modifier (MoB), two genes which influence $\beta$-carotene accumulation in fruit of tomato (Lycopersicon esculentum Mill.). TAG Theoretical and Applied Genetics, 100(3), 368-375.

Zhang, H., Zhou, L., \& Chen, X. (2008). Improving sensitivity by large-volume sample stacking combined with sweeping without polarity switching by capillary electrophoresis coupled to photodiode array ul traviolet detection. Electrophoresis, 29(7), 1556-1564. 


\section{OBJETIVOS}


La creciente preocupación de los consumidores sobre la calidad de los alimentos y los posibles beneficios para su salud hacen que la calidad funcional se vaya poco a poco consolidando como un valor añadido a tener en cuenta en la comercialización del tomate. Las casas de semillas se han adelantado a esta tendencia y ya hay disponibles variedades al to licopeno, que en función de la estrategia de mejora empleada pueden también ofrecer elevados niveles de polifenoles. Sin embargo, poco se conoce acerca de su respuesta real en campo y el ef ecto de factores ambientales y de cultivo.

La presente tesis pretende, por un lado, mejorar el conocimiento disponible sobre la acumulación de polifenoles en tomate en condiciones que maximicen otros aspectos de la calidad, como la calidad ambiental. Esta aproximación implica la producción con el máximo respeto al medioambiente y la ausencia de trazas de fitosanitarios. En este contexto, es importante conocer cómo afectan estrategias productivas como el cultivo ecológico, limitando el uso de abonado de síntesis y de fitosanitarios, o el riego deficitario, reduciendo el uso de un recurso tan valioso y escaso como el agua.

Por otro lado, el desarrollo de nuevas variedades ricas en polifenoles, la evaluación de estrategias productivas y el control de calidad requiere disponer de herramientas de análisis objetivas, precisas y que permitan analizar grandes cantidades de muestras en poco ti e mpo, tanto en tomate como en otras especies. Por ello, se ha considerado prioritario en la tesis el desarrollo de métodos de cuantificación de polifenoles mediante cromatografía líquida de al ta resolución (HPLC) y electroforesis capilar (CE). Se seleccionan dichas metodologías por la extensión del uso de la primera y su popularización en la mayor parte de laboratorios de análisis y la segunda por su sencillez y el ahorro de recursos que conlleva.

En este contexto, los objetivos planteados en la presente tesis fueron:

1- Desarrollo de metodologías de análisis conjunto de ácidos fenólicos y flavonoides mediante cromatografía líquida de alta resolución (HPLC) y electroforesis capilar (CE).

2- Evaluación del efecto del cultivo ecológico sobre la acumulación de polifenoles en variedades estándar y alto licopeno de tomate.

3- Evaluación del efecto del riego deficitario controlado sobre la acumulación de polifenoles en variedades estándar y alto licopeno de tomate.

De forma colateral, el desarrollo de los dos últimos objetivos nos ha permitido, según el caso, ampliar el estudio a otros compuestos funcionales como el ácido L-ascórbico o los carotenoides. Por otro lado, se consideró necesario comprobar, mediante el estudio de la bibliografía existente el verdadero valor de estos compuestos en la lucha contra el cáncer.

El desarrollo de estos objetivos se ha plasmado en la preparación de varios artículos, en su mayor parte publicados en revistas del primer cuartil del Journal Citation Reports o del Scimago Journal Rank:

- Martí, R., Roselló, S. and Cebolla-Cornejo, J., 2016. Tomato as a source of carotenoids and polyphenols targeted to cancer prevention. Cancers, 8(6), p.58. 
- Martí, R., Valcárcel, M., Herrero-Martínez, J.M., Cebolla-Cornejo, J. and Roselló, S., 2015. Fast simultaneous determination of prominent polyphenols in vegetables and fruits by reversed phase liquid chromatography using a fused-core column. Food chemistry, 169, pp.169-179.

- Martí, R., Valcárcel, M., Herrero-Martínez, J.M., Cebolla-Cornejo, J. and Roselló, S., 2017. Simultaneous determination of main phenolic acids and flavonoids in tomato by micellar electrokinetic capillary electrophoresis. Food chemistry, 221, pp.439-446.

- Martí, R., Leiva-Brondo, M., Lahoz, I., Campillo, C., Cebolla-Cornejo, J. and Roselló, S., 2018. Polyphenol and L-ascorbic acid content in tomato as influenced by high lycopene genotypes and organic farming at different environments. Food chemistry, 239, pp.148-156.

- Martí, R., Valcárcel, M., Leiva-Brondo, M., Lahoz, I., Campillo, C., Roselló, S. and Cebolla-Cornejo, J. 2018. Influence of controlled deficit irrigation on tomato functional value. Food chemistry (ENVIADO). 


\section{EL TOMATE COMO FUENTE DE CAROTENOIDES Y POLIFENOLES EN LA PREVENCIÓN DEL CÁNCER}


Martí, R., Roselló, S. and CebollaCornejo, J., 2016. Tomato as a source of carotenoids and polyphenols targeted to cancer prevention. Cancers, 8(6), p.58.

\section{Cancers}

Scimago JournalRank (SJR): 1,837

Posición 52 de 344 en Oncology (Q1)

\section{cancers}

MDPI

Tomato as a Source of Carotenoids and Polyphenols Targeted to Cancer Prevention

Raúl Marti ${ }^{1}$, Salvador Roselló ${ }^{1}$ and Jaime Cebolla-Comejo ${ }^{2, *}$

1 Unidad Mixta de lnvestigación Mejora de la Calidad Agroalimentaria UJI-UPV, Department de Ciencies Agraries i del Medi Natural, Universitat Jaume 1, Avda. Sos Baynat s/ a 12071 Castelló de la Plana, Spain; martireujies (R.M.); rosello@uipes (S.R.)

Unidad Mixta de Investigación Mejora de la Calidad Agroalimentaria UJ-UPV, COMAV

Universitat Politectnica de Valencia, Cno., De Vera s/n, 46022 València, Spair

Academic Editor: Alba Minelli

Abstract: A diet rich in vegetables has been associated with a reduced risk of many diseases related to aging and modern lifestyle. Over the past several decades, many researches have pointed ou the direct relation between the intake of bioactive compounds present in tomato and a reduced rist of suffering different types of cancer. These bioactive constituents comprise phytochemicals such as carotenoids and polyphenols. The direct intake of these chemoprotective molecules seems to show higher efficiencies when they are ingested in its natural biological matrix than when they are ingested isolated or in dietary supplements. Consequently, there is a growing trend for improvement of the contents of these bioactive compounds in foods. The control of growing environment and processing conditions can ensure the maximum potential accumulation or moderate the loss o bioactive componds, but hie best results are obtained developing new varieties via plant breeding. The modic aton single steps of metabolic pathways or their regulation via conventional breeding or genetic engineering has offered excellent results in crops such as tomato. In this review, we analys the the result of modern breeding programs as a strategy to increase the levels of these compounds in
the diet.

Keywords: breeding functional food; lycopene; $\beta$-carotene; flavonoid; anthocyanin

\section{Introduction}

Traditionally, the concept of quality in vegetables has been related with their external appearance. The main requirements of food industries and markets were focused on the demand of new varieties with higher uniformity, brighter colours and enhanced shelf life as essential characteristics. Following these market requirements, traditional breeding programs focused their attention in these external features together with higher yields and disease resistance, neglecting other important aspects such as flavour or functional characteristics. Over the past decades, flavour was reconsidered in breeding programs due to the continuous complaints of consumers about the loss of traditional organoleptic characteristics of vegetables [1]. More recently, following this lead, healt th benefits of food have also started to be valued [2]. Nowadays, consumers are aware of the functional characteristics agricultural food products, and more consumers choose foods considering their healthy characteristic. Although it is not clear whether marketing or for health functionality is spurring this interest, or vice versa, there is an increasing attention in the development of new phytochemical-rich vegetable varieties via breeding programs [3] 


\title{
Tomato as a Source of Carotenoids and Polyphenols Targeted to Cancer Prevention
}

Raúl Martí ${ }^{1}$, Salvador Roselló ${ }^{1}$ and Jaime Cebolla-Cornejo ${ }^{2, *}$

1 Unidad Mixta de Investigación Mejora de la Calidad Agroalimentaria UJI-UPV. Department de Ciències Agràries i del Medi Natural, Universitat Jaume I, Avda. Sos Baynat s/n, 12071 Castelló de la Plana, Spain; martir@uji.es (R.M.), rosello@uji.es (S.R.)

2 Unidad Mixta de Investigación Mejora de la Calidad Agroalimentaria UJI-UPV. COMAV. Universitat Politècnica de València, Cno. De Vera s/n, 46022 València, Spain

* Correspondence: jaicecor@btc.upv.es; Tel.: +34-96-387-94-23

\begin{abstract}
A diet rich in vegetables has been associated with a reduced risk of many diseases related to aging and modern lifestyle. Over the past several decades, many researches have pointed out the direct relation between the intake of bioactive compounds present in tomato and a reduced risk of suffering different types of cancer. These bioactive constituents comprise phytochemicals such as carotenoids and polyphenols. The direct intake of these chemoprotective molecules seems to show higher efficiencies when they are ingested in its natural biological matrix than when they are ingested isolated or in dietary supplements. Consequently, there is a growing trend for improvement of the contents of the se bioactive compounds in foods. The control of growing environment and processing conditions can ensure the maximum potential accumulation or moderate the loss of bioactive compounds, but the best results are obtained developing new varieties via plant breeding. The modification of single steps of metabolic pathways or their regulation via conventional breeding or genetic engineering has offered excellent results in crops such as tomato. In this review, we analyse the potential of tomato as source of the bioactive constituents with cancer-preventive properties and the result of modern breeding programs as a strategy to increase the levels of these compounds in the diet.
\end{abstract}

Keywords: breeding; functional food; lycopene; $\beta$-carotene; flavonoid; anthocyanin 


\section{Introduction}

Traditionally, the concept of quality in vegetables has been related with their external appearance. The main requirements of food industries and markets were focused on the demand of new varieties with higher uniformity, brighter colours and enhanced shelf life as essential characteristics. Following these market requirements, traditional breeding prog rams focused their attention in these external features together with higher yields and disease resistance, neglecting other important aspects such as flavour or functional characteristics. Over the past decades, flavour was reconsidered in breeding programs due to the continu ous complaints of consumers about the loss of traditional organoleptic characteristics of vegetables [1]. More recently, following this lead, health benefits of food have also started to be valued [2]. Nowadays, consumers are aware of the functional characteristics of agricultural food products, and more consumers choose foods considering their healthy characteristics. Although it is not clear whether marketing or for health functionality is spurring this in te rest, or vice versa, there is an increasing attention in the development of new phytochemical-rich vegetable varieties via breeding programs [3].

It is a well-known fact that fruits and vegetables are an important source for the daily intake of healthy constituents to the diet like minerals (calcium, phosphorous, magnesium and other minor minerals), water-soluble vitamins ( $B$ and $C$ ), fat-soluble vitamins ( $A$, E and $K$ ) and a wide variety of phytochemicals [4]. Among phytochemicals, we can find bioactive molecules capable to protect against diseases acting as free radical scavengers or antimicrobial agents. The most renowned phytochemicals from vegetables are polyphenols, carotenoids, organo-sulfur and seleno-compounds. Their presence in certain plants would, in part, justify the epidemiologic evidence of a protective role of diets rich in fruits, vegetables, legumes and whole grains [5].

The traditional Mediterranean diet would be an example of how a diet characterized by a high consumption of foods of plant origin, relatively low consumption of red meat and high consumption of olive oil results in reduced occurrence of cancer [6], coronary heart disease and other diet-related chronic diseases [7]. Among the components of the Mediterranean diet, fruits and vegetables outstand in their preventive role. In Western countries, such as in the United States, a goal of at least 9 to 13 servings a day of fruits and vegetables is promoted, though the real consumption does not reach half that figure [8]. This goal has proved to be quite difficult to reach, as studies developed in the late 90 s and early 2000s pointed out [9]. Increasing awareness of the need for consumption of these foods and a complete educational model starting at nursery schools would be required.

Although the bioactive constituents of fruits and vegetables may be delivered via dietary supplements, scientific evidences seem to point out that their direct intake in their natural matrix has more health benefits than if those chemoprotective molecules are ingested isolated or in dietary supplements [10]. In that line, some authors pointed out that whole tomato consumption is more effective than lycopene isolated for the prevention and the development of progression of prostate cancer in rats [11]. According to this, more researches suggested that the synergetic effects of these molecules with other phytochemicals presents in vegetables may enhance their health benefits $[12,13]$. Thus, a diet rich in vegetables is the best way to obtain a wide variety of phytochemicals [8]. It should be considered, though that in the case of liposoluble compounds the diet should be complemented with oils. It would be the case of 
carotenoids. Most fruits and vegetables rich in carotenes are low in lipids. Therefore, in order to promote their absorption, it would be necessary to promote the joint intake of lipids. For example, the addition of avocado to salads has proved to improve the absorption of tomato carotenoids [14] or in the case of cooked tomato, the use of olive oil in the cooking process would also greatly increase the absorption of lycopene [15].

We should be aware of the difficulty of clearly establishing the protective role of a certain compound in a complex diet over the development of chronic diseases, which are affected by many other risk factors. In this context, some studies have questioned the relation betwe en the ingestion of vitamin Cor carotenoids and a reduction in the risk of suffering cancer $[16,17]$ while other studies continue to establish this relation $[18,19]$. Apart from the difficulty of establishing the role of a single component of a complex diet certain considerations such as the measurement errors in the dietary intake of fruit and vegetables may also atten uate the relationships observed in epidemiological studies [20].

In this complex context, there is an increasing interest in the development of new vege table varieties with increased levels of bioactive components [3], in order to promote their protective role in well balanced diets such as the Mediterranean. Although, it is ne cessary to continue on research of the effects of phytochemicals on health to understand the mechanism of action and the associations of these molecules in cancer-risk prevention, the develop ment of long-term breeding programs should be started to promote the benefits of vegetable consumption.

The high level of consumption and the high economic value of tomato production has spurred the scientific and breeding efforts in this species. Although tomato does not outstand for its high concentration in bioactive compounds, the high levels of tomato intake both fresh and processed, position tomato as one of the main sources of chemoprotective compounds to diet [21], including vitamin C. Although tomato cultivars with increased vitamin C contents have been developed, vitamin $C$ content is rather unstable, as it is highly dependent on the environment (especially via genotype $x$ environment interactions) and it is quickly used as antioxidant under stress conditions. Thus, its management in breeding programs can be quite complicated [22]. Apart from vitamin C, the main bioactive compounds present in tomato (Solanum lycopersicum L.) are carotenoids and polyphenols. Here we review the chemoprotective characteristics of these last tomato bioactive compounds, their biosynthesis and the achievements in breeding programs targeted to increase their contents.

\section{Accumulation of Bioactive Compounds in Tomato}

In tomato, carotenoids are synthesized in the leaves, flowers and fruits. In the leaf tissues, carotenoids act as photoprotectors [23], being lutein the main carotenoid present mean while the presence of the xanthopylls violaxanthin and neoxanthin confer the characteristic yellow colouration to flowers [24]. In ripe tomato fruits, lycopene is the main carotenoid that can be found and it causes its red colouration (Table 1). 


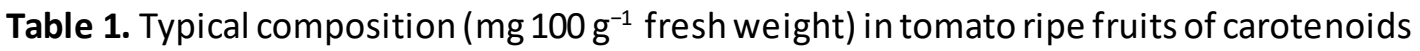
and polyphenols, (adapted from [24-27]).

\begin{tabular}{lclc}
\hline Carotenoid & Concentration & Polyphenol & Concentration \\
\hline Lycopene & $7.8-18.1$ & Naringenin chalcone & $0.9-18.2$ \\
Phytoene & $1.0-2.9$ & Rutin & $0.5-4.5$ \\
Phytofluene & $0.2-1.6$ & Quercetin & $0.7-4.4$ \\
$\beta$-Carotene & $0.1-1.2$ & Chlorogenic acid & $1.4-3.3$ \\
Y-Carotene & $0.05-0.3$ & Caffeic Acid & $0.1-1.3$ \\
S-Carotene & $0-0.2$ & Naringenin & $0-1.3$ \\
Lutein & 0.09 & Kaempferol-3-rutinoside & $0-0.8$ \\
Neurosporene & $0-0.03$ & p-Coumaricacid & $0-0.6$ \\
$\alpha$-Carotene & $0-0.002$ & Ferulic acid & $0.2-0.5$ \\
Neoxanthin & - & Kaempferol & $0-0.2$ \\
Violaxanthin & - & Myricetin & - \\
Anteraxanthin & - & Cyanidin & - \\
Zeaxanthin & - & Pelargonidin & - \\
& & Delphinidin & - \\
\hline
\end{tabular}

The contents of carotenoids, as well as other chemoprotective substances are highly conditioned by the genotype and environmental conditions (reviewed by Tiwari and Cummings [28]). Considering this variability, lycopene concentrations from standard tomato cultivars

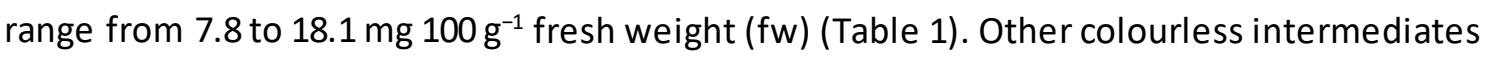
from the carotenoid biosynthetic pathway may be found in tomatoes. This is the case of phytoene and phytofluene with concentrations around 2.9 and $1.6 \mathrm{mg} 100 \mathrm{~g}^{-1} \mathrm{fw}$, respectively. The second main coloured carotenoid present in tomato is $\beta$-carotene, responsible for orangey

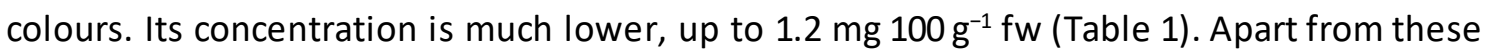
major carotenoids, lesser amounts of $\gamma$-carotene, $\delta$-carotene, lutein, neurosporene, $\alpha$ carotene and other carotenoids can also be found in tomatoes [24,29] (Table 1).

Carotenoid distribution in the fruit is not regular. Lycopene can be found at higher concentration in the pericarp if compared with the locules, meanwhile $\beta$-carotene concentration is higher in the locules compared with the pericarp [25]. Moreover, lycopene concentration varies during the ripening process. Initially it starts to be present in the locules at the breaker stage, and then its concentration rises during the ripening process [30].

Polyphenols are present in tomato at lower concentrations (Table 1). These powerful antioxidants can be divided into different groups according to their core structure. Main tomato polyphenols are hydroxycinnamic acids, flavanones, flavonols, and anthocyanins. In addition, flavonol glycosides like rutin and kaempferol-3-rutinoside are also present in tomato fruits. 
Naringenin chalcone is the main polyphenol found in tomato with concentrations up to 18.2 $\mathrm{mg} 100 \mathrm{~g}^{-1} \mathrm{fw}\left[{ }^{27}\right]$. The flavanone naringenin is present at lower concentrations, up to $1.3 \mathrm{mg} 100$ $\mathrm{g}^{-1} \mathrm{fw}$ [26]. Quercetin is the main flavonol and one of the most important flavonoids from

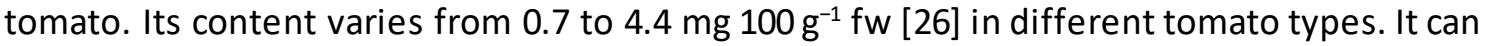
also be found in its glycosylated form as rutin, with concentrations up to $4.5 \mathrm{mg}^{100 \mathrm{~g}^{-1} \mathrm{fw}}$ [27]. The accumulation of rutin gives to the tomato peel its typical yellow colour. Chlorogenic acid is the main polyphenol from hydroxycinnamic acid family; its concentration ranges

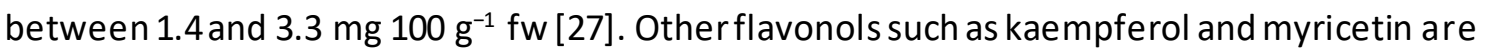
found in small quantities or traces in cultivated tomato, though they are present in related wild species [26,31,32].

The accumulation of flavonoids in tomato is tissue specific and develops at specific stages. For example, naringenin chalcone accumulates al most specifically in the peel simultaneously with the accumulation of carotenoids and degradation of chlorophylls, peaking up in overripe peels [33]. In fact, the flavonoid pathway is not active in the flesh due to the lack of expression of the genes involved in the flavonoid pathway [34]. Flavonol accumulation (mainly quercetin and kaempferol glucosides) is also almost (98\%) restricted to the peel [35].

Usually the production of anthocyanins in tomato is restricted to vegetative tissues, such as the hypocotyl. Under certain conditions, including high irradiance and low temperat ure, they can accumulate in the stem and leaves. The main anthocyanins in tomato are derived from delphinidin, malvidin and petunidin [36,37].

Apart from an evident genotype and environmental effect on the accumulation of these bioactive compounds, in processed food their contents will also depend on the processing method, which may help to liberate compounds or may degrade them (reviewed by Nicoli et al. [38]). The nutritional value of tomatoes may be increased after thermal processing, as described by Dewanto et al. [39]. Their results pointed out that lycopene concentration is increased as it may be released from its natural matrix during the heat process. Dewanto et al. [39] also evaluated phenolic and total flavonoid content of heat-processed tomatoes, revealing non-significant changes in their content after the thermal process. Other authors have found a reduction of polyphenol content as a consequence of cooking. In this sense, Crozier et al. [40] showed an $82 \%$ of loss of quercetin content if tomatoes are boiled, a $65 \%$ loss if they are microwaved and $35 \%$ if they are fried. On the other hand, carotenoid concentration remains constant if tomatoes are boiled or even it can be more concentrated in tomato paste [41].

The results on the retention of polyphenols in tomato processed products are variable. Muir et al. [33] found that $65 \%$ of flavonols present in high-flavonol tomatoes were retained in processed tomato paste, whileStewart et al. [35] found that tomato flavonols like querce tin, can resist common processing methods and therefore they can be found in tomato-derived products such as tomato juice or tomato puree which are particularly rich these compounds. Obviating the relative differences in these studies, it seems clear that health benefits of processed tomato products may be similar or even higher than raw tomatoes, and make tomato-derived products a perfect al ternative choice as functional food. 


\section{Chemoprotective Characteristics of Tomato Bioactive Compounds}

\subsection{Carotenoids}

During the last several decades, many studies highlight the beneficial effects of the intake of tomato and tomato-derived products with a lower cancer risk (reviewed by Giovannucci [42]) and mainly with lower prostate cancer risk [43-46].

Considering the intake of tomato products, results from a 6-year follow-up cohort study by Mills et al. [47] pointed out a lesser prostate cancer risk associated to tomato consumption among other vegetables. In agreement to that, a meta-analysis carried out by Etminan et al. [45] highlighted a lower prostate cancer relative risk (RR) related to a high consumption of raw tomatoes $(\mathrm{RR}=0.89,95 \% \mathrm{Cl})$ and specially cooked-tomato products $(\mathrm{RR}=0.81,95 \% \mathrm{Cl})$. Giovannucci et al. [44] also reported a lower relative risk $(\mathrm{RR}=0.77,95 \% \mathrm{Cl})$ from developing prostate cancer associated with the consumption of two servings of tomato sauce per week. In this study, a continuation of the Health Professionals Follow-Up Study (HPFS), the authors concluded that considering the moderate association found, it could be missed in a small studies or in those with substantial errors in measurement or based on a single dietary assessment. In a continuation of this study, Wu et al. [48] found a significant inverse association between higher plasma lycopene levels and lower risk of prostate cancer, though it was restricted to older men (age $>65$ ) without a family history of prostate cancer (highest vs. lowest quintile Odds Ratio, $\mathrm{OR}=0.43 ; 95 \% \mathrm{Cl}$ ). At that point, few studies considered lycopene levels in the plasma. With a smaller sample, Lu et al. [49] found significant inverse associations between prostate cancer and lycopene plasma concentration $(\mathrm{OR}=0.17,95 \% \mathrm{Cl})$. In this case, mean plasma lycopene level for the upper quartile was $401 \mathrm{mmol} \mathrm{L}^{-1}$. On the other hand, Kristal et al. [50] in the Prostate Cancer Prevention Trial (1,683 cases and 1,751 controls) analysed plasma lycopene levels ( $\geq 0.47 \mathrm{mg} \mathrm{L}^{-1}$ in the highest quartile) and found that prediagnostic serum lycopene concentration was not associated with the risk of total, low-, or high-grade prostate cancer incidence.

With the same cohort of the HPFS, in 2014 Zu et al. [51] pooled the results of 49,898 male health professionals from 1986 to 2010 and found a positive relationship between dietary lycopene intake and plasma lycopene levels, with mean plasma lycopene levels of $934.5 \mathrm{~mol}$ $\mathrm{L}^{-1}$ in the highest quintile of lycopene intake $(\mathrm{n}=1200)$, and concluded that higher lycopene intake was inversely associated with total prostate cancer and more strongly with lethal prostate cancer. In fact, higher lycopene intake was associated with biomarkers in the cancer indicative of less angiogenic potential, thus probably reducing aggressive potential of cancer. The authors suggested that lycopene may inhibit angiogenesis of prostate cancer cells by regulating vascular endothelial growth factor, taking in consideration the results obtained by Yang et al. [52] in mice.

On the other hand, Kirsh et al. [53] in the Prostate, Lung, Colorectal, and Ovarian Cancer Screening Trial including 29,361 men during 4 years found no reason to support the hypothesis that higher tomato product consumption protects from prostate cancer. Indeed, the relation of lycopene intake and cancer has been controversial. As an example, in 2007 the US Food and Drug Administration concluded that there was limited evidence supporting an association between tomato consumption and reduced risk of prostate cancer [16]. But almost simultaneously, the World Cancer Research Fund and the American Institute for Cancer 
Research [54] concluded that foods containing lycopene may have a positive effect against prostate cancer. Interestingly, Zu et al. [51] suggested that lycopene intake would primarily affect prostate cancer progression.

The role of lycopene supplements in the evolution of cancer has also been analysed in cl inical trials. In 2001 Kuckuk et al. [55] evaluated the impact of oral intake of lycopene (15 mg twice daily, during 3 weeks) in the evolution of patients with prostate cancer. In the intervention group, plasma prostate-specific antigen (PSA) levels decreased by $18 \%$ while in the control group they increased by $14 \%$, and considering all biomarkers the authors concluded that lycopene supplementation may decrease the growth of prostate cancer, though the sample was too small to be conclusive.

Ansari and Gupta [56] found a 96\% reduction of PSA levels after a 6-month supplementation of $2 \mathrm{mg}$ lycopene twice daily in orchidectomy patients in comparison with patients only with surgical treatment (up to 90\%). This study highlighted that the reduction turned to be more marked after two years of treatment (99\% and $96 \%$ respectively). In other study with located prostate cancer patients, the serum PSA levels as well as leukocyte oxidative and prostate oxidative DNA damages were reduced after lycopene supplementation (30 mg lycopene per day during 3 weeks) before their radical prostatectomy [57]. Vaishampayan et al. [58] found that lycopene supplementation alone (30 mg day ${ }^{-1}$ in two doses) or combined with soy isoflavones ( $40 \mathrm{mg} \mathrm{day}^{-1}$ in two doses) had activity in prostate cancer patients with PSA relapse disease and may delay progression of both hormone-refractory and hormone-sensitive prostate cancer. Although the number of patients was limited ( 37 and 33 in each group). Other works, also highlighted the effects of lycopene delaying a high-grade prostate in traepithel ial neoplastia (HGPIN) from developing into occult prostate cancer [59].

On the contrary, other authors have found no effect of lycopene supplementation and prostate cancer prevention or evolution. Regarding cancer evolution, Jatoi et al. [60] fou nd no relationship between lycopene supplementation (30 mg day ${ }^{-1}$ during 16 months) and the progression of prostate cancer in 46 men with androgen-independent prostate cancer. Clark et al. [61] tested wider dose ranges of lycopene supplementation (15-120 mg day ${ }^{-1}$ ) in 36 patients with biochemical relapse of prostate cancer, and found no stabilization of PSA levels as a consequence of the treatment. They al so found that plasma lycopene levels were similar for the 15-90 mg day ${ }^{-1}$ doses when the concentration reached a plateau after three months of supplementation. Bunker et al. [62] studied the evolution of 81 men with high-grade prostatic intraepithelial neoplasia, atypical foci or repeated non-cancerous biopsies and found no effect of lycopene supplementation ( $30 \mathrm{mg} \mathrm{day}^{-1}$ ) after the first month of treatment. But the same authors suggested that lowering of serum PSA may not be an appropriate endpoint for the long-term studies on the effect of lycopene supplementation for reducing prostate cancer initiation or progression.

Prostate cancer preventing properties of other tomato carotenoids have also been questioned in otherworks. In that sense, Neuhouser et al. [63] revealed in the Beta-Carotene and Retinol Efficacy Trial (CARET) that the supplementation with $\beta$-carotene $\left(30 \mathrm{mg} \mathrm{day}^{-1}\right)$ and retinol $\left(25,000\right.$ IU retinyl palmitate day $\left.{ }^{-1}\right)$ had no significant effect on total prostate cancer incidence. In fact, it could be negative, as they found that supplemented individuals had higher relative risk $(R R=1.52,95 \% \mathrm{Cl})$ of developing an aggressive prostate cancer (Gleason score $7-10)$ that 
was reduced in the post-intervention period $(\mathrm{RR}=0.75,95 \% \mathrm{Cl})$. CARET only included smokers, thus this results may not apply to non-smokers.

Apart from prostate cancer, the incidence of other cancers has been also associated with tomato carotenoids. In 2007, the World Cancer Research Fund and the American Institute for Cancer Research [54] concluded that apart from the positive effects of lycopene containing foods on prostate cancer, foods containing carotenoids probably protected against cance rs of the mouth, pharynx, and larynx, and also lung cancer, and specifically, those containing $\beta$ carotene would probably protect against oesophageal cancer. In this sense, the meta-analys is performed by Ge et al. [64] confirmed that higher intake of $\beta$-carotene, $\alpha$-carotene, lycopene, $\beta$-cryptoxanthin, lutein, and zeaxanthin reduced oesophageal cancer risk with pooled ORs of $0.58,0.81,0.75,0.80$, and $0.71(95 \% \mathrm{Cl})$, respectively.

Regarding lung cancer, in 1996 Ziegler et al. [65] concluded that $\beta$-carotene may have a role in the prevention of lung cancer, but the dosage should be carefully studied, as lung cancer incidence and mortality were increased in studies with $\beta$-carotene supplementation with male smokers. In fact, results from Alpha-Tocopherol Beta-Carotene (ATBC) study re ve ale d higher lung cancer incidence in participants who received $\beta$-carotene supplementation, $20 \mathrm{mg} \mathrm{day}^{-1}$ during 8 years [66], especially among smokers [67]. Similarly, the CARET study highlighted that $\beta$-carotene supplementation had an adverse effect on lung cancer incidence and lung cance $r$ mortality in smokers and workers exposed to asbestos [68]. It has been proposed that this procarcinogenic effect may be explained by the activity of $\beta$-carotene-oxidized products produced as a consequence of the free radical-rich environment in the lungs of cigarette smokers [69]. Wright et al. [70] suggested that the increased risk of lung cancer would be related to aberrant cell growth, while Mondul et al. [71] found that the metabolomic profiles of response to $\beta$-carotene supplementation pointed to the induction of cytochrome $\mathrm{p} 450$ enzymes CYP1A2 and CYP2E1. As several medications used for cardiovascular diseases are metabolized by CYP1A2, an interaction between the supplemented $\beta$-carotene and prescribe $d$ medication may have resulted in the increased mortality found in the ATBC study, though a dysregulated glycemic control could also have contributed. These findings stressed the importance to increase our knowledge on the possible interactions between dietary supplements and other pharmacological agents. Nevertheless, the fact that supple me ntation at high doses may have adverse effects, does not exclude a positive effect at dietary levels [72]. Other works have found no effect of $\beta$-carotene supplementation and lung cancer incidence [73].

Controversy also applies in the case of breast cancer. Eliassen et al. [74] carried out a pooled analysis of eight cohort studies where serum carotenoids and breast cancer risk were evaluated. This study pointed out a reduced relative risk of suffering breast cancer among women with higher plasma carotenoids. Among tomato carotenoids, the authors found a lower relative risk for lycopene $(\mathrm{RR}=0.78,95 \% \mathrm{Cl})$ followed by $\beta$-carotene $(\mathrm{RR}=0.83,95 \% \mathrm{Cl})$. Pantavos et al. [75] analysing dietary intake of antioxidants in 3,209 women found that low intake of $\alpha$-carotene and $\beta$-carotene was associated with a higher risk of breast cancer among smokers (Hazard Ratio, $\mathrm{HR}=2.48,95 \% \mathrm{Cl}$ and $\mathrm{HR}=2.31,95 \% \mathrm{Cl}$ for $\alpha$ - and $\beta$-carotene, respectively). On the other hand, Greenlee et al. [76] studying the Life After Cancer Epidemiology (LACE) cohort (2,264 women diagnosed of breast cancer) concluded that 
frequent use of combination carotenoids was associated with increased risk of death from breast cancer $(\mathrm{HR}=2.07,95 \% \mathrm{Cl})$ and all-cause mortality $(\mathrm{HR}=1.75,95 \% \mathrm{Cl})$.

Results from the Linxian Cancer Prevention Study highlighted a significant reduction in cance $r$ mortality $(R R=0.87,95 \% \mathrm{Cl})$, especially from stomach cancer $(R R=0.79,95 \% \mathrm{Cl})$ after $\beta$ carotene, vitamin $\mathrm{E}$ and selenium supplementation [77]. But a recent meta-analysis [78] concluded that al though data from case-control studies suggested a protective role of $\alpha$ - and $\beta$-carotene against gastric cancer, there were inconsistencies compared with cohort studies, and no conclusive evidence was found for this suggestion.

The mechanism of action of carotenoids in cancer prevention was extensively reviewed by Tanaka et al. [72] and Trejo-Solís et al. [79]. Antioxidant capacity of these compounds may justify part of this protection. Carotenoids exert strong antioxidant capacity because they contain many double-conjugated bonds. In that sense, lycopene can act as antioxidant because its ability to trap the ${ }^{1} \mathrm{O}_{2}$ twice as effective as that of $\beta$-carotene. Moreover, another antioxidant potential of lycopene is to react with free radicals. The elimination of these Reactive Oxygen Species (ROS) is important in the cancer chemoprevention since they can facilitate the carcinogenesis-related processes by means of the oxidation of cellular biomolecules. In addition, lycopene may exert its effect though the regulation of the antioxidant response element (reviewed by Trejo-Solís et al. [79]).

But apart from their antioxidant capacity, other mechanisms contribute to cancer prevention, including immune modulation, hormone and growth factor signaling, regulatory mech anisms of cell cycle progression, cell differentiation and apoptosis. In fact, the existence of this variety of mechanisms has led to propose that the initial effect of carotenoids should involve modulation of transcription (reviewed by Tanaka et al. [72]).

\subsection{Polyphenols}

Plant polyphenols have been reported to interfere with the initiation, promotion and progression of cancer [80]. In fact, polyphenols exert numerous effects on tumorigenic cell transformation, on tumour cells in vitro and in vivo, and may interact with conventional antitumour therapies [81]. There exist different polyphenol families and they differ in their chemoprotective capabilities. For example, among 68 polyphenols, the order of their potency to suppress in vitro the human liver cancer cells resulted to be chalcones $>$ flavones $>$ chromones $>$ isoflavones $>$ flavanones $>$ coumarins [82].

The effect of the different classes of polyphenols on cancer risk incidence has been evaluated in several case-control studies [83-86]. In that line, Bosetti et al. [85] evaluated the in take of different families of polyphenols and their effect on women breast cancer incidence in a large case-control study carried out in Italy during 4 years. A reduced risk of suffering breast cancer was related with a high dietary intake of flavonols $\left(>29.9 \mathrm{mg} \mathrm{day}^{-1}\right.$ ) (highest vs. lowest quintile $\mathrm{OR}=0.80,95 \% \mathrm{Cl})$ and flavones $\left(>0.6 \mathrm{mg} \mathrm{day}^{-1}\right)(\mathrm{OR}=0.81,95 \% \mathrm{Cl})$, but no significant associations were found for other tomato polyphenols such as flavanones ( $>62.2 \mathrm{mg} \mathrm{day}^{-1}$ ) $(\mathrm{OR}=0.95,95 \% \mathrm{Cl})$ and anthocyanidins $\left(>20.5 \mathrm{mg} \mathrm{day}^{-1}\right)(\mathrm{OR}=1.09,95 \% \mathrm{Cl})$. Specifically, a diet rich in quercetin ( $\left.4.7 \mathrm{mg} \mathrm{day}^{-1}\right)$ have also been associated with a lower breast cancer risk in women $(\mathrm{RR}=0.62,95 \% \mathrm{Cl})[87]$. On the other hand, another case-control study carried out 
in Greece evaluating fruit and vegetable consumption found no associations between dietary intake of flavonols, flavanones, flavan-3-ols, isoflavones or anthocyandins and breast cance $r$ risk; however, a statistically lower risk $(\mathrm{OR}=0.87,95 \% \mathrm{Cl})$ were found for flavone intake $(0.5$ $\mathrm{mg} \mathrm{day}^{-1}$ ) [84].

Phenolic compounds also seem to protect against colorectal cancer. In this case, a large casecontrol study carried out by Rossi et al. [86] in Italy showed that diets with a higher intake of flavonols ( $\left.>28.5 \mathrm{mg} \mathrm{day}^{-1}\right)(\mathrm{OR}=0.64,95 \% \mathrm{Cl})$ and anthocyanidins $\left(>31.7 \mathrm{mg} \mathrm{day}^{-1}\right)(\mathrm{OR}=$ $0.67,95 \% \mathrm{Cl}$ ) among other phenolic compounds were associated with a lower risk of suffe ring colorectal cancer. However, the same study found no associations between total flavonoids and flavanones and colorectal cancer. Other studies went further and tested the doseresponse activity of quercetin. In that line, Cruz-Correa et al. [88] found that a joint supplementation of $20 \mathrm{mg}$ quercetin together with $480 \mathrm{mg}$ curcumin thrice per day prior colectomy were capable to decrease the number and size $(60.4 \%$ and $50.9 \%$ from baseline respectively) of ileal and rectal adenomas in patients with familial adenomatous polyposis (FAP).

Flavonols also would exert a protective effect against stomach cancer. García-Closas et al. [83] evaluating food habits in Spanish participants found a lower risk of suffering stomach cancer in participants with higher dietary intakes of quercetin $\left(>8.5 \mathrm{mg} \mathrm{day}^{-1}\right)(\mathrm{OR}=0.62,95 \% \mathrm{Cl})$. Other flavonols like kaempferol and myricetin were also evaluated in this work, but the authors found that only kaempferol (dietary intakes higher than $1.3 \mathrm{mg} \mathrm{day}^{-1}$ ) also had protective effects $(\mathrm{OR}=0.48,95 \% \mathrm{Cl})$. Some studies though have discarded a significant protective affect against these types of cancer [87].

The chemopreventive effects of polyphenols against lung cancer have also been proven (reviewed by Neuhouser [89]). Among them, the results from the Finnish Mobile Clinic Health Examination Survey pointed that these chemoprotective effects of dietary flavonoid intake (3.51 $\left.\mathrm{mg} \mathrm{day}^{-1}\right)(\mathrm{RR}=0.54,95 \% \mathrm{Cl})$ may be mainly attributed to quercetin [90]. Knekt et al. [87] evaluated the dietary intakes of participants in basis of flavonoid concentration in the same study, reporting a lower incidence of total cancer associated with higher intakes of que rce tin $(\mathrm{RR}=0.77,95 \% \mathrm{Cl})$, especially for lung cancer in men $\left(3.9 \mathrm{mg} \mathrm{day}^{-1}\right)(\mathrm{RR}=0.42,95 \% \mathrm{Cl})$. The cohort study carried out by Hirvonen et al. [91] also revealed an inverse relationship bet we en the joint dietary intake of flavones and flavonols $\left(16.3 \mathrm{mg} \mathrm{day}^{-1}\right)$ and lung cancer risk ( $R R=0.56$, 95\% Cl) in male smokers from the ATBC study.

Regarding liver cancer, Lagiou et al. [92] also found a chemoprotective effect of dietary flavone intake ( $\left.>1.16 \mathrm{mg} \mathrm{day}^{-1}\right)$ and hepatocellular carcinoma $(\mathrm{OR}=0.41,95 \% \mathrm{Cl})$ for patients without hepatitis. An inverse association was also found between dietary consumption of flavan-3-ol (> $66.3 \mathrm{mg} \mathrm{day}^{-1}$ ), anthocyanidins (> $152.7 \mathrm{mg} \mathrm{day}^{-1}$ ) and total flavonoids (>358.1 $\mathrm{mg} \mathrm{day}^{-1}$ ) and cholangiocarcinoma (though only few cases were available for the study).

Anti-cancer properties of other tomato polyphenols such as chlorogenic and caffeic acids have been less studied in patients; however there are many studies where they have been tested using cellular models (reviewed by Weng and Yen [93]). In that line, Yang et al. [94] found that chlorogenicacid may induce apoptosis in vitro in human leukemia U937 cells by the reduction of the levels of mitochondrial membrane potential and increasing the activation of caspase -3pathways. The effect of caffeic acid on fibrosarcoma HT-1080 cell line was evaluated by 
Rajendra-Prasad et al. [95]. Their results pointed out that caffeic acid treatments can lower the cell viability of fibrosarcoma cells. Other tomato phenolic compounds likenaringenin prese nt anti-cancer properties in vitro. In that line, some works pointed out the anti-proliferative effects of naringenin in different cancer cell lines like HT29 colon cancer cells [96] or MCF-7 breast cancer cells [97]. Moreover, combinations of different polyphenols have been also evaluated revealing that naringenin and quercetin are effective inhibitors of the MDA-MB- 435 human breast carcinoma cell line [98].

The ability of phenolic compounds as reactive oxygen scavengers is the main motivator of its antioxidant properties. Among the main polyphenols present in vegetables, the action of quercetin in in vivo studies seems to be related with the inhibition and induction of survival and death signalling pathways respectively in liver cancer cells and its strong antioxidant activity and consequent prevention of ROS-induced DNA mutations in critical genes for cell cycle control [99]. In addition to ROS quenching, the antioxidant protective effect of flavonoids may be related to their modulating activity of several detoxifying enzymes like li poxyge nase, cycl ooxygenase, inducible nitric oxide synthase, monooxygenase, xanthine oxidase and NADH oxidase (reviewed by Gibell ini et al. [100]). Moreover, quercetin also can act in the chromatin remodelling and thus interfering with epigenetic alterations which are important in cancer progression. The effect of polyphenols on phase-I and -II enzymes can also modulate procarcinogenic metabolism. The modulation of NF-KB molecular pathway is another mechanism of polyphenol chemoprevention properties. In that sense, caffeic acid would inhibit growth and metastasis of HCC through modulation of expression of proteins involved mainly in NF-kB molecular pathway. Anyway, more research should be done in this field due to the vast number of potential antioxidant compounds from the polyphenol family.

\section{Breeding Strategies for the Improvement of Carotenoid and Polyphenol Content in Tomato}

Improvement of functional quality is a complex task because the accumulation of any antioxidant compound is the result of complex metabolic processes. Consequently, the increase in the available information on antioxidant biosynthetic pathways (enzymes involved and regulation mechanisms) and the identification of mutant genotypes with beneficial pathway alterations for the antioxidant accumulation is essential to obtain higher precision and better results in the development of breeding programs. Different breeding strategies can be followed with this purpose, and they all depend on the existence of variability for the accumulation of bioactive compounds in the cultivated species or wild relatives. Additionally, a different approach can be followed via genetic engineering. Advances in the improve ment of carotenoid and polyphenol composition of tomato are reviewed herein.

\subsection{Carotenoids}

In tomato, breeding for fruit colour was one of the first fruit quality objectives de manded by markets. As this feature is conferred by carotenoid pigments (mainly lycopene and $\beta$-carotene) with important antioxidant properties, the improvement of fruit colour has indirectly led to the improvement of tomato nutritional and functional value. This situation justifies that 
breeding for improved carotenoid content is far more advanced than any other bioactive compounds. The high colour variability present in genus Solanum section Lycopersicum allowed the first studies of diversegenetic variants (natural mutants) for this attribute (Table 2). Studies on tomato natural mutants for carotenoid accumulation and on tomato tran sgen ic plants with different carotenoid biosynthetic pathway alterations has allowed a detailed knowledge of the complete tomato carotenoid biosynthesis pathway (Figure 1) and its regulation strategies.

Table 2. Mutants used in tomato breeding related to carotenoid accumulation.

\begin{tabular}{|c|c|c|c|}
\hline $\begin{array}{l}\text { Altered } \\
\text { activity }\end{array}$ & Mutant/gene & $\begin{array}{l}\text { Fruit } \\
\text { colour }\end{array}$ & Details \\
\hline \multirow{6}{*}{$\begin{array}{l}\text { Single step of } \\
\text { biosynthesis } \\
\text { pathway }\end{array}$} & $r$ (yellow flesh) & $\begin{array}{l}\text { Yellow } \\
\text { fruits }\end{array}$ & $\begin{array}{l}\text { Null mutation of PSY-1 gene arrests } \\
\text { carotenoid synthesis and the yellow colour } \\
\text { is due to rutin accumulation }\end{array}$ \\
\hline & $t$ (tangerine) & $\begin{array}{l}\text { Orange } \\
\text { fruits }\end{array}$ & $\begin{array}{l}\text { Defective CRTISO enzyme. Prolycopene } \\
\text { (orange colour) is accumulated }\end{array}$ \\
\hline & $\begin{array}{l}\text { og (old gold) and } \\
\text { og }^{c}(\text { old gold } \\
\text { crimson) }\end{array}$ & $\begin{array}{l}\text { Intense } \\
\text { red fruits }\end{array}$ & $\begin{array}{l}\text { Frameshift mutations originating defective } \\
\text { CYC-B Lycopene is accumulated at the } \\
\text { expense of } \beta \text {-carotene }\end{array}$ \\
\hline & $B($ Beta $)$ & $\begin{array}{l}\text { Orange } \\
\text { fruits }\end{array}$ & $\begin{array}{l}\text { Mutation in the promoter of CYC-B gene } \\
\text { (increased transcription). } \beta \text {-carotene } \\
\text { increases at the expense of lycopene }\end{array}$ \\
\hline & Del (Delta) & $\begin{array}{l}\text { Orange } \\
\text { fruits }\end{array}$ & $\begin{array}{l}\text { LCY-E transcription is increased, and more } \\
\delta \text {-carotene is produced at the expense of } \\
\text { lycopene }\end{array}$ \\
\hline & $\begin{array}{l}\text { hp-3(high pigment } \\
\text { 3) }\end{array}$ & $\begin{array}{l}\text { Intense } \\
\text { red fruits }\end{array}$ & $\begin{array}{l}\text { Defective ZE mutant. Biosynthesis of ABA is } \\
\text { decreased, resulting in increased plastid } \\
\text { division and higher accumulation of } \\
\text { carotenoids }\end{array}$ \\
\hline \multirow{3}{*}{ Regulation } & $\begin{array}{l}h p-1, h p-1^{w}(h i g h \\
\text { pigment 1) }\end{array}$ & $\begin{array}{l}\text { Intense } \\
\text { red fruits }\end{array}$ & $\begin{array}{l}\text { Mutation of DD1 homolog. Altered light } \\
\text { regulation. Increased total carotenoids, } \\
\text { vitamin C and polyphenols }\end{array}$ \\
\hline & $\begin{array}{l}h p-2, h p-2^{j}, h p-2^{d g} \\
\text { (high pigment 2) }\end{array}$ & $\begin{array}{l}\text { Intense } \\
\text { red fruits }\end{array}$ & $\begin{array}{l}\text { Mutation of TDET1. Altered light signal- } \\
\text { transduction machinery. Increased total } \\
\text { carotenoids, vitamin C and quercetin }\end{array}$ \\
\hline & Ip (Intense pigment) & $\begin{array}{l}\text { Intense } \\
\text { red fruits }\end{array}$ & $\begin{array}{l}\text { Promotion of phytochrome signal } \\
\text { amplification. Increased soluble solids and } \\
\text { total carotenoids }\end{array}$ \\
\hline
\end{tabular}

In common red tomatoes, from the start of the maturing process (breaker stage) a high increment in synthesis of the enzymes PSY [101], PDS [102] and CRTISO [103] occurs, which results in a high increment in the all-trans-lycopene synthesis (marked with thickness arrows in Figure 1). At the same time, a strong repression of the synthesis of lycopene cyclases (enzymes involved in the formation of $6 C$ cyclic end groups) occurs [104]. Usually, in common red tomatoes, only lycopene- $\beta$-cyclases, LCY-B [102] and the chromoplast specific CYC-B [105] enzymes are present. The drastic diminution of the lycopene- $\beta$-cyclases entails that only a low amount of $\beta$-carotene synthesis at the expense of Iycopene can be achieved (Figure 1). 
Consequently, the prominent carotenoid in mature fruits will be all-trans-lycopene, which confers to the ripe fruits its typical red colour. Several natural mutant genes with altered steps in this biosynthetic pathway have been identified (Table 2). As a result, altered fruit carotenoid profile and fruit colours are obtained [103,105-107]. In green tissues of the plant, the carotenoid biosynthesis pathway does not stop with lycopene accumulation, but it continues with the xanthophyll biosynthesis pathway (Figure 1) and neoxanthin would be the last product synthesized, deriving in the abscisic acid (ABA) synthesis pathway [24].

Regulation of the carotenoid biosynthesis process can be done at three different levels. The first level consists in the regulation of the initial amount of the precursor of the synthesis of carotenoids (pre-pathway substrate regulation, Figure 1), the isopentenyl diphos shate (IPP), which determines the total amount of carotenoids that can be synthesised. IPP may arise at some developmental stages partly from the citoplasmic mevalonic (MVA) pathway [108], but it is mainly synthesised through the methylerythritol-4-pho sphate (MEP) pathway, apparently bound to the plastidic compartment [109]. The first enzyme of MEP pathway, 1-deoxy-Dxylulose-5-phosphate synthase (DXS), has been proved to catalyse the first regulatory step in carotenoid biosynthesis [110] and, consequently, highly influences the final amount of carotenoids. This pre-pathway substrate regulation also can be altered by a reduction of ABA synthesis which has as consequence an increase of plastid division enabling higher biosynthesis and accumulation of carotenoids [111]. This was observed in high pigment-3 (hp-3) mutants. These mutants coding a defective zeaxanthin epoxidase (ZE) enzyme (Xanthophyll biosynthesis pathway, Figure 1) which arrest ABA synthesis and, as explained above, increased caroten oid accumulation.

A second level of regulation consists in the hormonal growth regulation of the fruit ripening process (light independent regulation, Figure 1) which also plays a major role in the control of the described carotenoid synthesis pathway. During the ripening process, ethylene has a strong positive control of the increment in the mRNA levels for the lycopene-producing enzymes phytoene synthase (PSY) and phytoene desaturase (PDS), at the same time, the mRNA levels of the genes for the lycopene $\beta$ - and $\varepsilon$-cyclases diminish and completely disappear [104]. This explains that mutations affecting ethylene synthesis or perception, such as long life mutations rin, nor, alç..., not only delay the normal ripening process al so re sult in altered carotenoid content [112].

Finally, there is a third level of regulation in which fruit localized phytochromes al so regulate the extent of carotenoid accumulation [113]. Phytochrome response to light presence enables carotenoid synthesis that stops in darkness, thus conditioning day-cyclical biosynthesis periods (light-dependent regulation box, Figure 1). Several natural mutants present alteration s in the normal phytochrome regulation with enhanced global carotenoid content (Table 2): the mutation high pigment-1 ( $h p-1)$, and the allelic $h p-1^{w}$ results in the plant acting as perceiving continuously the light [114]. The mutation high pigment-2 ( $h p-2)$, and the allelic $h p-2^{j}$ and $h p-$ $2^{d g}$ [115], affects the photomorphogenesis regulatory gene TDET1, and also affects the light signal-transduction machinery [116]. Another mutant, Intense pigment $(I p)$ is implicated in a promotion of phytochrome signal amplification [117,118].

All the breeding strategies targeted to improve carotenoid content in tomato try to achieve a gene combination enabling a higher accumulation of one or more carotenoids in a desired 
genotype with good agronomic performance. Two main strategies can be used to do it: one is the use of germplasm with a high potential to accumulate one or more antioxidants as a gene donor in order to transfer them by conventional breeding programs and the other the use of advanced biotechnology to transferforeign genes (genetic engineering) to allow a be neficial biosynthesis alteration of the desired antioxidant compound.

Both strategies can be complementary, and in fact genetic engineering can be used to avoid the negative side effects of certain geneschanging their promotor (reviewed by Cebolla-Cornejo et al. [112]). Nevertheless, the level of public scepticism in certain regions (e.g., Europe) hinders the commercial ization of transgenic varieties [3] and commercial approaches are right now based in conventional breeding programs.

In summary, the first approach involved the exploitation of natural diversity present in the genus (mainly genotypes with natural gene mutations identified in many studies and described before) as their use as donor parents in conventional breeding programs following different hybridization strategies and selection generations. Following this approach, some of the more successful fresh tomato cultivars developed carrying the Beta, B, gene with its modifier Be tamodifier, moB (Figure 1) have been Caro Red [119] and Caro Rich [120] and the processing tomato cultivar Caro beta [121]. These cultivars show orange fruits with $\beta$-carotene contents up to $5 \mathrm{mg} 100 \mathrm{~g}^{-1} \mathrm{fw}$ (roughly up to 10 -fold the normal content in standard red cultivars). Unfortunately, these orange fruited cultivars with high $\beta$-carotene content have not been commercially successful, as consumers seem to prefer red tomato fruits.

Other approaches focused in the increase of lycopene content have obtained improved cultivars using mutants old gold $(\mathrm{og})$ and old gold crimson $\left(\mathrm{og}^{c}\right)$ which inhibits the synthes is of $\beta$-carotene by cyclisation of lycopene resulting in higher lycopene contents (up to $30 \%$ of normal content) and lower $\beta$-carotene accumulations [122]. Tomato cultivars of the crimson type have been successfully commercialized due to their intense red pigmentation even when the fruits are not completely ripe. One of the problems of the use of mutants affecting single steps of the biosynthesis pathway is that the increase in the level of one carotenoid is obtained at the expense of another, thus little effect can be expected for total carotenoid content. Thus, mutants affecting the regulation of the pathway would have a more dramatic effect. In fact, better results have been obtained with cultivars carrying both crimson and high pigment genes ( $h p$-1 or $h p$-2 alleles), as increments in the lycopene content up to 3- to 4-fold of common cultivars has been obtained [124]. Although, some deleterious effects on seed germination, plant vigour and yield have been associated with the high pigment mutants. The best expectations where deposited in the use of Intense pigment $(I p)$ mutant gene. This gene allows carotenoid accumulation similar to those of $h p$ genes, but with lower deleterious effects and it is dominant (commercial hybrid development more interesting than with recessive genes as $h p$ mutants) [125].

Regarding the second breeding strategy, the high advances in the knowledge of the carotenoid biosynthesis (metabolic pathway, precursors and regulation mechanisms) allowed the use of this information to obtain several experimental transgenic tomato lines with modified ge nes controlling some biosynthetic steeps. Most of this works try to emulate the carotenoid biosynthetic performance of some of the natural mutants identified, and some of them also try to avoid undesirable side-effects found in these mutants. 
One approach used has been the modification of isoprenoid precursor's pathway (pre-pathway substrate regulation) intervening in the both mevalonate (MVA; [109]) and methylerythritol-4phosphate (MEP; [126]) pathways (Figure 1) trying to increase the total amount of carotenoids increasing the levels of the precursor. Only transformation with gene encoding 1-deoxy-Dxylulose-5-phosphate synthase (DXS) from Escherichia coli to increase MEP pathway showed interesting results (2.2 times higher $\beta$-carotene content).



Figure 1. Carotenoid and xanthophyll biosynthesis pathway in tomato (adapted from; $[24,110,112,122,123])$. The most important products and steps in carotenoid biosynthesis in common red tomatoes are underlined and marked with thick arrows respectively. The three regulation mechanisms are indicated with $90^{\circ}$ rotated boxes.

The most explored approach has been placed in the development of transgenic lines with altered expression of the most important enzymes in the carotenoid synthetic path way with 
the objective to alter the carotenoid profile and to increase the content of certain of interesting carotenoids. The focus was put on the enzymes phytoene synthase $[127,128]$, phytoene desaturase [129] and mainly on lycopene cyclases [105,130-134] due to their role in the regulation of the whole pathway and its role in the partition of the main carotenoids lycopene and $\beta$-carotene. Several strategies have been used: constitutive or selective expression of foreign genes from several species and overexpression or re pression of target genes by several mechanisms, but results obtained were contradictory. To avoid these problems, in recent years, a more refined strategy targeted to obtain a better expression of transgenes using more selective and specific promoters have been explored. In this sense, the characterization of the tomato PDS promoter [135], as well as $S$. habrochaites lycopene $\beta$ cyclase (CYC-B) promoter [136] bring information to enhance the use of new transgenes. Other efforts were targeted to use promoters which allows a selective expression of transgenes in fruit tissues and adequate developmental stages as occurs with fruit specific promoters such as ethylene responsegenes $\mathrm{E} 8$ and $\mathrm{E} 4 \mathrm{~m}$ polygalacturonase and lipoxygenase, mainlyacting in the late-ripening stage or the LA22CD07 and LesAffx.6852.1.SI at in green and red-ripening fruits [137].

Finally, the third approach used is based on the modification of some of the regulatory mechanisms of the carotenoid biosynthesis pathway. In this sense, some transgenic experimental lines tried to emulate the performance of high pigments mutants $h p-1$ [114] and $h p-2$ [138]. In this last case, the strategy used involved the suppression of photomorphogenesis regulatory gene TDET1 in fruits (using fruit specific promoters combined with a RNA interference approach based in inverted repeat constructs) to reduce negative collateral vegetative effects, and gave interesting results. Other works were focused in the development of transgenic experimental lines simulating performance of $h p-3$ mutants. In this sense, the down-regulation of $A B A$ synthesis during ripening using an RNAi construct of the SINCED1 gene driven by the fruit specific promoter E8 $[139,140]$, caused a reduction in ABA concentration, an increase of ethylene production and resulted in an increment in lycopene and $\beta$-carotene contents.

\subsection{Polyphenols}

The polyphenol content of tomatoes has gained importance during the last decade. Consequently, the achievements of breeding efforts still lag behind those obtained for carotenoids. Nevertheless, quite a lot of information is available regarding polyphenol biosynthesis in this crop. In fact, the polyphenol metabolic pathway has also been ascertained. Several transcription factors related with the regulation of polyphenol biosynthesis have be en identified, but a lot of information regarding the spatial accumulation of polyphenols in the fruit and how it can be reverted is still required.

The phenylpropanoid biosynthetic pathway is the first step in the polyphenol biosynthesis and it uses the amino acid phenylalanine from the shikimate pathway as initial substrate (Figure 2). This biosynthetic pathway is common for two of the main classes of tomato polyphenols: hydroxycinnamic acids and flavonoids. The first step involves the conversion of phenylal anine into trans-cinnamic acid using the enzyme phenylalanine ammonia lyase (PAL). The enzyme cinnamate 4-hydroxylase $(\mathrm{C} 4 \mathrm{H})$ catalyses the conversion of the resulting product into $p$ - 
coumaric acid. At this point, the flavonoid biosynthetic pathway continues with the conversion of $p$-coumaric acid into 4-coumaroyl-COA as a result of the action of 4-coumarate-CoA ligase (4CL) [141].

Meanwhile the hydroxycinnamic acid pathway continues with the transformation of $p$ coumaric acid into caffeic acid catalysed by the p-coumarate 3-hydroxylase (C3H) [142]. Chlorogenic acid, one of the main polyphenols present in tomato [26], is formed from caffeoyl$\mathrm{CoA}$, which is transesterificated with quinic acid by hydroxycinnamoyl-Coenzyme A:quinate hydroxycinnamoyl transferase, HQT [143]. Caffeoyl-CoA would be obtained from 4-coumaroylCoA in three steps involving the successive activities of cinnamoyl CoA shikimate/quinate transferase (HCT), p-coumaroyl ester 3-hydroxylase (C3H) and HCT [144]. Finally, the third main hydroxycinnamic acid in tomato, ferulic acid, would be obtained from caffeic acid with the enzyme caffeic acid $O$-methyltransferase (COMT) [142].

On the other hand, the core flavonoid biosynthetic pathway starts with the conversion of the resulting 4-coumaroyl-CoA from the phenylpropanoid pathway into the yellow-coloured naringenin chalcone [141]. This key reaction is performed by the enzyme chalcone synthase (CHS) which begins with the condensation of one molecule of 4-coumaroyl-CoA with three molecules of malonyl-CoA. In most plants, including tomato, chalcones are not the endproduct of the pathway. The enzyme chalcone isomerase $(\mathrm{CHI})$ isomerizes naringenin chal cone into the flavanone naringenin. Finally, the core flavonoid intermediates pathway finishes with the formation of the dihydroflavonol dihydrokaempferol as a result of the action of the flavanone 3-hydroxylase (F3H). From this central intermediate, the flavonoid biosynthetic pathway diverges into several side branches, each resulting in a different class of flavonoid [141].

One of the most important classes of flavonoids in tomato are flavonols [26,149], which are synthesised from dihydrokaempferol. The three more important in tomato are kaempferol, quercetin, and myricetin. The three are formed from the corresponding dihydroflavonol, and have dihydrokaempferol as a starting point.

Flavonol synthase (FLS) catalyses the direct conversion of dihydrokaempferol into kaempferol. On the other hand, with dihydrokaempferol as substrate, the enzymes flavonoid 3'hydroxylase $\left(\mathrm{F}^{\prime} \mathrm{H}\right)$ and $\mathrm{FLS}$ would produce respectively dihydroquercetin and quercetin [147]. Quercetin is especially important in tomato, as it is the base for the formation of rutin. This quercetin glycoside is quite abundant in tomato [32], and it is obtained from quercetin by the action of the enzymes glucosyltransferase (GTF) and rhamnosyltransferase (RTF) [146].

The third flavonol, myricetin, would be derived in from dihydroquercetin in two steps. The first one catalysed by flavonoid 3' $5^{\prime}$-hydroxylase, F3' $5^{\prime} \mathrm{H}$ [145], would produce dihy dromyricentin which would be converted into myricetin by FLS. Moreover, myricetin could also be directly obtained from dihydrokaempferol by means of the action of F3' $5^{\prime} \mathrm{H}$ and FLS [145-147].

Anthocyanins are not naturally accumulated in the tomato fruit, but as it will be shown, interspecific crosses can restore this pathway in the fruit. Their synthesis would start from the three commented dihydroflavonols. Dihydroflavonol 4-reductase (DFR) would catalyse the conversion of dihydroflavonols into flavan-3,4-diols, which would be then transformed into anthocyanidins by anthocyanidin synthase (ANS). The final step would require the addition of sugars to form anthocyanins, which are anthocyanidin glycosides [141,144]. The main 
anthocyanins present in tomato would be derived from three anthocyanidins: delphid in, that would be synthesised following this scheme from dihydromyricetin, cyaniding from dihydroquercetin and pelargonidin from dihydrokaempferol. Other anthocyanidins would be derived from these. For example, delphinidin can be methylated on its $3^{\prime}$ hydroxyl group to form petunidin or on both its $3^{\prime}$ and $5^{\prime}$ hydroxyl groups to form malvidin [150].

As in the case of carotenoids, several mutants have been identified regarding polyphenol accumulation (Table 3), and those more used in breeding programs are related to the regulation of the pathway. It seems that $\mathrm{CHI}$ plays a central role in the rate determining step in the production of flavonols [151]. In fact, its over-expression increases dramatically the levels of flavonols at the expense of naringenin chalcone [33]. Ballester et al. [152] suggested that upon ripening an increase in the expression CHS expression and a coordinated decrease in the expression of $\mathrm{CHI}$ would result in the accumulation of naringen in chalcone and in a limitation of flavonol contents. Previously, Willits et al. [153] suggested that the lack of expression of CHI in the peel of the fruit, probably caused by a mutation in a fruit specific promoter would explain the high levels of naringenin chalcone in this tissue. The authors also assumed that cultivated tomato would have lost the expression of $\mathrm{CHI}$ in the peel in an early step of the domestication process.

Naringenin chalcone is one of the prominent polyphenols in tomato. Its accumulation in the peel gives a yellow colour that in combination with red flesh results in an external red colour of the fruit. Several tomato landraces are characterized by an external pink colour, resulting from the lack of accumulation of naringenin chalcone and a consequent transparent peel. The evaluation of introgression lines of Solanum chmielewskiiin tomato enabled the identification of the gene responsible for this mutation (yellow, y), initially described in 1925 [154]. This gene encodes SIMYB12, a transcription factor involved in the regulation of the phenylpropanoid and/orflavonoid pathway [152].

The expression of the Arabidopsis form AtMYB12 in tomato induced primary and secondary metabolism, binding directly to the promoters of different genes encoding enzymes of the primary metabolism such as 3-deoxy-D-arabino-heptulosonate 7-phosphate synthase, DAHPS, and plastidial enolase, ENO [155]. DAHPS is a key determinant if the flow of the shikimate pathway. A first step needed for the accumulation of phenylalanine, a substrate necessary for the flavonoid pathway. Additionally, it would also bind to promoters of genes related enzymes participating in the flavonoid pathway (PAL5A, PAL5C, PAL5D, CHS1 and F3H). As result a dramatic increase in flavonol and hydroxycinnamates is observed, reaching up to $10 \%$ of fruit dry weight.

Pandey et al. [156] also expressed constitutively AtMYB15, obtaining similar results. In this case, 305 unigenes were upregulated in the fruit tissue and 419 downregulated. Specifically, several enzymes of the flavonoid pathway were upregulated, especially CHS (300-fold enhanced expression in the fruit) and FLS (300-fold enhanced expression in the fruit). Additionally, genes involved in ethylene biosynthesis and signalling, ABA, auxin and Ga signalling were also modulated. Primary metabolism was also altered, and a differential regulation of genes involved in aromatic amino acid biosynthesis and carbohydrate metabolism was observed. Probably this modulation may be related to the elevated de mand of C-source to support the enhanced biosynthesis of polyphenols. 


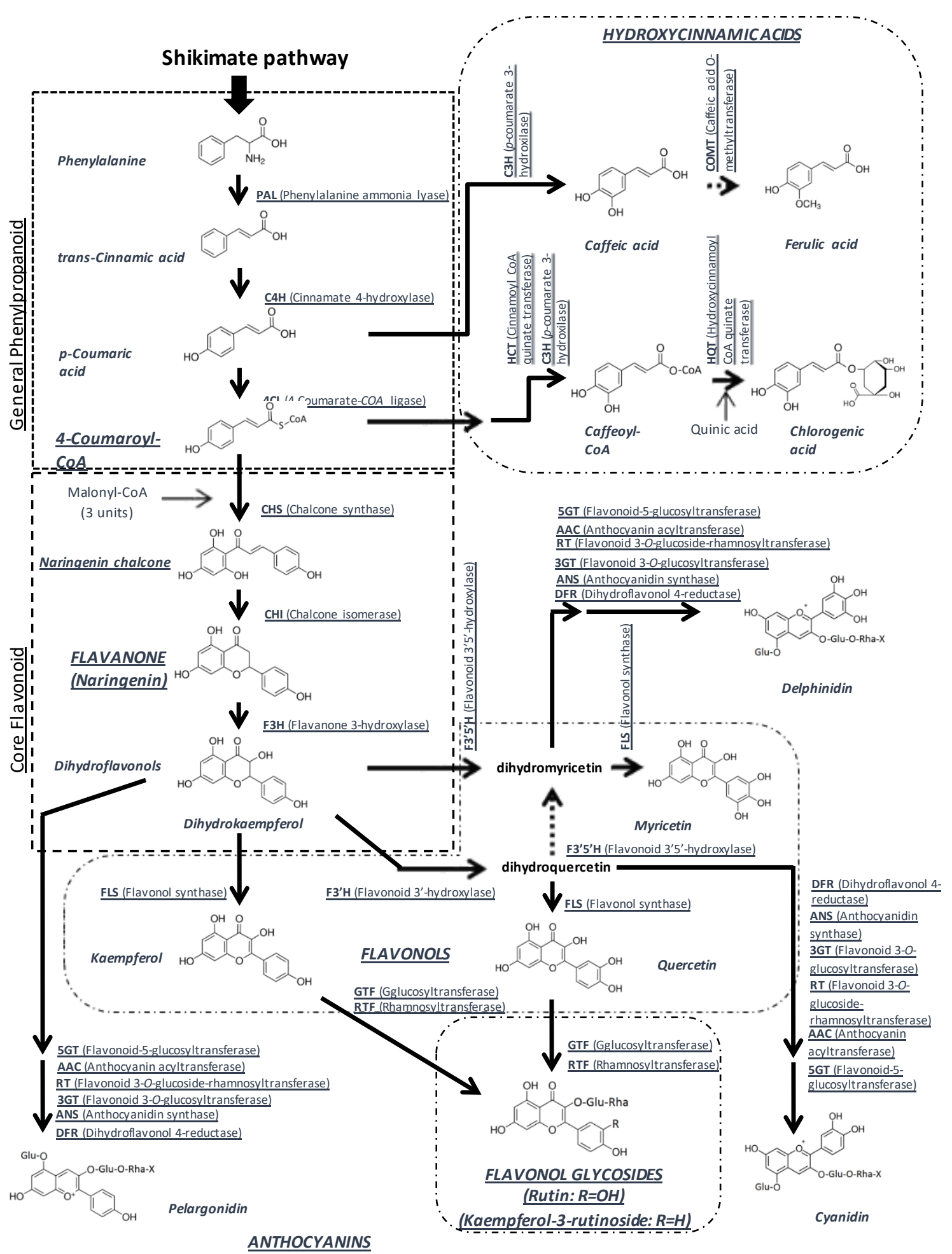

Figure 2. Polyphenol biosynthesis pathway in tomato (adapted from [141,142,145-148]. Broken arrows indicate common pathways in plants, which would probably apply to tomato. Solid lines confirmed in tomato.

Recent transcriptome analysis has identified additional transcription factors involved in the regulation of the pathway [157]. At least 20 transcription factors would correlate with expression of genes participating in the flavonoid biosynthesis pathway. As expected, SIMYB12 is included in this set. Other examples include LIM, which is highly correlated with the 
expression of genes involved in both the biosynthesis of ascorbic acid and flavonoids, and other MYB and bHLH genes.

Table 3. Mutants used in tomato breeding related to polyphenol accumulation.

\begin{tabular}{|c|c|c|c|}
\hline $\begin{array}{l}\text { Altered } \\
\text { activity }\end{array}$ & Mutant/gene & Fruit colour & Details \\
\hline \multirow{6}{*}{ Regulation } & $Y($ yellow $)$ & Pink fruits & $\begin{array}{l}\text { Mutation of SIMYB12, transcription } \\
\text { factor involved in the regulation of } \\
\text { phenylpropanoid/flavonoid } \\
\text { pathway. Lack of accumulation of } \\
\text { naringenin chal cone in fruit peel }\end{array}$ \\
\hline & $\begin{array}{l}\text { Aft (Anthocyanin } \\
\text { fruit) }\end{array}$ & $\begin{array}{l}\text { Purple } \\
\text { fruits } \\
\text { (external) }\end{array}$ & $\begin{array}{l}\text { Probable regulation of } \\
\text { flavonoid/anthocyanidin synthesis } \\
\text { in fruits. Increased levels of } \\
\text { flavonols, delphinidin, malvidin and } \\
\text { petunidin }\end{array}$ \\
\hline & Abg (Aubergine) & $\begin{array}{l}\text { Purple } \\
\text { fruits } \\
\text { (external) }\end{array}$ & Possible allele of $A f t$. \\
\hline & atv (atroviolacea) & $\begin{array}{l}\text { Light } \\
\text { purple } \\
\text { fruits } \\
\text { (external) }\end{array}$ & $\begin{array}{l}\text { Possible role in the phytochrome } \\
\text { phyB1 high irradiance response } \\
\text { pathway. Strong accumulation of } \\
\text { anthocyanins in vegetative parts. } \\
\text { Small effect on fruit, but it has } \\
\text { synergic effects with } A f t\end{array}$ \\
\hline & $\begin{array}{l}h p-1, h p-1^{w}(\text { high } \\
\text { pigment } 1)\end{array}$ & $\begin{array}{l}\text { Intense red } \\
\text { fruits }\end{array}$ & $\begin{array}{l}\text { Mutation of DD1 homolog. Altered } \\
\text { light regulation. Increased total } \\
\text { carotenoids, vitamin C and } \\
\text { polyphenols }\end{array}$ \\
\hline & $\begin{array}{l}h p-2, h p-2^{j}, h p-2^{d g} \\
\text { (high pigment } 2 \text { ) }\end{array}$ & $\begin{array}{l}\text { Intense red } \\
\text { fruits }\end{array}$ & $\begin{array}{l}\text { Mutation of TDET1. Altered light } \\
\text { signal-transduction machinery. } \\
\text { Increased total carotenoids, } \\
\text { vitamin C and quercetin }\end{array}$ \\
\hline
\end{tabular}

The expression of endogenous genes encoding key enzymes of the flavonoid pathway (PAL, $\mathrm{CHS}, \mathrm{CHI}, \mathrm{F} 3 \mathrm{H}$ and FLS) in tomato pericarp and collumela tissues has been found to be under detection limits [146]. This lack of expression would explain the low amounts of flavonoids found in these tissues. The expression of these genes can be achieved. For example, an overall increase in flavonol accumulation in the whole fruit was achieved with the expression Lc and C1 transcription factors from maize [151]. In this case, a clear over-expression of genes encoding $\mathrm{CHS}$ and $\mathrm{F} 3 \mathrm{H}$ was observed, suggesting that the expression of these two genes would be necessary to improve flavonoid accumulation in tomato flesh. Other studies confirmed that the expression of the gene encoding FLS would also be required alter all [34]. In fact, the joint over-expression of genes encoding CHS and FLS would be required to pull the carbon flux towards the accumulation of flavonols [146].

Regarding the light regulation of the pathway, Giuntini et al. [158] showed that UV-B radiation differentially affects the expression of genes of the flavonoid pathway and re sults in al tered 
content of flavonoids and hydroxycinnamic acids. The conventional cultivar Esperanza showed higher levels of naringenin chalcone, quercetin and rutin and of sinapic, caffeic, ferulic and $p$ coumaric acids in the flesh of UV-B shielded fruits at the red ripe stage, while in the high lycopene cultivar DRW5981 limited effects were observed at this stage, especially for flavonoid content. In the conventional cultivar Esperanza, the expression of genes encoding $\mathrm{CHS}$ and $\mathrm{CHI}$ expression was higher and that corresponding to $\mathrm{F} 3 \mathrm{H}$ and $\mathrm{F}^{\prime} \mathrm{H}$ was reduced in UV-B shielded fruits. In both cultivars, carotenoid accumulation followed the same response of flavonoid accumulation. In the high lycopene cultivar DRW5981 several genes of the flavonoid path way were upregulated in the fruit flesh with the exception of $\mathrm{CHI}$. As a result a dramatic increase in naringenin chalcone and a modest increase in quercetin were observed.

As commented in the carotenoid section, the high pigment $(h p)$ tomato mutants al so affect the light regulation of flavonoid synthesis. This overproduction of bioactive compounds is also associated with increased plastid biogenesis and therefore plastid-accumulating me tabolites would be expected (reviewed by Azari et al. [159]).

The increase in the accumulation of flavonoids in conventional breeding programs, exclu ding genetic engineering has offered limited results. In fact, the analysis of different tomato germplasm for flavonol accumulation offered limited levels of variation (up to 10-fold). Quercetin in hydrolysed peel extracts varied between 6.3 and $64.9 \mu \mathrm{g} \mathrm{g}^{-1} \mathrm{fw}$, but the highest levels only represented a 2.5 -fold increase compared to a standard commercial variety [34]. Similar levels of variation have been found by other authors, with the highest levels been found in the smaller cherry tomato fruits originating from sunny climates [35]. The limited variation found in the cultivated tomato suggested that it would be difficult to improve flavonol accumulation via conventional breeding.

Nevertheless, the use of the primary gene pool has enabled the identification and use of wild species from the Solanum section lycopersicum as sources of variation. Following this approach, tomato flavonoid content has been increased using the wild tomato species Solanum pennellii Correl, in order to restore the flavonoid pathway in fruit flesh. With this objective, germplasm expressing chalcone isomerase in the flesh was selected and used in the development of hybrids with the cultivated species with higher levels of quercetin diglycoside [153].

Something similar happened with the improvement of anthocyanins in tomato. In fact, in the cultivated species anthocyanins are not produced in the fruit, but as a result of interspecific crossed in breeding programs, several mutants with anthocyanin accumulation in the fruit have been identified. The three mutants that can lead to increased anthocyanin content in the peel of the fruit are Anthocyanin fruit (Aft) Aubergine ( $a b g$ ) and atroviolacea (atv).

The Anthocyanin fruit, Aft, mutant was identified in crosses with Solanum chilense Dunal. This gene is located in chromosome 10 and its presence in tomato leads to increased levels of delphinidin, malvidin and petunidin, as well as higher levels of the flavonols quercetin, 3.6-fold, and kaempferol, 2.7-fold [37].

Sapir et al. [37] proved that $A f t$ fruits not only showed high levels of anthocyanins in the skin and outer pericarp of the fruit, but also of the flavonols quercetin and kaempferol. They also showed that Aft is encoded by a single locus on chromosome 10 fully associated with Anthocyacin1(Ant1). Slant1 was discovered in a T-DNA insertional mutagenesis program and 
was identified as a MYB transcription factor. Vegetative tissues of Slant1 showed intense purple colour and fruits displayed purple spotting on the epidermis and pericarp. The overexpression of Slant1 upregulated genes encoding enzymes of early and later steps of anthocyanidin biosynthesis as well as genes involved in the glycosylation and transport of anthocyanins into the vacuole [160]. It seems that the original allele from S. chilense ScAnt1 would be more efficient in the production of anthocyanins than the tomato counterpart [161].

The Ant1 paral og gene SIAn2, similar to Petunia anthocyanin2, is found in chromosome 10 and has also been related with the Aft mutant. SIAn2 encodes an R2R3-MYB transcription factor and its overexpression in tomato results in increased anthocyanin accumulation in fruit peel [162]. Additionally, overexpressing fruits display ripening related phenotypes, with en hanced ethylene levels, reduced carotenoid accumulation and faster fruit softening. In fact, the authors found a concomitant accumulation of Rin (Ripening inhibitor) transcripts suggesting that the functions of SIAn2 and Rin may be related. It has been recently studied that between SIAnt1 and SIAn2 only the latter acts as a positive regulator of anthocyanin synthesis in vegetative tissues under high light or low temperature conditions [163].

The Aubergine $(\mathrm{Abg})$ mutant was identified in a cross with Solanum lycopersicoides [164]. This gene also relies in the chromosome 10 and it may be allelic to Aft. The difficulties in the management of $S$. lycopersicoides introgressions has hindered the development of allelic studies to confirm or discard this relation. In this sense, a paracentric inversion has been identified in the long arm of chromosome 10 of S. lycopersicoides, resulting in the absence of recombination events in this segment [165].

The recessive gene atroviolacea (atv), mapping in chromosome 7, was identified in a segregant population S. cheesmaniae (L. Riley) Fosberg [166]. It has a strongest effect on the accumulation of anthocyanins of vegetative tissues and has a limited effect on the fruit. The atv mutant shows an exaggerated response in the red broad band light, suggesting specificity for the phytochrome phyB1 high irradiance response pathway [167]. Thus, this mutation per se has no important effect on the accumulation of anthocyanins on the fruit. Nonetheless, it has been proved that in the double homozygous mutants Aft Aft atv atv a synergistic effect of both genes arises on the transcription of specific genes of the anthocyanin pathway, resulting in higher anthocyanin contents than in the individual mutants [168]. This effect also applies to the combination $A b g$ with atv. In fact the best combinations to improve anthocyanin content in the fruit include Abg_atvatv and Aft Aft atvatv in small fruits, with contents up to 415 and

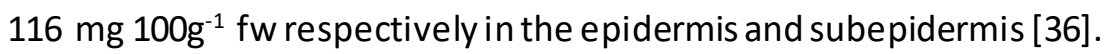

Another mutant, anthocyanin free (af), was identified in the fifties as a mutagenesis variant characterized by the lack of anthocyanin production in all plant tissues. Recently, Kang et al. [169] showed that af encodes SICHI1, but complementation assays demonstrated that SICHII not only complements flavonoid synthesis in the af mutant, but also complements a defect in terpenoid production, suggesting a link between both pathways.

None of these mutants result in the accumulation of anthocyanins in the fruit flesh. Alternatively, tomatoes with purple flesh have been obtained via genetic engineering. In this sense, the transcription Del and Ros1 have been involved in the activation of the flavonoid pathway in tomato [147], as the expression of thesefactors from Antirrhinum resulted in the accumulation of purple anthocyanins in both peel and flesh. It seems that these factors would 
stimulate the transcription of the genes encoding PAL, $\mathrm{CHI}$ and $\mathrm{F}^{\prime} 5^{\prime} \mathrm{H}$. This upregulation of the flavonoid pathway and the opening of the anthocyanin gate $\left(\mathrm{F}^{\prime} \mathrm{5}^{\prime} \mathrm{H}\right)$ resulted in anthocyan in levels up to $3 \mathrm{mg} \mathrm{g}^{-1} \mathrm{fw}$. Another possible success of the combination of both transcription factors may be related with the upregulation of genes involved in the side chain modification of anthocyanins and genes associated with the transport and accumulation in vacuoles [170]. Later works with the same genes obtained higher levels up $5.2 \mathrm{mg} \mathrm{g}^{-1}$ dry weight (dw), with petunidin-3-(trans-coumaroyl)-rutinoside-5-glucosideand del phinidin-3-(trans-co umaroyl)rutinoside-5-glucoside representing an $86 \%$ of the total anthocyanins [171].

The enzyme $\mathrm{F3}^{\prime} \mathrm{5}^{\prime} \mathrm{H}$ would be in fact a key enzyme in restoring the accumulation of anthocyanins in tomato. In fact, the absence of anthocyanins in LC/C1 fruits was attributable primarily to an insufficient expression of $\mathrm{F}^{\prime} \mathrm{S}^{\prime} \mathrm{H}$, in combination with a strong preference of the tomato dihydroflavonol reductase (DFR) to use dihydromyricetin as a substrate [151].

\subsection{Joint Accumulation of Carotenoids and Polyphenols}

Following the objective of maximizing the functional value of tomato, several efforts have been made in order to maximize the accumulation of carotenoids and polyphenols in the same material. As stated in the carotenoids section, the use of the high pigment (DDB1:hp-1, hp - ${ }^{w}$, DET1: $\left.h p-2, h p-2^{j}, h p-2^{d g}\right)$ mutants enables an improvement in the accumulation of both type s of bioactive compounds. Lines carrying $h p-1$ apart from increased carotenoid levels can show 13-fold higher levels of quercetin [172]. Long et al. [173] also found higher levels of chlorogenicacid in $h p$-1-lines (4.3-fold) and similar levels of hydroxycinnamic acids co mpared to a standard variety. The $h p-2^{d g}$ increased the level of quercetin aglycone 3.2-fold at the red stage, while the differences were not significant for naringenin chalcone [115]. It is not clear the connection of the two pathways, but considering that vitamin C contents are also higherin $h p-1$ and $h p-2$ plants $[115,174]$ it could be possible that the expression of these all el es would trigger stress tolerance mechanisms activating the overproduction of antioxidants. Alth ough both pathways seem to be completely independent, surprisingly, the combination of anthocyanin mutants with carotenoid defective mutants (Beta, $B$, and yellow flesh, $r$ ) results in lower total anthocyanin levels [36].

High pigment mutants have also been used in combination with anthocyanin synthesising mutants. Following this strategy, double homozygotes for $A f t$ and $h p 1$ displayed a more than additive effect on the accumulation in anthocyanins and flavonols, with 5-, 19-, and 33-fold increase in the content of petunidin, malvidin and delphinidin respectively [37]. Mes et al. [36] also obtained higher anthocyanin levels combining $A f t$ and $h p-1$, though the levels obtained were lower than the combination Aft-atv.

Stacking carotenoid and anthocyanin related genes is currently being used in the development of new cultivars with enhanced functional value. As an example, Sestari et al. [175] stacked the genes $h p-2$, Aft and atv into a commercial cultivar of cherry tomato. Cherry cultivars are selected due to their high ratio surface to volume, as carotenoids and polyphenols tend to accumulate in the external layers of the fruit, and more light is received by the peel increas ing anthocyanin synthesis. 


\section{Conclusions}

It is difficult to establish a clear link between a specific component of a complex diet with the prevention of different types of cancer. Especially, when their efficiency may depend on the matrix in which the bioactive compound is present. Consequently, supplementation studies may differ from their natural ingestion in food. Despite these difficulties, carotenoids and polyphenols have proved in different studies to play a role as functional compounds in the prevention of cancer. In this context, despite not outstanding for its nutritional value, the high level of consumption of tomato all year round makes it an important source of bioactive compounds. During the last decades, efforts have been placed in the breeding sector in order to develop new functional tomato varieties with increased levels of carotenoids and polyphenols. These materials would represent an alternative to isolated compounds found in dietary supplements, with the benefits of synergetic effects of these molecules with other phytochemicals presents in the natural matrix. The use of high pigment genes in combination with a restoration of anthocyanin accumulation in the fruit, especially in smaller materials such as cherry varieties, may represent a promising alternative to increment the intake of these bioactive compounds in their natural matrices in the near future. These new materials will obviously be an interesting tool to be combined with other recommendations in order to prevent or even to contribute to delay the progression of cancer.

Acknowledgments: The Author's thank the editorial office of Cancers for covering the costs to publish in Open Access.

Author Contributions: All the authors contributed to the review of bibliography (especially R.M.) and the writing of the paper.

Conflicts of Interest: The authors declare no conflict of interest. 


\section{References}

1. Bruhn, C.M.; Feldman, N.; Garlitz, C.; Harwood, J.; Ivans, E.; Marshall, M.; Riley, A.; Thurber, D.; Williamson, E. Consumer perceptions of quality: Apricots, cantaloupes, peaches, pears, strawberries, and tomatoes. J. Food Qual. 1991, 14, 187-195.

2. Cappellano, K.L. Influencing food choices: Nutrition labeling, health claims, and front-of-thepackage labeling. Nutr. Today 2009, 44, 269-273.

3. Goldman, I.L. Molecular breeding of heal thy vegetables. EMBO Rep. 2011, 12, 96-102.

4. Shahidi, F.; Chandrasekara, A.; Zhong, Y. Bioactive phytochemicals in vegetables. In Handbook of Vegetables and Vegetable Processing; Sinha, N.K., Hui, Y.H., Evranuz, E.Ö., Siddiq, M., Ahmed, J., Eds.; Wiley-Blackwell:Ames, IA, USA, 2011; pp. 125-158.

5. $\quad$ Kris-Etherton, P.M.; Hecker, K.D.; Bonanome, A.; Coval, S.M.; Binkoski, A.E.; Hilpert, K.F.; Griel, A.E.; Etherton, T.D. Bioactive compounds in foods: their role in the prevention of cardiovasculardisea se and cancer. Am. J. Med. 2002,113, 71-88.

6. Trichopoulou, A.; Lagiou, P.; Kuper, H.; Trichopoulos, D. Cancer and Mediterranean dietary traditions. Cancer Epidemiol. Biomarkers Prev. 2000, 9, 869-873.

7. Willett, W.C.; Sacks, F.; Trichopoulou, A.; Drescher, G.; Ferro-Luzzi, A.; Helsing, E.; Trichopoulos, D. Mediterranean diet pyramid: a cultural model for healthy eating. Am. J. Clin. Nutr. 1995, 61, 14021406.

8. Liu, R.H. Dietary bioactive compounds and their health implications. J. Food Sci. 2013, 78, 18-25.

9. Blanck, H.M.; Gillespie, C.; Kimmons, J.E.; Seymour, J.D.; Serdula, M.K. Trends in fruit and vegetable consumption among U.S. men and women, 1994-2005. Prev. Chronic Dis. 2008, 5, A35. Avaliable online: http:// www.cdc.gov/pcd/issues/2008/apr/07 0049.htm (accessed on 1 May 2016).

10. Vattem, D.A.; Ghaedian, R.; Shetty, K. Enhancing health benefits of berries through phenolic antioxidant enrichment: Focus on cranberry. Asia Pac. J. Clin. Nutr. 2005, 14, 120-130.

11. Boileau, T.W.; Liao, Z.; Kim, S.; Lemeshow, S.; Erdman, J.W.; Clinton, S.K. Prostate Carcinogenesis in N-methyl-N-nitrosourea (NMU)-Testosterone-Treated Rats Fed Tomato Powder, Lycopene, or Energy-Restricted Diets. J. Natl. Cancer Inst. 2003, 95, 1578-1586.

12. Wang, S.; DeGroff, V.L.; Clinton, S.K. Tomato and soy polyphenols reduce insulin-like growth factorI-stimulated rat prostate cancer cell proliferation and apoptotic resistance in vitro via inhibition of intracellular signaling pathways involving tyrosine kinase. J. Nutr. 2003, 133, 2367-2376.

13. Liu, R.H. Potential synergy of phytochemicals in cancer prevention: Mechanism of action. J. Nutr. 2004, 134, 3479-3485.

14. Unlu, N.Z.; Bohn, T.; Clinton, S.K.; Schwartz, S.J. Carotenoid absorption from salad and salsa by humans is enhanced by the addition of avocado or avocado oil.J. Nutr. 2005, 135, 431-436.

15. Fielding, J.M.; Rowley, K.G.; Cooper, P.; O’Dea, K. Increases in plasma lycopene concentration after consumption of tomatoes cooked with olive oil. Asia Pac. J. Clin. Nutr. 2005, 14, 131-136.

16. Kavanaugh, C.J.; Trumbo, P.R.; Ellwood, K.C. The U.S. food and drug administration's evidencebased review for qualified health claims: Tomatoes, Iycopene, and cancer. J. Natl. Cancer Inst. 2007, 99, 1074-1085.

17. Lin, J.; Cook, N.R.; Albert, C.; Zaharris, E.; Gaziano, J.M.; Van Denburgh, M.; Buring, J.E.; Manson, J.E. Vitamins $\mathrm{C}$ and $\mathrm{E}$ and beta carotene supplementation and cancer risk: A randomized controlled trial. J. Natl. Cancer Inst. 2009, 101,14-23. 
18. Mente, A.; de Koning, L.; Shannon, H.; Anand, S. A Systematic Review of the Evidence Supporting a Causal Link Between Dietary Factors and Coronary Heart Disease. Arch. Intern. Med. 2009, 169, 659-669.

19. Mignone, L.I.; Giovannucci, E.; Newcomb, P.A.; Titus-Ernstoff, L.; Trentham-Dietz, A.; Hampton, J.M.; Willett, W.C.; Egan, K.M. Dietary carotenoids and the risk of invasive breast cancer. Int. J. Cancer 2009, 124, 2929-2937.

20. Aune, D.; Chan, D.S.; Vieira, A.R.; Rosenblatt, D.A.; Vieira, R.; Greenwood, D.C.; Norat, T. Dietary compared with blood concentrations of carotenoids and breast cancer risk: A systematic review and meta-analysis of prospective. Am. J. Clin. Nutr. 2012, 2007, 356-373.

21. Chun, O.K.; Kim, D.O.; Smith, N.; Schroeder, D.; Han, J.T.; Lee, C.Y. Daily consumption of phenolics and total antioxidant capacity from fruit and vegetables in the American diet. J. Sic. Food Agric. 2005, 85, 1715-1724.

22. Leiva-Brondo, M.; Valcárcel, M.; Cortés-Olmos, C.; Roselló, S.; Cebolla-Cornejo, J.; Nuez, F. Exploring alternative germplasm for the development of stable high vitamin $\mathrm{C}$ content in tomato varieties. Sci. Hortic. 2012, 133, 84-88.

23. Standfuss, J.; Terwisscha van Scheltinga, A.C.; Lamborghini, M.; Kühlbrandt, W. Mechanisms of photoprotection and nonphotochemical quenching in pea light-harvesting complex at $2.5 \mathrm{~A}$ resolution. EMBO J. 2005, 24, 919-928.

24. Galpaz, N.; Galpaz, N.; Ronen, G.; Ronen, G.; Khalfa, Z.; Khalfa, Z.; Zamir, D.; Zamir, D.; Hirschberg, J.; Hirschberg, J. A Chromoplast-Specific Carotenoid Biosynthesis Pathway Is Revealed by Cloning of the Tomato white-flower Locus. Plant Cell 2006, 18, 1-14.

25. Davies, J.N.; Hobson, G.E.; McGlasson, W.B. The constituents of tomato fruit-the influence of environment, nutrition, and genotype. Crit. Rev. Food Sci. Nutr. 1981, 15, 205-280.

26. Martínez-Valverde, I.; Periago, M.J.; Provan, G.; Chesson, A. Phenolic compounds, Iycopene and antioxidant activity in commercial varieties of tomato (Lycopersicum esculentum). J. Sci. food Agric. 2002, 82, 323-330.

27. Slimestad, R.; Fossen, T.; Verheul, M.J. The flavonoids of tomatoes. J. Agric. Food Chem. 2008, 56, 2436-2441.

28. Tiwari, U.; Cummins, E. Factors influencing levels of phytochemicals in selected fruit and vegetables during pre- and post-harvest food processing operations. Food Res. Int. 2013, 50, 497-506.

29. Fray, R.G.; Grierson, D. Identification and genetic analysis of normal and mutant phytoene synthase genes of tomato by sequencing, complementation and co-suppression. Plant Mol. Biol. 1993, 22, 589-602.

30. Qin, J.; Chao, K.; Kim, M.S. Investigation of Raman chemical imaging for detection of Iycopene changes in tomatoes during postharvest ripening. J. Food Eng. 2011, 107, 277-288.

31. Shen, Y.C.; Chen, S.L.; Wang, C.K. Contribution of tomato phenolics to antioxidation and downregulation of blood lipids. J. Agric. Food Chem. 2007, 55, 6475-6481.

32. Martí, R.; Valcárcel, M.; Herrero-Martínez, J.M.; Cebolla-Cornejo, J.; Roselló, S. Fast simultaneous determination of prominent polyphenols in vegetables and fruits by reversed phase liquid chromatography using a fused-core column. Food Chem. 2015, 169, 169-179.

33. Muir, S.R.; Collins, G.J.; Robinson, S.; Hughes, S.; Bovy, A.; Ric De Vos, C.H.; van Tunen, A.J.; Verhoeyen, M.E. Overexpression of petunia chalcone isomerase in tomato results in fruit containing increased levels of flavonols. Nat. Biotechnol. 2001, 19,470-474. 
34. Colliver, S.; Bovy, A.; Collins, G.; Muir, S.; Robinson, S.; De Vos, C.H.; Verhoeyen, M.E. Improving the nutritional content of tomatoes through reprogramming their flavonoid biosynthetic pathway. Phytochem. Rev. 2002, 1, 113-123.

35. Stewart, A.J.; Bozonnet, S.; Mullen, W.; Jenkins, G.I.; Lean, M.E.; Crozier, A. Occurrence of flavonols in tomatoes and tomato-based products.J. Agric. Food Chem. 2000, 48, 2663-2669.

36. Mes, P.J.; Boches, P.; Myers, J.R.; Durst, R. Characterization of tomatoes expressing anthocyanin in the fruit. J. Am. Soc. Hortic. Sci. 2008, 133, 262-269.

37. Sapir, M.; Oren-Shamir, M.; Ovadia, R.; Reuveni, M.; Evenor, D.; Tadmor, Y.; Nahon, S.; Shlomo, H.; Chen, L.; Meir, A.; et al. Molecular aspects of Anthocyanin fruit tomato in relation to high pigment1. J. Hered. 2008, 99, 292-303.

38. Nicoli, M.; Anese, M.; Parpinel, M. Influence of processing on the antioxidant properties of fruit and vegetables. Trends Food Sci. Technol. 1999, 10, 94-100.

39. Dewanto, V.; Wu, X.; Adom, K.K.; Liu, R.H. Thermal processing enhances the nutritional value of Tomatoes by increasing total antioxidant activity. J. Agric. Food Chem. 2002, 50, 3010-3014.

40. Crozier, A.; Lean, M.E.; McDonald, M.S.; Black, C. Quantitative analysis of the flavonoid content of commercial tomatoes, onions, lettuce, and celery. J. Agric. Food Chem. 1997, 45, 590-595.

41. Khachik, F.; Goli, M.B.; Beecher, G.R.; Holden, J.; Lusby, W.R.; Tenorio, M.D.; Barrera, M.R. Effect of food preparation on qualitative and quantitative distribution of major carotenoid constituents of tomatoes and several green vegetables. J. Agric. Food Chem. 1992, 40, 390-398.

42. Giovannucci, E. Tomatoes, tomato-based products, lycopene, and cancer: Review of the epidemiologic literature. J. Natl. Cancer Inst. 1999, 91, 317-331.

43. Clinton, S.K. Lycopene: Chemistry, biology, and implications for human health and disease. Nutr. Rev. 1998, 56, 35-51.

44. Giovannucci, E.; Rimm, E.B.; Liu, Y.; Stampfer, M.J.; Willett, W.C. A prospective study of tomato products, Iycopene, and prostate cancer risk.J. Natl. Cancer Inst. 2002, 94, 391-398.

45. Etminan, M.; Takkouche, B.; Caamaño-isorna, F. The role of tomato products and lycopene in the prevention of prostate cancer: A meta-analysis of observational studies. Cancer Epidemiol. Biomarkers Prev. 2004, 13, 340-345.

46. Canene-Adams, K.; Campbell, J.K.; Zaripheh, S.; Jeffery, E.H.; Erdman, J.W. The tomato as a functional food.J. Nutr. 2005, 134, 1226-1230.

47. Mills, P.K.; Beeson, W.L.; Phillips, R.L.; Fraser, G.E. Cohort study of diet, lifestyle, and prostate cancer in Adventist men. Cancer 1989, 64, 598-604.

48. Wu, K.; Erdman, J.W.; Schwartz, S.J.; Platz, E.A.; Leitzmann, M.; Clinton, S.K.; Degroff, V. Plasma and dietary carotenoids, and the risk of prostate cancer: A nested case-control study. 2004, 13, 260269.

49. Lu, Q.Y.; Hung, J.C.; Heber, D.; Go, V.L.; Reuter, V.E.; Cordon-Cardo, C.; Scher, H.I.; Marshall, J.R.; Zhang, Z.F. Inverse associations between plasma lycopene and other carotenoids and prostate cancer. Cancer Epidemiol. Biomarkers Prev. 2001, 10, 749-756.

50. Kristal, A.R.; Till, C.; Platz, E.A.; Song, X.; King, I.B.; Neuhouser, M.L.; Ambrosone, C.B.; Thompson, I.M. Serum Iycopene concentration and prostate cancer risk: Results from the prostate cancer prevention trial. Cancer Epidemiol. Biomarkers Prev. 2011, 20, 638-646. 
51. Zu, K.; Mucci, L.; Rosner, B.A.; Clinton, S.K.; Loda, M.; Stampfer, M.J.; Giovannucci, E. Dietary lycopene, angiogenesis, and prostate cancer: a prospective study in the prostate-specific antigen era. J. Natl. Cancer Inst. 2014, 106, 1-10.

52. Yang, C.M.; Yen, Y.T.; Huang, C.S.; Hu, M.L. Growth inhibitory efficacy of lycopene and betacarotene against androgen-independent prostate tumor cells xenografted in nude mice. Mol. Nutr. Food Res. 2011, 55, 606-612.

53. Kirsh, V.A.; Mayne, S.T.; Peters, U.; Chatterjee, N.; Leitzmann, M.F.; Dixon, L.B.; Urban, D.A.; Crawford, E.D.; Hayes, R.B. A prospective study of lycopene and tomato product intake and risk of prostate cancer. Cancer Epidemiol. Biomarkers Prev. 2006, 15, 92-98.

54. AICR. Food, nutrition, physical activity, and the prevention of cancer: A global perspective. Avaliable online: http://www.aicr.org/assets/docs/pdf/reports/Second Expert Report.pdf (accessed on 1 May 2016).

55. Kuckuk, O.; Sarkar, F.H.; Sakr, W.; Djuric, Z.; Pollak, M.N.; Khachik, F.; Li, Y.W.; Banerjee, M.; Grignon, D.; Bertram, J.S.; et al. Phase II randomized clinical trial of lycopene supplementation before radical prostatectomy. Cancer Epidemiol. Biomarkers Prev. 2001, 10, 861-868.

56. Ansari, M.S.; Gupta, N.P. A comparison of lycopene and orchidectomy vs. orchidectomy alone in the management of advanced prostate cancer. BJU Int. 2003,92, 375-378.

57. Chen, L.; Stacewicz-Sapunatzakis, M.; Duncan, C.; Sharifi, R.; Ghosh, L.; van Breemen, R.; Ashton, D.; Bowen, P.E. Oxidative DNA damage in prostate cancer patients consuming tomato sauce-based entrees as a whole-food intervention. J. Natl. Cancer Inst. 2001, 93, 1872-1879.

58. Vaishampayan, U.; Hussain, M.; Banerjee, M.; Seren, S.; Sarkar, F.H.; Fontana, J.; Forman, J.D.; Cher, M.L.; Powell, I.; Pontes, J.E.; et al. Lycopene and soy isoflavones in the treatment of prostate cancer. Nutr. Cancer 2007, 59, 1-7.

59. Mohanty, N.K.; Saxena, S.; Singh, U.P.; Goyal, N.K.; Arora, R.P. Lycopene as a chemopreventive agent in the treatment of high-grade prostate intraepithelial neoplasia. Urol. Oncol. Semin. Orig. Investig. 2005, 23, 383-385.

60. Jatoi, A.; Burch, P.; Hillman, D.; Vanyo, J.M.; Dakhil, S.; Nikcevich, D.; Rowland, K.; Morton, R.; Flynn, P. J.; Young, C.; et al. A tomato-based, lycopene-containing intervention for androgen-independent prostate cancer: Results of a phasell study from the north central cancer treatment group. Urology 2007, 69, 289-294.

61. Clark, P.E.; HalI, M.C.; Borden, L.S.; Miller, A.A.; Hu, J.J.; Lee, W.R.; Stindt, D.; D’Agostino, R.; Lovato, J.; Harmon, M.; et al. Phase I-II prospective dose-escalating trial of Iycopene in patients with biochemical relapse of prostate cancer after definitive local therapy. Urology 2006, 67, 1257-1261.

62. Bunker, C.; McDonald, A.; Evans, R.; de la Rosa, N.; Boumosleh, J.; Patrick, A. A randomized trial of Iycopene supplementation in tobago Men with high prostate cancer risk. Nutr. Cancer 2007, 57, 130-137.

63. Neuhouser, M.L.; Barnett, M.J.; Kristal, A.R.; Ambrosone, C.B.; King, I.B.; Thornquist, M.; Goodman, G.G. Dietary supplement use and prostate cancer risk in the Carotene and Retinol Efficacy Trial. Cancer Epidemiol. biomarkers Prev. 2009, 18, 2202-2206.

64. Ge, X.; Xing, M.; Yu, L.; Shen, P. Carotenoid intake and esophageal cancer risk: A meta-analysis. Asian Pacific J. cancer Prev. 2012, 14, 1911-1918.

65. Ziegler, R.G.; Mayne, S.T.; Swanson, C.A. Nutrition and Iung cancer. Cancer Causes Control 1996, 7, 157-177. 
66. Heinonen, O.; Albanes, D. The effect of vitamin E and beta carotene on the incidence of lung cancer and other cancers in male smokers. N. Engl. J. Med. 1994, 330, 1029-1035.

67. Albanes, D.; Heinonen, O.P.; Taylor, P.R.; Virtamo, J.; Edwards, B.K.; Rautalahti, M.; Hartman, A.M.; Palmgren, J.; Freedman, L.S.; Haapakoski, J.; et al. Alpha-tocopherol and beta-carotene supplements and lung cancer incidence in the alpha-tocopherol, beta-carotene cancer prevention study: Effects of base-line characteristics and study compliance. J. Natl. Cancer Inst. 1996, 88, 1560-1570.

68. Omenn, G.S.; Goodman, G.E.; Thornquist, M.D.; Balmes, J.; Cullen, M.R.; Glass, A.; Keogh, J.P.; Meyskens, F.L.; Valanis, B.; Williams, J.H.; et al. Effects of a combination of beta carotene and vitamin a on Lung cancer and cardiovascular disease. N. Engl. J. Med. 1996, 334, 1150-1155.

69. Wang, X.; Russell, R. Procarcinogenic and anticarcinogenic effects of beta-carotene. Nutr. Rev. $1999,57,263-272$.

70. Wright, M.E.; Groshong, S.D.; Husgafvel-Pursiainen, K.; Genova, E.; Lucia, M.S.; Wolff, H.; Virtamo, J.; Albanes, D. Effects of beta-carotene supplementation on molecular markers of lung carcinogenesis in male smokers. Cancer Prev. Res. 2010, 3, 745-752.

71. Mondul, A.M.; Sampson, J.N.; Moore, S.C.; Weinstein, S.J.; Evans, A.M.; Karoly, E.D.; Virtamo, J.; Albanes, D. Metabolomic profile of response to supplementation with beta-carotene in the alphatocopherol, beta-carotene cancer prevention Study. Am. J. Clin. Nutr. 2013, 98, 488-493.

72. Tanaka, T.; Shnimizu, M.; Moriwaki, H. Cancer chemoprevention by carotenoids. Molecules 2012, $17,3202-3242$.

73. Hennekens, C.H.; Buring, J.E.; Manson, J.E.; Stampfer, M.; Rosner, B.; Cook, N.R.; Belanger, C.; LaMotte, F.; Gaziano, J.M.; Ridker, P.M.; et al. Lack of effect of Iong-term supplementation with beta carotene on the incidence of malignant neoplasms and cardiovascular disease. N. Engl. J. Med. 1996, 334, 1145-1149.

74. Eliassen, A.H.; Hendrickson, S.J.; Brinton, L.A.; Buring, J.E.; Campos, H.; Dai, Q.; Dorgan, J.F.; Franke, A.A.; Gao, Y.T.; Goodman, M.T.; et al. Circulating carotenoids and risk of breast cancer: Pooled analysis of eight prospective studies. J. Natl. Cancer Inst. 2012,104, 1905-1916.

75. Pantavos, A.; Ruiter, R.; Feskens, E.F.; De Keyser, C.E.; Hofman, A.; Stricker, B.H.; Franco, O.H.; Kiefte-De Jong, J.C. Total dietary antioxidant capacity, individual antioxidant intake and breast cancer risk: The Rotterdam study. Int. J. Cancer 2015, 136, 2178-2186.

76. Greenlee, H.; Kwan, M.L.; Kushi, L.H.; Song, J.; Castillo, A.; Weltzien, E.; Quesenberry, C.P.; Caan, B.J. Antioxidant supplement use after breast cancer diagnosis and mortality in the Life after Cancer Epidemiology (LACE) cohort. Cancer 2012, 118, 2048-2058.

77. Blot, W.J.; Li, J.Y.; Taylor, P.R.; Guo, W.; Dawsey, S.; Wang, G.Q.; Yang, C.S.; Zheng, S.F.; Gail, M.; Li, G.Y.; et al. Nutrition intervention trials in linxian, China: Supplementation with specific vitamin/mineral combinations, cancer incidence, and disease-specific mortality in the general population. J. Natl. Cancer Inst. 1993, 85, 1483-1491.

78. Zhou, Y.; Wang, T.; Meng, Q.; Zhai, S. Association of carotenoids with risk of gastric cancer: A metaanalysis. Clin. Nutr. 2015, 35, 109-116.

79. Trejo-Solís, C.; Pedraza-Chaverrí, J.; Torres-Ramos, M.; Jiménez-Farfán, D.; Cruz Salgado, A.; Serrano-García, N.; Osorio-Rico, L.; Sotelo, J. Multiple molecular and cellular mechanisms of acti on of lycopene in cancer inhibition. Evid. Based Complement. Altern. Med. 2013.

80. Ramos, S. Cancer chemoprevention and chemotherapy: dietary polyphenols and signalling pathways. Mol. Nutr. Food Res. 2008, 52, 507-526. 
81. Korkina, L.; De Luca, C.; Kostyuk, V.; Pastore, S. Plant polyphenols and tumors: From mechanisms to therapies, prevention, and protection against toxicity of anti-cancer treatments. Curr. Med. Chem. 2009, 16, 3943-3965.

82. Loa, J.; Chow, P.; Zhang, K. Studies of structure-activity relationship on plant polyphenol-induced suppression of human liver cancer cells. Cancer Chemother. Pharmacol. 2009, 63, 1007-1016.

83. Garcia-Closas, R.; Gonzalez, C.A.; Agudo, A.; Riboli, E. Intake of specific carotenoids and flavonoids and the risk of gastric cancer in Spain. Cancer Causes Control 1999, 10, 71-75.

84. Peterson, J.; Lagiou, P.; Samoli, E.; Lagiou, A.; Katsouyanni, K.; La Vecchia, C.; Dwyer, J.; Trichopoulos, D. Flavonoid intake and breast cancer risk: A case-control study in Greece. Br. J. Cancer 2003, 89, 1255-1259.

85. Bosetti, C.; Spertini, L.; Parpinel, M.; Gnagnarella, P.; Lagiou, P.; Negri, E.; Franceschi, S.; Montella, M.; Peterson, J.; Dwyer, J.; et al. Flavonoids and breast cancer risk in Italy. Cancer Epidemiol. Biomarkers Prev. 2005, 14, 805-808.

86. Rossi, M.; Negri, E.; Talamini, R.; Bosetti, C.; Parpinel, M.; Gnagnarella, P.; Franceschi, S.; Dal Maso, L.; Montella, M.; Giacosa, A.; et al. Flavonoids and colorectal cancer in italy. Cancer Epidemiol. Biomarkers Prev. 2006, 15, 1555-1558.

87. Knekt, P.; Kumpulainen, J.; Järvinen, R.; Rissanen, H.; Heliövaara, M.; Reunanen, A.; Hakulinen, T.; Aromaa, A. Flavonoid intake and risk of chronic diseases. Am. J. Clin. Nutr. 2002, 76, 560-568.

88. Cruz-Correa, M.; Shoskes, D.; Sanchez, P.; Zhao, R.; Hylind, L.; Wexner, D.; Giardiello, F. Combination treatment with curcumin and quercetin of adenomas in familial adenomatous polyposis. Clin. Gastroenterol. Hepatol. 2006,4, 1035-1038.

89. Neuhouser, M.L. Review: Dietary flavonoids and cancer risk: Evidence from human population studies. Nutr. Cancer 2004, 50, 1-7.

90. Knekt, P.; Järvinen, R.; Seppänen, R.; Hellövaara, M.; Teppo, L.; Pukkala, E.; Aromaa, A. Dietary flavonoids and the risk of lung cancer and other malignant neoplasms. Am. J. Epidemiol. 1997, 146, 223-230.

91. Hirvonen, T.; Virtamo, J.; Korhonen, P.; Albanes, D.; Pietinen, P. Flavonol and flavone intake and the risk of cancer in male smokers (Finland). Cancer Causes Control 2001, 12, 789-796.

92. Lagiou, P.; Rossi, M.; Lagiou, A.; Tzonou, A.; La Vecchia, C.; Trichopoulos, D. Flavonoid intake and liver cancer: A case-control study in Greece. Cancer Causes Control 2008, 19, 813-818.

93. Weng, C.J.; Yen, G.C. Chemopreventive effects of dietary phytochemicals against cancer invasion and metastasis: Phenolic acids, monophenol, polyphenol, and their derivatives. Cancer Treat. Rev. 2012, 38, 76-87.

94. Yang, J.; Liu, C.; Ma, Y.; Weng, S.; Tang, N.; Wu, S.; Ji, B.-C.; Ma, C.-Y.; Ko, Y.-C.; Funayama, S.; et al. Chlorogenic acid induces apoptotic cell death in U937 leukemia cells through caspase- and mitochondria-dependent pathways. In Vivo 2012, 26, 971-978.

95. Rajendra Prasad, N.; Karthikeyan, A.; Karthikeyan, S.; Venkata Reddy, B. Inhibitory effect of caffeic acid on cancer cell proliferation by oxidative mechanism in human HT-1080 fibrosarcoma cell Iine. Mol. Cell. Biochem. 2011, 349, 11-19.

96. Frydoonfar, H.R.; McGrath, D.R.; Spigelman, A.D. The variable effect on proliferation of a colon cancer cell line by the citrus fruit flavonoid Naringenin. Color. Dis. 2003, 5, 149-152.

97. Harmon, A.W.; Patel, Y.M. Naringenin inhibits glucose uptake in MCF-7 breast cancer cells: A mechanism for impaired cellular proliferation. Breast Cancer Res. Treat. 2004, 85, 103-110. 
98. So, F.; Guthrie, N.; Chambers, A.; Moussa, M.; Carroll, K. Inhibition of human breast cancer cell proliferation and delay of mammary tumorigenesis by flavonoids and citrus juices. Nutr. Cancer 1996, 26, 167-181.

99. Stagos, D.; Amoutzias, G.D.; Matakos, A.; Spyrou, A.; Tsatsakis, A.M.; Kouretas, D. Chemoprevention of liver cancer by plant polyphenols. Food Chem. Toxicol. 2012, 50, 2155-2170.

100. Gibellini, L.; Pinti, M.; Nasi, M.; Montagna, J.P.; De Biasi, S.; Roat, E.; Bertoncelli, L.; Cooper, E.L.; Cossarizza, A. Quercetin and cancer chemoprevention. Evid. Based Complement. Altern. Med. 2011, doi:10.1093/ecam/neq053.

101. Fraser, P.D.; Enfissi, E.M. A.; Halket, J.M.; Truesdale, M.R.; Yu, D.; Gerrish, C.; Bramley, P.M. Manipulation of phytoene levels in tomato fruit: Effects on isoprenoids, plastids, and intermediary metabolism. Plant Cell 2007, 19, 3194-3211.

102. Pecker, I.; Chamovitz, D.; Linden, H.; Sandmann, G.; Hirschberg, J. A single polypeptide catalyzing the conversion of phytoene to zeta-carotene is transcriptionally regulated during tomato fruit ripening. Proc. Natl. Acad. Sci. USA 1992, 89, 4962-4966.

103. Isaacson, T.; Ronen, G.; Zamir, D.; Hirschberg, J. Cloning of tangerine from tomato reveals a carotenoid isomerase essential for the production of beta-carotene and xanthophylls in plants. Plant Cell 2002, 14, 333-342.

104. Klee, H.J.; Giovannoni, J.J. Genetics and control of tomato fruit ripening and quality attributes. Annu. Rev. Genet. 2011, 45, 41-59.

105. Ronen, G.; Carmel-Goren, L.; Zamir, D.; Hirschberg, J. An alternative pathway to beta-carotene formation in plant chromoplasts discovered by map-based cloning of beta and old-gold color mutations in tomato. Proc. Natl. Acad. Sci. USA 2000, 97, 11102-11107.

106. Ronen, G.; Cohen, M.; Zamir, D.; Hirschberg, J. Regulation of carotenoid biosynthesis during tomato fruit development: expression of the gene for lycopene epsilon cyclase is down- regulated during ripening and is elevated in the mutant Delta. Plant J. 1999, 17, 341-351.

107. Zhang, Y.; Stommel, J.R. RAPD and AFLP tagging and mapping of Beta (B) and Beta modifier (MoB), two genes which influence beta-carotene accumulation in fruit of tomato (Lycopersicon esculentum Mill.). Theor. Appl. Genet. 2000, 100, 368-375.

108. Kasahara, H. Contribution of the mevalonate and methylerythritol phosphate pathways to the biosynthesis of gibberellins in Arabidopsis. J. Biol. Chem. 2002, 277, 45188-45194.

109. Lichtenthaler, H.K. The 1-Deoxy-D-Xylulose-5-Phosphate pathway of isoprenoid biosynthesis in plants. Annu. Rev. Plant Physiol. Plant Mol. Biol. 1999, 50, 47-65.

110. Lois, L.M.; Rodríguez-Concepción, M.; Gallego, F.; Campos, N.; Boronat, A. Carotenoid biosynthesis during tomato fruit development: Regulatory role of 1-deoxy-D-xylulose 5-phosphate synthase. Plant J. 2000, 22, 503-513.

111. Galpaz, N.; Wang, Q.; Menda, N.; Zamir, D.; Hirschberg, J. Abscisic acid deficiency in the tomato mutant high-pigment 3 leading to increased plastid number and higher fruit lycopene content. Plant J. 2008, 53, 717-730.

112. Cebolla-Cornejo, J.; Roselló, S.; Nuez, F. Selection of tomato rich in nutritional terpenes. In Natural Products; Ramawat, K., Mérillon, J., Eds.; Springer-Verlag: Berlin-Heidelberg, Germany, 2013; pp. 2853-2881.

113. Alba, R.; Cordonnier-Pratt, M.-M.; Pratt, L.H. Fruit-localized phytochromes regulate Iycopene accumulation independently of ethylene production in tomato. Plant Physiol. 2000, 123, 363-370. 
114. Liu, Y.; Roof, S.; Ye, Z.; Barry, C.; Van Tuinent, A.; Vrebalov, J.; Bowler, C.; Giovannoni, J. Manipulation of light signal transduction as a means of modifying fruit nutritional quality in tomato. Proc. Natl. Acad. Sci. USA 2004, 101, 9897-9902.

115. Bino, R. J.; De Vos, C. H. R.; Lieberman, M.; Hall, R.D.; Bovy, A.; Jonker, H.H.; Tikunov, Y.; Lommen, A.; Moco, S.; Levin, I. The light-hyperresponsive high pigment-2dg mutation of tomato: Alterations in the fruit metabolome. New Phytol. 2005, 166, 427-438.

116. Mustilli, A.C.; Fenzi, F.; Ciliento, R.; Alfano, F.; Bowler, C. Phenotype of the tomato high pigment-2 mutant is caused by a mutation in the toma to homolog of DEETIOLATED1. Plant Cell 1999, 11, 145157.

117. Kendrick, R.E.; Kerckhoffs, L.H.; Van Tuinen, A.; Koornneef, M. Photomorphogenic mutants of tomato. Plant Cell Environ. 1997, 20, 746-751.

118. Lavi, N.; Tadmor, Y.; Meir, A.; Bechar, A.; Oren-Shamir, M.; Ovadia, R.; Reuveni, M.; Nahon, S.; Shlomo, H.; Chen, L.; et al. Characterization of the intense pigment tomato genotype emphasizing targeted fruit metabolites and chloroplast biogenesis. J. Agric. Food Chem. 2009, 57, 4818-4826.

119. Tomes, M.L.; Quackenbush, F.W. Caro-red, a new provitamin a rich tomato. Econ. Bot. 1958, 12, 256-260.

120. Tigchelaar, C.C.; Tomes, M.L. “Caro-Rich" Tomato. HortScience 1974, 9, 82. Avaliable online: http://hortsci.ashspublications.org/content/by/year (accessed on 1 May 2016).

121. Georgiev, H.; Vulkova-Atchkova, Z.; Vladimirov, B.G.; Baralieva, D. Breeding determinate tomatoes with higt Beta-carotene content. Gr. Lozar. Nauk. 1981, 18, 28-31.

122. Vogel, J.T.; Tieman, D.M.; Sims, C.A.; Odabasi, A.Z.; Clark, D.G.; Klee, H.J. Carotenoid content impacts flavor acceptability in tomato (Solanum lycopersicum). J. Sci. Food Agric. 2010, 90, 22332240.

123. Stigliani, A.L.; Giorio, G.; D’Ambrosio, C. Characterization of P450 Carotenoid B- And E-hydroxylases of tomato and transcriptional regulation of xanthophyll biosynthesis in root, leaf, petal and fruit. Plant Cell Physiol. 2011, 52, 851-865.

124. Stommel, J.R. Genetic enhancement of tomato fruit nutritive value. In Genetic Improvement of Solanaceous Crops (Volume 2); Razdan, M., Matoo, A., Eds.; CRC Press: Boca Raton, FL, USA, 2007; pp. 193-238.

125. Rick, C.M. High soluble-solids content in large-fruited tomato lines derived from a wild greenfruited species. Hilgardia 1974, 42,493-510.

126. Enfissi, E.M.; Fraser, P.D.; Lois, L.-M.; Boronat, A.; Schuch, W.; Bramley, P.M. Metabolic engineering of the mevalonate and non-mevalonate isopentenyl diphosphate-forming pathways for the production of health-promoting isoprenoids in tomato. Plant Biotechnol. J. 2005, 3, 17-27.

127. Fraser, P.D.; Romer, S.; Shipton, C.A.; Mills, P.B.; Kiano, J.W.; Misawa, N.; Drake, R.G.; Schuch, W.; Bramley, P.M. Evaluation of transgenic tomato plants expressing an additional phytoene synthase in a fruit-specific manner. Proc. Natl. Acad. Sci. USA 2002, 99, 1092-1097.

128. Fray, R.G.; Wallace, A.; Fraser, P.D.; Valero, D.; Hedden, P.; Bramley, P.M.; Grierson, D. Constitutive expression of a fruit phytoene synthase gene in transgenic tomatoes causes dwarfism by redirecting metabolites from the gibberellin pathway. Plant J. 1995, 8, 693-701.

129. Römer, S.; Fraser, P.D.; Kiano, J.W.; Shipton, C.A.; Misawa, N.; Schuch, W.; Bramley, P.M. Elevation of the provitamin A content of transgenic tomato plants. Nat. Biotechnol. 2000, 18, 666-669. 
130. Rosati, C.; Aquilani, R.; Dharmapuri, S.; Pallara, P.; Marusic, C.; Tavazza, R.; Bouvier, F.; Camara, B.; Giuliano, G. Metabolic engineering of beta-carotene and Iycopene content in tomato fruit. Plant J. 2000, 24, 413-419.

131. D’Ambrosio, C.; Giorio, G.; Marino, I.; Merendino, A.; Petrozza, A.; Salfi, L.; Stigliani, A.L.; Cellini, F. Virtually complete conversion of lycopene into $\beta$-carotene in fruits of tomato plants transformed with the tomato lycopene $\beta$-cyclase (tlcy-b) cDNA. Plant Sci. 2004, 166, 207-214.

132. Apel, W.; Bock, R. Enhancement of carotenoid biosynthesis in transplastomic tomatoes by induced Iycopene-to-provitamin A conversion. Plant Physiol. 2009, 151, 59-66.

133. Ma, C.; Ma, B.; He, J.; Hao, Q.; Lu, X.; Wang, L. Regulation of carotenoid content in tomato by silencing of lycopene $\beta / \varepsilon$-cyclase genes. Plant Mol. Biol. Report. 2011, 29, 117-124.

134. Guo, F.; Zhou, W.; Zhang, J.; Xu, Q.; Deng, X. Effect of the citrus lycopene $\beta$-Cyclase transgene on carotenoid metabolism in transgenic tomato fruits. PLOS ONE 2012, 7, e32221.

135. Corona, V.; Aracri, B.; Kosturkova, G.; Bartley, G.E.; Pitto, L.; Giorgetti, L.; Scolnik, P.A.; Giuliano, G. Regulation of a carotenoid biosynthesis gene promoter during plant development. Plant J. 1996, 9, 505-512.

136. Dalal, M.; Chinnusamy, V.; Bansal, K.C. Isolation and functional characterization of lycopene betacyclase (CYC-B) promoter from Solanum habrochaites. BMCPlant Biol. 2010, 10, 1-15.

137. Hiwasa-Tanase, K.; Kuroda, H.; Hirai, T.; Aoki, K.; Takane, K.; Ezura, H. Novel promoters that induce specific transgene expression during the green to ripening stages of tomato fruit development. Plant Cell Rep. 2012, 31, 1415-1424.

138. Davuluri, G.R.; van Tuinen, A.; Fraser, P.D.; Manfredonia, A.; Newman, R.; Burgess, D.; Brummell, D.A.; King, S.R.; Palys, J.; Uhlig, J.; et al. Fruit-specific RNAi-mediated suppression of DET1 enhances carotenoid and flavonoid content in tomatoes. Nat. Biotechnol. 2005, 23, 890-895.

139. Sun, L.; Yuan, B.; Zhang, M.; Wang, L.; Cui, M.; Wang, Q.; Leng, P. Fruit-specific RNAi-mediated suppression of SINCED1 increases both lycopene and beta-carotene contents in tomato fruit. J. Exp. Bot. 2012, 63, 3097-3108.

140. Sun, L.; Sun, Y.; Zhang, M.; Wang, L.; Ren, J.; Cui, M.; Wang, Y.; Ji, K.; Li, P.; Li, Q.; et al. Suppression of 9-cis-Epoxycarotenoid dioxygenase, which encodes a key enzyme in abscisic acid biosynthesis, al ters fruit texture in transgenic tomato. Plant Physiol. 2012, 158, 283-298.

141. Levin, I. Regulating phytonutrient levels in plants-toward modification of plant metabolism for human health. In Recent Advances in Plant Biotechnology; Kirakosyan, A., Kaufman, P.B., Eds.; Springer: New York, NY, USA, 2009;pp. 289-330.

142. Humphreys, J.M.; Chapple, C. Rewriting the lignin roadmap. Curr. Opin. Plant Biol. 2002, 5, 224229.

143. Niggeweg, R.; Michael, A.J.; Martin, C. Engineering plants with increased levels of the antioxidant chlorogenic acid. Nat. Biotechnol. 2004, 22, 746-754.

144. Luo, J.; Butelli, E.; Hill, L.; Parr, A.; Niggeweg, R.; Bailey, P.; Weisshaar, B.; Martin, C. AtMYB12 regulates caffeoyl quinic acid and flavonol synthesis in tomato: Expression in fruit results in very high levels of both types of polyphenol. Plant J. 2008, 56, 316-326.

145. Holton, T.A.; Cornish, E.C. Genetics and biochemistry of anthocyanin biosynthesis. Plant Cell 1995, 7, 1071-1083. 
146. Verhoeyen, M.E.; Bovy, A.; Collins, G.; Muir, S.; Robinson, S.; de Vos, C.H.; Colliver, S. Increasing antioxidant levels in tomatoes through modification of the flavonoid biosynthetic pathway. J. Exp. Bot. 2002, 53, 2099-2106.

147. Butelli, E.; Titta, L.; Giorgio, M.; Mock, H.P.; Matros, A.; Peterek, S.; Schijlen, E.G.; Hall, R.D.; Bovy, A.G.; Luo, J.; et al. Enrichment of tomato fruit with health-promoting anthocyanins by expression of select transcription factors. Nat. Biotechnol. 2008, 26, 1301-1308.

148. Yahia, E.M.; Ornelas-Paz, J. de J. Chemistry, stability, and biological actions of carotenoids. In Fruit and Vegetable Phytochemicals; de la Rosa, L.A., Alvarez-Parrilla, E., González -Aguilar, G.A., Eds.; Wiley-Blackwell, IA, USA, 2010; pp. 177-222.

149. Sakakibara, H.; Honda, Y.; Nakagawa, S.; Ashida, H.; Kanazawa, K. Simultaneous determination of all polyphenols in vegetables, fruits, and teas. J. Agric. Food Chem. 2003, 51, 571-581.

150. Zhang, Y.; Butelli, E.; Martin, C. Engineering anthocyanin biosynthesis in plants. Curr. Opin. Plant Biol. 2014, 19, 81-90.

151. Bovy, A.; de Vos, R.; Kemper, M.; Schijlen, E.; Pertejo, M.A.; Muir, S.; Collins, G.; Robinson, S.; Verhoeyen, M.; Hughes, S.; et al. High-flavonol tomatoes resulting from the heterologous expression of the maize transcription factor genes. Plant Cell 2002, 14, 2509-2526.

152. Ballester, A.-R.; Molthoff, J.; de Vos, R.; Hekkert, B.T.; Orzaez, D.; Fernández-Moreno, J.-P.; Tripodi, P.; Grandillo, S.; Martin, C.; Heldens, J.; et al. Biochemical and molecular analysis of pink toma toes: Deregulated expression of the gene encoding transcription factor SIMYB12 leads to pink tomato fruit color. Plant Physiol. 2010, 152, 71-84.

153. Willits, M.G.; Kramer, C.M.; Prata, R.T.; De Luca, V.; Potter, B.G.; Steffens, J.C.; Graser, G. Utilization of the genetic resources of wild species to create a nontransgenic high flavonoid tomato. J. Agric. Food Chem. 2005, 53, 1231-1236.

154. Lindstrom, E. Inheritance in tomatoes. Genetics $1925,10,305-317$.

155. Zhang, Y.; Butelli, E.; Alseekh, S.; Tohge, T.; Rallapalli, G.; Luo, J.; Kawar, P.G.; Hill, L.; Santino, A.; Fernie, A.R.; et al. Multi-level engineering facilitates the production of phenylpropanoid compounds in tomato. Nat. Commun. 2015, 6, 1-11.

156. Pandey, A.; Misra, P.; Choudhary, D.; Yadav, R.; Goel, R.; Bhambhani, S.; Sanyal, I.; Trivedi, R.; Kumar Trivedi, P. AtMYB12 expression in tomato leads to large scale differential modulation in transcriptome and flavonoid content in leaf and fruit tissues. Sci. Rep. 2015, doi:10.1038/srep12412.

157. Ye, J.; Hu, T.; Yang, C.; Li, H.; Yang, M.; ljaz, R.; Ye, Z.; Zhang, Y. Transcriptome profiling of tomato fruit development reveals transcription factors associated with ascorbic acid, carotenoid and flavonoid biosynthesis. PLOS ONE 2015, 10, e0130885.

158. Giuntini, D.; Lazzeri, V.; Calvenzani, V.; Dall'Asta, C.; Galaverna, G.; Tonelli, C.; Petroni, K.; Ranieri, A. Flavonoid profiling and biosynthetic gene expression in flesh and peel of two tomato genotypes grown under UV-B-depleted conditions during ripening. J. Agric. Food Chem. 2008, 56, 5905-5915.

159. Azari, R.; Tadmor, Y.; Meir, A.; Reuveni, M.; Evenor, D.; Nahon, S.; Shlomo, H.; Chen, L.; Levin, I. Light signaling genes and their manipulation towards modulation of phytonutrient content in tomato fruits. Biotechnol. Adv. 2010, 28, 108-118.

160. Mathews, H.; Clendennen, S.K.; Caldwell, C.G.; Liu, X.L.; Connors, K.; Matheis, N.; Schuster, D.K.; Menasco, D.J.; Wagoner, W.; Lightner, J.; et al. Activation tagging in tomato identifies a transcriptional regulator of anthocyanin biosynthes is, modification, and transport. Plant Cell 2003, 15, 1689-1703. 
161. Schreiber, G.; Reuveni, M.; Evenor, D.; Oren-Shamir, M.; Ovadia, R.; Sapir-Mir, M.; Bootbool-Man, A.; Nahon, S.; Shlomo, H.; Chen, L.; et al. ANTHOCYANIN1 from Solanum chilense is more efficient in accumulating anthocyanin metabolites than its Solanum lycopersicum counterpart in association with the ANTHOCYANIN FRUIT phenotype of tomato. Theor. Appl. Genet. 2012, 124, 295-307.

162. Meng, X.; Yang, D.; Li, X.; Zhao, S.; Sui, N.; Meng, Q. Physiological changes in fruit ripening caused by overexpression of tomato SIAN2, an R2R3-MYB factor. Plant Physiol. Biochem. 2015, 89, 24-30.

163. Kiferle, C.; Fantini, E.; Bassolino, L.; Povero, G.; Spelt, C.; Buti, S.; Giuliano, G.; Quattrocchio, F.; Koes, R.; Perata, P.; et al. Tomato R2R3-MYB proteins SIANT1 and SIAN2: Same protein activity, different roles. PLOS ONE 2015, 10, e0136365.

164. Rick, C.M.; Cisneros, P.; Chetelat, R.T.; DeVerna, J.W. Abg-a gene on chromosome 10 for purple fruit derived from S. Iycopersicoides. Rep. Tomato Genet. Coop. 1994, 44, 29-30.

165. Canady, M.A.; Ji, Y.; Chetelat, R.T. Homeologous recombination in Solanum lycopersicoides introgression lines of cultivated tomato. Genetics 2006, 174, 1775-1788.

166. Rick, C.M.; Reeves, A.F.; Zobel, R.W. Inheritance and linkage relations of four new mutants. Tomato Genet. Coop. Rep. 1968, 18, 34-35.

167. Kerckhoffs, L.H.; De Groot, N.A.; Van Tuinen, A.; Schreuder, M.E.; Nagatani, A.; Koornneef, M.; Kendrick, R.E. Physiological characterization of exaggerated-photoresponse mutants of tomato. J. Plant Physiol. 1997, 150, 578-587.

168. Povero, G.; Gonzali, S.; Bassolino, L.; Mazzucato, A.; Perata, P. Transcriptional analysis in highanthocyanin tomatoes reveals synergistic effect of Aft and atv genes. J. Plant Physiol. 2011, 168, 270-279.

169. Kang, J.-H.; Mcroberts, J.; Shi, F.; Moreno, J.E.; Jones, A.D.; Howe, G.A. The flavonoid biosynthetic enzyme chalcone isomerase modulates terpenoid production in glandular trichomes of tomato. Plant Physiol. 2014, 164, 1161-1174.

170. Gonzali, S.; Mazzucato, A.; Perata, P. Purple as a tomato: Towards high anthocyanin tomatoes. Trends Plant Sci. 2009, 14, 237-241.

171. Su, X.; Xu, J.; Rhodes, D.; Shen, Y.; Song, W.; Katz, B.; Tomich, J.; Wang, W. Identification and quantification of anthocyanins in transgenic purple tomato. Food Chem. 2016, 202,184-188.

172. Yen, H.C.; Shelton, B.A.; Howard, L.R.; Lee, S.; Vrebalov, J.; Giovannoni, J.J. The tomato highpigment (hp) locus maps to chromosome 2 and influences plastome copy number and fruit quality. Theor. Appl. Genet. 1997, 95, 1069-1079.

173. Long, M.; Millar, D.J.; Kimura, Y.; Donovan, G.; Rees, J.; Fraser, P.D.; Bramley, P.M.; Bolwell, G.P. Metabolite profiling of carotenoid and phenolic pathways in mutant and transgenic lines of tomato: identification of a high antioxidant fruit line. Phytochemistry 2006, 67, 1750-1757.

174. Giuntini, D.; Graziani, G.; Lercari, B.; Fogliano, V.; Soldatini, G.F.; Ranieri, A. Changes in carotenoid and ascorbic acid contents in fruits of different tomato genotypes related to the depletion of UV-B radiation. J. Agric. Food Chem. 2005, 53, 3174-3181.

175. Sestari, I.; Zsögön, A.; Rehder, G.G.; Teixeira, L. de L.; Hassimotto, N.M.; Purgatto, E.; Benedito, V.A.; Pereira-Peres, L.E. Near-isogenic lines enhancing ascorbic acid, anthocyanin and carotenoid content in tomato (Solanum lycopersicum L. cv Micro-Tom) as a tool to produce nutrient-rich fruits. Sci. Hortic. 2014, 175, 111-120. 
IV. DETERMINACIÓN RÁPIDA Y SIMULTÁNEA DE LOS PRINCIPALES POLIFENOLES EN FRUTAS $Y$ HORTALIZAS MEDIANTE CROMATOGRAFÍA LÍQUIDA DE FASE REVERSA USANDO UNA COLUMNA DE NÚCLEO FUNDIDO 
Martí, R., Valcárcel, M., HerreroMartínez, J.M., Cebolla-Cornejo, J. and Roselló, S., 2015. Fast simultaneous determination of prominent polyphenols in vegetables and fruits by reversed phase liquid chromatography using a fused-core column. Food chemistry, 169, pp.169-179.

\section{Food Chemistry}

Journal Citation Reports (JCR): 4.052

Posición 7 de 125 en Food Science and Technology (Q1)

\begin{tabular}{|c|c|c|}
\hline \multirow{3}{*}{ 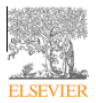 } & Contents lists available at Sciencebirect & \multirow{2}{*}{$\begin{array}{l}\text { FOOOD } \\
\text { CHEMISTRY }\end{array}$} \\
\hline & Food Chemistry & \\
\hline & journal homepage: www.elsevier.com/locate/foodchem & $=$ \\
\hline
\end{tabular}

Fast simultaneous determination of prominent polyphenols in vegetables and fruits by reversed phase liquid chromatography using a fused-core column

Raúl Martía ${ }^{a}$. Mercedes Valcárcel ${ }^{b}$. José Manuel Herrero-Martínez ${ }^{c}$, Jaime Cebolla-Cornejo ${ }^{\natural}$.
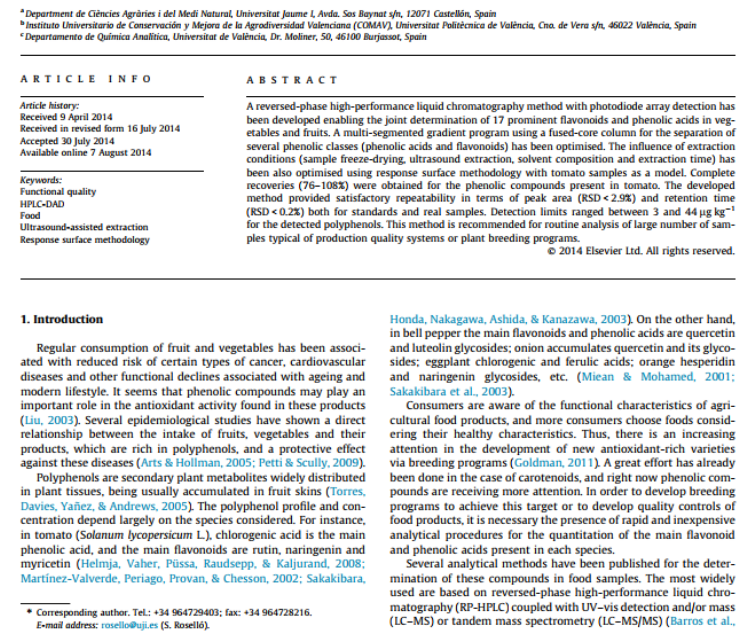

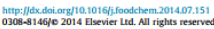


Fast simultaneous determination of prominent polyphenols in vegetables and fruits by reversed phase liquid chromatography using a fused-core column

Raúl Martíi, Mercedes Valcárcel², José Manuel Herrero-Martínez ${ }^{3}$, Jaime Cebolla-Cornejo ${ }^{2}$, Salvador Roselló ${ }^{*}$

${ }^{1}$ Department de Ciències Agràries i del Medi Natural, Universitat Jaume l, Avda. Sos Baynats $/ n$, 12071 Castellón, Spain

${ }^{2}$ Instituto Universitario de Conservación y Mejora de la Agrodiversidad Valenciana (COMAV). Universitat Politècnica de València, Cno. de Vera, s.n. 46022 València, Spain

${ }^{3}$ Departamento de Química Analítica. Universitat de València, Dr. Moliner, 50, 46100 Burjassot, Spain

\begin{abstract}
A reversed-phase high-performance liquid chromatography method with photodiode array detection has been developed enabling the joint determination of 17 prominent flavonoids and phenolic acids in vegetables and fruits. A multi-segmented gradient program using a fused-core column for the separation of several phenolic classes (phenolic acids and flavonoids) has been optimized. The influence of extraction conditions (sample freeze-drying, ultrasound extraction, solvent composition and extraction time) has been al so optimized using response surface methodology with tomato samples as a model. Complete recoveries (76-108 $\%)$ were obtained for the phenolic compounds present in tomato. The developed method provided satisfactory repeatability in terms of peak area (RSD $<2.9 \%$ ) and retention time (RSD $<0.2 \%$ ) both for standards and real samples. Detection limits ranged between 3 and $44 \mu \mathrm{kg}^{-1}$ for the detected polyphenols. This method is recommended for routine analysis of large number of samples typical of production quality systems or plant breeding programs.
\end{abstract}

Keywords: Functional quality; HPLC-DAD; food; ultrasound-assisted extraction; response surface methodology. 
V. DETERMINACIÓN SIMULTÁNEA DE LOS PRINCIPALES ÁCIDOS FENÓLICOS $Y$ FLAVONOIDES EN TOMATE POR CROMATOGRAFÍA MICELAR ELECTROCINÉTICA (MEKC) 
Martí, R., Valcárcel, M., HerreroMartínez, J.M., Cebolla-Cornejo, J. and Roselló, S., 2017. Simultaneous determination of main phenolic acids and flavonoids in tomato by micellar electrokinetic capillary electrophoresis. Food chemistry, 221, pp.439-446.

\section{Food Chemistry}

Journal Citation Report (JCR): 4.529 (2016)

Posición 6 de 130 en Food Science and Technology (Q1)
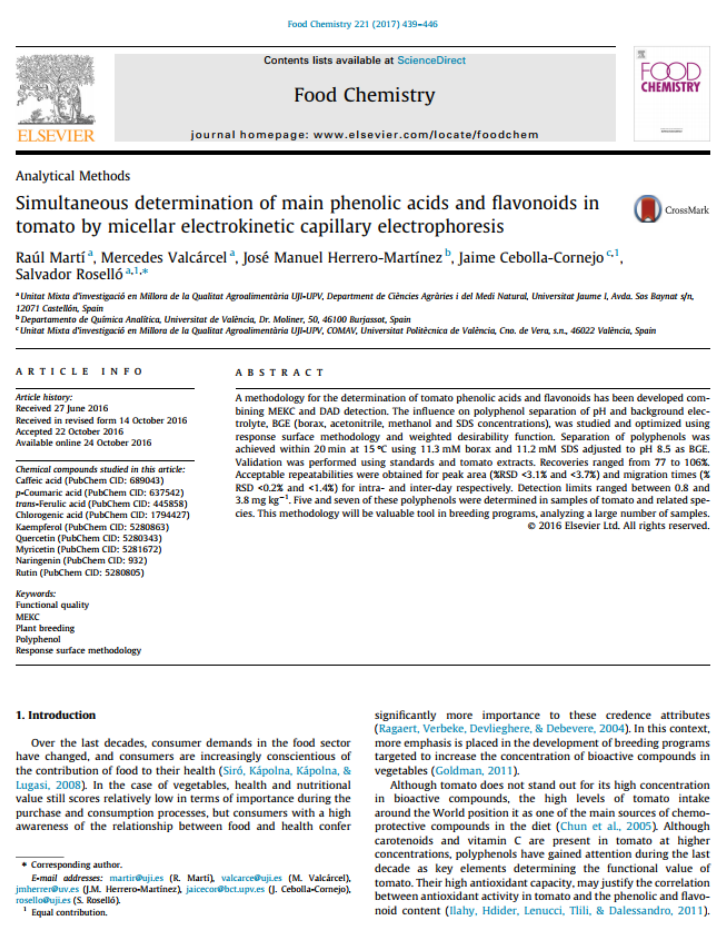

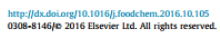


Simultaneous determination of main phenolic acids and flavonoids in tomato by micellar electrokinetic capillary electrophoresis

Raúl Martí ${ }^{1}$, Mercedes Valcárcel ${ }^{1}$, José Manuel Herrero-Martínez ${ }^{2}$, Jaime Cebolla-Cornejo ${ }^{3 \neq}$, Salvador Roselló ${ }^{17^{*}}$

${ }^{1}$ Unitat Mixta d'investigació en Millora de la Qualitat Agroalimentària UJI-UPV, Department de Ciències Agràries i del Medi Natural, Universitat Jaume I, Avda. Sos Baynat s/n, 12071 Castellón, Spain.

${ }^{2}$ Departamento de Química Analítica. Universitat de València, Dr. Moliner, 50, 46100 Burjassot, Spain

${ }^{3}$ Unitat Mixta d'investigació en Millora de la Qualitat Agroalimentària UJI-UPV, COMAV, Universitat Politècnica de València, Cno. de Vera, s.n. 46022 València, Spain.

${ }^{\ddagger}$ Equalcontribution

\section{Abstract}

A methodology for the determination of tomato phenolic acids and flavonoids has been developed combining MEKC and DAD detection. The influence on polyphenol separation of $\mathrm{pH}$ and background electrolyte, BGE (borax, acetonitrile, methanol and SDS concentrations), was studied and optimized using response surface methodology and weighted desirability function. Separation of polyphenols was achieved within 20 minutes at $15 \circ \mathrm{C}$ using $11.3 \mathrm{mM}$ borax and 11.2mM SDS adjusted to $\mathrm{pH} 8.5$ as BGE. Validation was performed using standards and tomato extracts. Recoveries ranged from 77 to $106 \%$. Acceptable repeatabilities were obtained for peak area (\%RSD $<3.1 \%$ and $<3.7 \%$ ) and migration times ( $\% \mathrm{RSD}<0.2 \%$ and $<1.4 \%$ ) for intraand inter-day respectively. Detection limits ranged between 0.8 and $3.8 \mathrm{mg} \mathrm{kg}^{-1}$. Five and seven of these polyphenols were determined in samples of tomato and related species. This methodology will be valuable tool in breeding programs, analyzing a large number of samples.

Keywords: Functional quality; MEKC; Plant breeding; Polyphenol; Response surface methodology. 
VI. CONTENIDO EN POLIFENOLES Y ÁCIDO LASCÓRBICO EN TOMATE INFLUENCIADO POR GENOTIPOS DE ALTO LICOPENOY AGRICULTURA ECOLÓGICA EN DIFERENTES AMBIENTES 
Martí, R., Leiva-Brondo, M., Lahoz, I., Campillo, C., Cebolla-Cornejo, J. and Roselló, S., 2018. Polyphenol and Lascorbic acid content in tomato as influenced by high lycopene genotypes and organic farming at different environments. Food chemistry, 239, pp.148-156.

\section{Food Chemistry}

Journal Citation Report (JCR): 4.529 (2016)

Posición 6 de 130 en Food Science and Technology (Q1)

\begin{tabular}{|c|c|c|}
\hline & Contents lists available at ScienceDirect & OD \\
\hline \$net & Food Chemistry & \\
\hline ELSEVIER & journal homepage: www.elsevier.com/locate/foodchem & - \\
\hline
\end{tabular}

Polyphenol and L-ascorbic acid content in tomato as influenced by high lycopene genotypes and organic farming at different environments

Raúl Martí ${ }^{a}$, Miguel Leiva-Brondo ${ }^{b}$, Inmaculada Lahoz ${ }^{c}$, Carlos Campillo ${ }^{d}$, Jaime Cebolla-Cornejo ${ }^{b, 1}$.

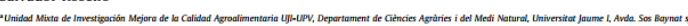

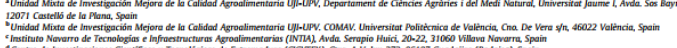

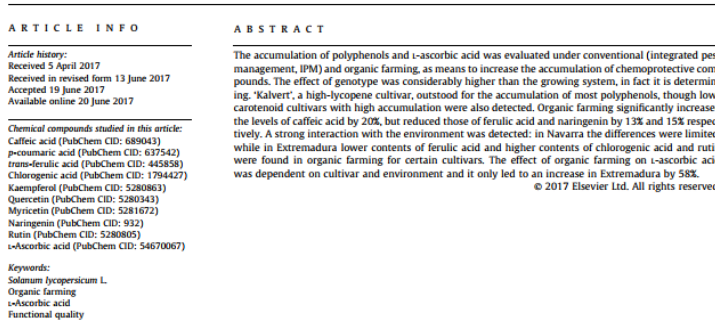

$\equiv$



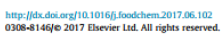


Polyphenol and L-ascorbic acid content in tomato as influenced by high lycopene genotypes and organic farming at different environments

Raúl Martí, Miguel Leiva-Brondo ${ }^{b}$, Inmaculada Lahoz ${ }^{c}$, Carlos Campillo ${ }^{d}$ Jaime CebollaCornejo ${ }^{\text {b1 }}$, Salvador Rosellóa ${ }^{2} *$

a Unidad Mixta de Investigación Mejora de la Calidad Agroalimentaria UJI-UPV. Departament de Ciències Agràries i del Medi Natural, Universitat Jaume I, Avda. Sos Baynat s/n, 12071 Castelló de la Plana, Spain.

${ }^{b}$ Unidad Mixta de Investigación Mejora de la Calidad Agroalimentaria UJI-UPV. COMAV. Universitat Politècnica de València, Cno. De Vera s/n, 46022 València, Spain.

'Instituto Navarro de Tecnologías e Infraestructuras Agroalimentarias (INTIA), Avda. Serapio Huici, 20-22, 31060 Villava Navarra, Spain.

${ }^{\mathrm{d}}$ Centro de Investigaciones Científicas y Tecnológicas de Extremadura (CICYTEX), Ctra. A-V, km 372, 06187 Guadajira (Badajoz), Spain.

${ }^{1}$ These authors contributed equally to the work

\begin{abstract}
The accumulation of polyphenols and L-ascorbic acid was evaluated under conventional (integrated pest management, IPM) and organic farming, as means to increase the accumulation of chemoprotective compounds. The effect of genotype was considerably higher than the growing system, in fact it is determining. 'Kalvert', a high-lycopene cultivar, outstood for the accumulation of most polyphenols, though low-carotenoid cultivars with high accumulation were also detected. Organic farming significantly increased the levels of caffe ic acid by $20 \%$, but reduced those of ferulicacid and naringenin by $13 \%$ and $15 \%$ respectively. $A$ strong interaction with the environment was detected: in Navarra the differences were limited, while in Extremadura lower contents of ferulic acid and higher contents of chlorogenic acid and rutin were found in organicfarming for certain cultivars. The effect of organic farming on L-ascorbic acid was dependent on cultivar and environment and it only led to an increase in Extremadura by $58 \%$.
\end{abstract}

Keywords: Solanum lycopersicum L.; Organic farming; L-ascorbic acid; Functional quality. 


\section{INFLUENCIA DEL DÉFICIT DE RIEGO CONTROLADO SOBRE LA CALIDAD}

FUNCIONAL DEL TOMATE 
Martí, R., Valcárcel, M., Leiva-Brondo, M., Lahoz, I., Campillo, C., Roselló, S. and Cebolla-Cornejo, J. Influence of controlled deficit irrigation on tomato functional value. Food chemistry, ENVIADO.

\section{Food Chemistry}

Journal Citation Report (JCR): 4.529 (2016)

Posición 6 de 130 en Food Science and Technology (Q1)

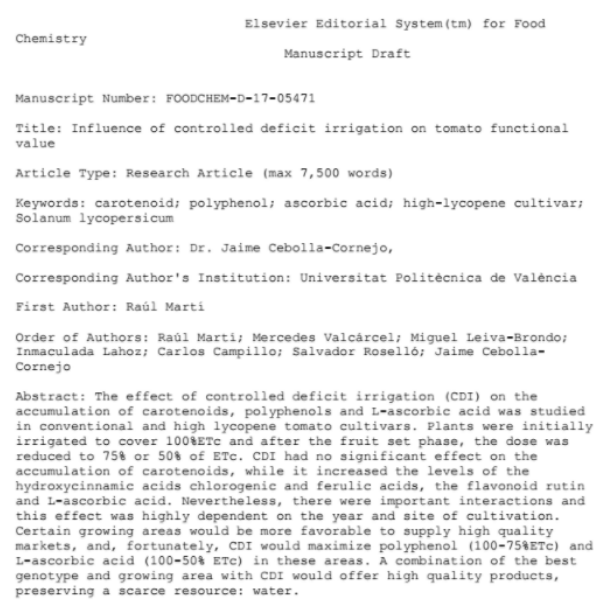

gentype and growing area with cDr would offer high quality products. 


\title{
Influence of controlled deficit irrigation on tomato functional value
}

Raúl Martía, Mercedes Valcárcel ${ }^{b}$, Miguel Leiva-Brondo ${ }^{a}$, Inmaculada Lahoz ${ }^{c}$, Carlos Campillo , Salvador Rosellób1 , Jaime Cebolla-Cornejo ${ }^{\text {a1* }}$

aUniversitat Politècnica de València. Unidad Mixta de Investigación Mejora de la Calidad Agroalimentaria UJI-UPV. COMAV. Cno. de Vera s/n, 46022 Valencia, Spain

${ }^{b}$ Universitat Jaume I, Unidad Mixta de Investigación Mejora de la Calidad Agroalimentaria UJIUPV. Departament de Ciències Agràries i del Medi Natural, Avda. Sos Baynat s/n, 12071 Castellón, Spain

'Instituto Navarro de Tecnologías e Infraestructuras Agroalimentarias (INTIA), Avda. Serapio Huici, 20-22, 31060 Villava (Navarra), Spain

${ }^{d}$ Centro de Investigaciones Científicas y Tecnológicas de Extremadura (CICYTEX), Ctra. A-V, km 372, 06187 Guadajira (Badajoz), Spain

${ }^{1}$ These authors contributed equally to the work

\begin{abstract}
The effect of controlled deficit irrigation (CDI) on the accumulation of carotenoids, polyphenols and L-ascorbic acid was studied in conventional and high lycopene tomato cultivars. Plants were initially irrigated to cover $100 \% \mathrm{ET}_{\mathrm{c}}$ and after the fruit set phase, the dose was reduce $d$ to $75 \%$ or $50 \%$ of $\mathrm{ET}_{\mathrm{c}}$. $\mathrm{CDI}$ had no significant effect on the accumulation of carotenoids, while it increased the levels of the hydroxycinnamic acids chlorogenic and ferulic acids, the flavonoid rutin and L-ascorbic acid. Nevertheless, there were important interactions and this effect was highly dependent on the year and site of cultivation. Certain growing areas would be more favorable to supply high quality markets, and, fortunately, CDI would maximize polyphenol $\left(100-75 \% \mathrm{ET}_{\mathrm{c}}\right)$ and L-ascorbic acid (100-50\% $\left.\mathrm{ET}_{\mathrm{c}}\right)$ in these areas. A combination of the best genotype and growing area with CDI would offer high quality products, preserving a scarce resource: water.
\end{abstract}

Keywords: carotenoid, polyphenol, ascorbic acid, high-lycopene cultivar, Solanum lycopersicum 


\section{DISCUSIÓN GENERAL}


La agricultura española, y la europea en general, difícilmente puede competir con los menores costes laborales y exigencias medioambientales de otros países. Es por tanto necesario buscar alternativas que permitan justificar de cara al consumidor un mayor precio de venta de bi do a los mayores costes productivos. Se trata de buscar un valor añadido ligado a un diferencial de precio que permita dotar de competitividad al sector.

Por otro lado, el consumidor europeo está cada vez más preocupado por los posible s efectos sobre la salud de las dietas y en general de los productos que ingiere. Laidentificación de un valor funcional elevado podría a la vez responder a las demandas de los consumidores respecto un producto funcional que ayude a preveniry combatir enfermedades degenerativas y por otro lado dotar a la producción de un valor añadido. De esta forma tanto productores como consumidores europeos se verían satisfechos en sus demandas y necesidades.

Para abordar este reto sería necesario responder a dos preguntas. La primera sería si realmente disponemos de productos agrícolas que tengan un valorfuncional y que se puedan llevar a mercado. Dentro del sector hortofrutícola el tomate podría representar un model o de comercialización de variedades y condiciones de cultivo que maximicen el valor funcional. Esto es así por dos razones, la primera es por su elevado nivel de consumo y la segunda porque ya existen nichos de marcado dispuestos a pagar un diferencial de precio a cambio de una mayor calidad (Cebolla-Cornejo et al., 2007).

Una vez identificado un posible producto, hay que considerar que el desarrollo de la Regulación Europea 1927/2006 (DOUE, 2006) establece que, con el fin de proteger al consumidor, es necesario que las propiedades saludables que se definan en el etiquetado y comercialización de los alimentos sean demostrables. Este es un aspecto clave para poder justificar la identificación por parte del consumidor de aquellos productos con mayor valor funcional. Por ello, en la primera parte de la presente tesis ha pretendido dar respuesta a esta pregunta ¿realmente el tomate puede ayudar a prevenir enfermedades de tipo degen erativo como, por ejemplo, el cáncer? La respuesta es que sí. Se han revisado numerosos trabajos relativos al estudio de cohortes que demuestran que a pesar de las reticencias mostrad as por la Food and Drug Administration de los EE.UU. (Kavanaugh et al., 2007), los carotenoides y polifenoles presentes en tomate realmente tendrían un papel en la prevención y contención del desarrollo de determinados tipos de cáncer (Martí et al., 2016).

Precisamente por ello se han desarrollado nuevas variedades que permiten elevar el contenido bien de determinados carotenoides, actuando sobre pasos concretos de la ruta de biosíntesis, bien del contenido global, actuando sobre la regulación de la ruta y la generación de los plastidios (Cebolla-Cornejo et al., 2013). Con mayor retraso, también se dispone de estrategias que permitan acumular antocianinas en la parte exterior del fruto o incluso recuperar la expresión de la ruta de síntesis de flavonoides en la pulpa del fruto (Martí et al., 2016).

Una vez disponiendo de un modelo como el tomate, con posibilidades de ofrecer un mayor valor funcional en función del material vegetal seleccionado y con pruebas acerca del posible beneficio para la salud, cabe hacerse la segunda pregunta: ¿realmente hay un mercado dispuesto a pagar un mayor precio por alimentos funcionales más allá del sector lácteo? Esta pregunta ya se ha respondido en sectores afines y parece que hay posibilidades más allá de los lácteos enriquecidos. Por ejemplo, Barreiro-Hurlé et al. (2008), considerando el mercado español de vinos y las posibilidades comerciales de vinos con mayor contenido en resverat rol, 
sugirieron que efectivamente existe un mercado en el que la voluntad de pagar un diferencial de precio por mayor valor funcional llega a ser tan importante como el envejecimiento, destinado a mejorar la calidad organoléptica del producto. No sólo los consumidores están valorando cada vez más este aspecto en frutas y hortalizas, sino que incluso los gobiernos empiezan a darse cuenta de que la promoción de al imentos funcionales permitiría rebajar los gastos en sanidad (Sun-Waterhouse, 2011). En el caso del tomate se han desarrollado estudios similares con resultados que confirman la voluntad de pagar un diferencial de precio por un mayor valor funcional en tomate. Así, ya en 2002, en uno de los estudios más amplios realizados en Canadá, West et al. (2002) demostraron que el consumidor estaba dispuesto a pagar hasta $0.66 \$$ extra por lata de tomate triturado a cambio de mayores propiedades anticancerígenas.

Una vez comprobado que efectivamente el tomate aúna todos los requisitos para poder desarrollar un valor añadido basado en la calidad funcional, el objetivo debe centrarse en la obtención de materiales que realmente satisfagan ese valor añadido. La forma natural de hacerlo consiste lógicamente en seleccionar el material vegetal que potencie al máximo la acumulación de compuestos funcionales como la vitamina C, los carotenoides y los polifenoles y por otro lado cultivarlos en condiciones que permitan explotar al máximo el potencial genotípico. Es cierto que en estos momentos se dispone de variedades alto licopeno desarrolladas mediante distintas estrategias que pueden representar el material idóneo para lograr este objetivo. Sin embargo, no deja de ser cierto que la mayor acumulación de carotenoides puede conllevar una considerable menor producción, de hasta el $28 \%$, respecto a materiales convencionales (Lahoz et al., 2016a). Es por ello, que sigue siendo necesario continuar desarrollando programas de cribado que permitan identificar nuevas alternativas genéticas (Leiva-Brondo et al., 2016).

Para ello es necesario contar con técnicas analíticas que permitan cribar grandes cantidades de material en el menor tiempo y con el menor coste posible. Estas técnicas también serían necesarias para evaluar por lado los efectos del manejo agronómico sobre la acumulación de compuestos funcionales y por otro lado para desarrollar controles de calidad que permitan asegurar que realmente la mayor acumulación se está produciendo. Por eso, se decidió desarrollar en el marco de la presente tesis metodologías basadas en dos de las técnicas instrumentales más ampliamente utilizadas, la cromatografía líquida de alta resolución (HPLC) y electroforesis capilar (CE), de modo que permitan cuantificar de forma conjunta los principales polifenoles de tomate: los ácidos fenólicos y los flavonoides.

En el primer caso, se desarrolló una metodología basada en la utilización de columnas de núcleo fundido y HPLC de fase reversa que puede ser empleada no sólo en tomate sino en una amplia variedad de frutas y hortalizas, permitiendo la cuantificación conjunta de 17 polifenoles en menos de 20 minutos (Martí et al., 2015). Este mismo trabajo sirvió para poner a punto un método eficiente de extracción, ya que esta suele ser una parte limitante del análisis de polifenoles. Este análisis no sólo permitió optimizar las condiciones de extracción de forma que fueran lo más rápidas y sencillas posible, sino que además permitió descartar del uso de liofilización como sistema de conservación ya que afectaría a las concentraciones de naringenina recuperadas. Siguiendo esta metodología, los valores de repetibilidad ob te ni dos llegan a ser mejores de los correspondientes a tecnologías más avanzada como la cromatografía líquida de ultra alta resolución acoplada a espectrometría de masas, UHPLC-MS 
(De Paepe et al., 2013), con límites de detección (LOD) menores a los publicados empleando también detección en matriz de diodos, DAD (Ribas-Agustí et al., 2012) y con niveles de recuperación muy competitivos, comparados con los publicados por Sakakibara et al. (2003) y De Paepe et al. (2013).

La puesta a punto de este método ya permitió continuar el desarrollo de la tesis evaluando los efectos del genotipo y el ambiente en la acumulación de polifenoles. No obstante, se consideró que también sería muy interesante disponer de un método basado en $\mathrm{CE}$, ya que los costes operativos de esta tecnología suelen ser mucho menores al requerir cantidades mínimas de tampón de separación y por otro lado generan menos residuos tóxicos que tratar. Esta fase era técnicamente más sencilla, puesto que la extracción ya estaba puesta a pun to en el trabajo anterior. Así, se consiguió obtener un método basado en cromatografía capilar micelar electrocinética (MECK) optimizado para muestras de tomate cultivado y silvestre que permitía cuantificar 9 de los principales polifenoles de tomate en menos de 20 minutos. De nuevo, las repetibilidades obtenidas fueron mejores que otros métodos basados en CE (Arce, et al., 1998; Herrero-Martínez et al., 2007) e incluso en HPLC (Ribas-Agustí et al., 2012; De Paepe et al. 2013). De hecho, en compuestos como la quercetina o la naringenina la repetibilidad inter-día en nuestras reales fue mejor empleando CE que HPLC con los métodos desarrollados en esta tesis (Martí et al., 2015, 2017). Aunque los LOD obtenidos fueron similares a otros métodos basados en CE (Herrero-Martínez et al., 2007), lo cierto es que la menor longitud de paso óptica de la CE dio lugar a mayores LOD que los obtenid os me diante HPLC, por ejemplo, en los propios métodos desarrollados en esta tesis.

Una vez se disponía de métodos adaptados de análisis se propuso valorar los efectos del genotipo (variedades convencionales y alto licopeno), del ambiente (localidad y año) y de estrategias de cultivo respetuosas con el ambiente (cultivo ecológico y riego deficitario). Estos estudios se realizaron durante dos años en dos de las principales áreas de cultivo de tomate de industria en España: Extremadura y Navarra.

De ambos estudios se deprende que el genotipo es el factor más determinante en la consecución de los mayores niveles de polifenoles. El cultivar de alto licopeno 'Kalvert' fue el que destacó por sus elevadas acumulaciones de polifenoles entre las que sobresalen la alta acumulación de ácido clorogénico, ácido caféico, rutina, myricetina, quercetina y naringenina. El cultivar 'Kalvert' destaca además por la elevada acumulación de carotenoides, de azúcares y ácidos (Lahoz et al., 2016a) y de compuestos volátiles relacionados con el aroma (Lahoz et al., 2016b), por lo que aunaría elevada calidad funcional y organoléptica. Sin embargo, es de los cultivares que más resienten su producción en comparación con cultivares convencionales (Lahoz et al., 2016a). Otros cultivares también destacaron por sus elevadas acumulaciones de algunos polifenoles. En ese sentido, los cultivares 'H-9661' y 'H-9997' destacaron por la acumulación de rutina y naringenina respectivamente. El cultivar ' $\mathrm{H}-9661$ ' tiene un interés añadido, ya que al no contar con genes high pigment no se esperaba tal capacidad de acumulación, lo que abre la puerta de futuros estudios sobre la herencia y modo de acción de este carácter. Por otro lado, 'H-9997' también tiene niveles de polifenoles que, no sie ndo tan altos como los de 'Kalvert', son elevados y además ofrece niveles competitivos de producción (Lahoz et al., 2016a). 
Dentro de la estrategia de lograr el mayor contenido en polifenoles, tanto en el estudio del efecto del cultivo ecológico como en el de riego deficitario se ha puesto de manifiesto que la zona de cultivo puede ser un aspecto clave a tener en cuenta. Así, las condiciones más suaves de áreas como Navarra parecen las idóneas a la hora de extraer el máximo potencial de los genotipos empleados.

Respecto a la estrategia de cultivo, no parece que el cultivo ecológico realmente suponga una mejora en los niveles de acumulación de polifenoles. Es cierto que este sistema de cultivo aumentó significativamente el contenido de ácido cafeico, pero tuvo efectos negativos sob re el contenido de ácido ferúlico y naringenina. No obstante, existe una importante in te racción genotipo x ambiente, algo que también se puso de manifiesto en el estudio del efecto del riego deficitario. Ya en estudios previos del efecto del cultivo ecológico sobre la acumulación de carotenoides se vio que el efecto era limitado (Lahoz et al., 2016a). En aquel caso, I os niveles de licopeno no se veían afectados por el sistema de cultivo, mientras que el cultivo e col ógico favorecía, aunque de forma limitada la acumulación de $\beta$-caroteno. En conjunto, no se pue de decir que este sistema de cultivo, respetuoso con el medio ambiente, mejore la calidad funcional del tomate. No obstante, no la perjudica, por lo que para aquellos consumidores y productores que valoren la calidad medioambiental y la ausencia de trazas de fitosanitarios puede ser una opción, siempre que se combine con los genotipos más adecuad os y las zonas de producción más favorables para la acumulación de compuestos funcionales.

El riego deficitario controlado, es decir, aplicado a partir de la fase de cuajado, también tuvo un efecto limitado sobre la acumulación de polifenoles y otros compuestos funcionales. Concretamente, aumentó la acumulación de los ácidos hidroxicinámicos clorogénico y ferúlico, el flavonol rutina y el ácido L-ascórbico, pero no afectó a la acumulación de carote noid es y el resto de polifenoles. El escaso efecto sobre los carotenoides se esperaba, ya que un riego deficitario continuado, mucho más agresivo en la misma zona de cultivo no lograba a ume ntar la acumulación de estos compuestos (Lahoz et al., 2016b).

En cualquier caso, como se ha comentado, debido al efecto de las interacciones estos resultados fueron muy dependientes de año y área de cultivo. Así, en Navarra, un área que optimiza la acumulación de polifenoles, ésta se maximizó con un riego deficitario controlado de $100-75 \% \mathrm{ET}_{c}$, mientras que la acumulación de ácido L-ascórbico se maximizó con un riego deficitario controlado de $100-50 \% \mathrm{ET}_{\mathrm{c}}$.

En definitiva, es difícil dar una respuesta única a preguntas generales sobre las bondades de las estrategias de cultivo respetuosas con el medioambiente sobre la acumulación de compuestos como los polifenoles que ayuden a maximizar el valorfuncional del tomate. Pare ce evidente que, en este caso, la pieza clave sobre la que puede actuar el productor es a través del material vegetal. Aunque se dispone de cultivares muy interesantes desde este punto de vista, parece evidente que todavía queda camino por recorrer, especialmente en lo que se refiere a los efectos colaterales sobre la producción. Sin duda, los métodos desarrollados en esta tesis ayudarán a abordar este objetivo de mejora. Por otrolado, parece claro que la selección de la zona de cultivo también puede ser importante, ya que las condiciones más suaves como las de Navarra parecen maximizar el potencial de los genotipos. En este tipo de zonas, un riego deficitario controlado suave podría aumentar todavía más los niveles de polifenoles, conllevando un importante ahorro de un recurso tan valioso como escaso: el agua. Finalmente, 
aunque el cultivo ecológico no tenga un efecto importante sobre la acumulación de polifenoles y de compuestos bioactivos en general, lo cierto es que puede contribuir a obtener un producto de la máxima calidad global.

\section{Bibliografía}

Arce, L., Ríos, A., \& Valcárcel, M. (1998). Determination of anti-carcinogenic polyphenols present in green tea using capillary electrophoresis coupled to a flow injection system. Journal of Chromatography A, 827(1), 113-120.

Barreiro-Hurlé, J., Colombo, S., \& Cantos-Villar, E. (2008). Is there a market for functional wines? Consumer preferences and willingness to pay for resveratrol-enriched red wine. Food Quality and Preference, 19(4), 360-371.

Cebolla-Cornejo, J., Soler, S., \& Nuez, F. (2007). Genetic erosion of traditional varieties of vegetable crops in Europe: tomato cultivation in Valencia (Spain) as a case study. International Journal of Plant Production, 1(2), 113-128.

Cebolla-Cornejo, J., Roselló, S., \& Nuez, F. (2013). Selection of tomato rich in nutritional terpenes. In Ramawat, K. \& Mérillon, J. (eds.), Natural products Springer (pp. 2853-2881). Berlin Heidel berg.

De Paepe, D., Servaes, K., Noten, B., Diels, L., De Loose, M., Van Droogenbroeck, B., \& Voorspoels, S. (2013). An improved mass spectrometric method for identification and quantification of phenolic compounds in apple fruits. Food chemistry, 136(2), 368-375.

DOUE, Diario Oficial de la Unión Europea. (2006). Directiva 2006/24/CE del Parlamento Europeo y del Consejo de 15 de marzo de 2006 sobre la conservación de datos generados o tratados en relación con la prestación de servicios de comunicaciones electrónicas de acceso público o de redes públicas de comunicaciones y por la que se modifica la Directiva 2002/58/CE. Diario Oficial de la Unión Europea, L105, 54-63.

Herrero-Martínez, J. M., Oumada, F. Z., Rosés, M., Bosch, E., \& Ràfols, C. (2007). Determination of flavonoid aglycones in several food samples by mixed micellar el ectrokinetic chromatography. Journal of separation science, 30(15), 2493-2500.

Kavanaugh, C. J., Trumbo, P. R., \& Ellwood, K. C. (2007). The US Food and Drug Administration's evidence-based review for qualified health claims: tomatoes, lycopene, and cancer. Journal of the National Cancer Institute, 99(14), 1074-1085.

Lahoz, I., Leiva-Brondo, M., Martí, R., Macua, J. I., Campillo, C., Roselló, S., \& Cebolla-Cornejo, J. (2016a). Influence of high lycopene varieties and organic farming on the production and quality of processing tomato. Scientia Horticulturae, 204,128-137.

Lahoz, I., Pérez-de-Castro, A., Valcárcel, M., Macua, J. I., Beltrán, J., Roselló, S., \& Cebolla-Cornejo, J. (2016b). Effect of water deficit on the agronomical performance and quality of processing tomato. Scientia Horticulturae, 200, 55-65.

Leiva-Brondo, M., Valcarcel, M., Martí, R., Roselló, S., \& Cebolla-Cornejo, J. (2016). New opportunities for developing tomato varieties with enhanced carotenoid content. Scientia Agricola, 73(6), 512-519. 
Martí, R., Valcárcel, M., Herrero-Martínez, J. M., Cebolla-Cornejo, J., \& Roselló, S. (2015). Fast simultaneous determination of prominent polyphenols in vegetables and fruits by reversed phaseliquid chromatography using a fused-core column. Food chemistry, 169, 169-179.

Martí, R., Roselló, S., \& Cebolla-Cornejo, J. (2016). Tomato as a source of carotenoids and polyphenols targeted to cancer prevention. Cancers, 8(6), 58.

Martí, R., Valcárcel, M., Herrero-Martínez, J.M., Cebolla-Cornejo, J. \& Roselló, S. (2017). Simultaneous determination of main phenolic acids and flavonoids in tomato by micellar electrokinetic capillary el ectrophoresis. Food chemistry, 221, 439-446.

Ribas-Agustí, A., Cáceres, R., Gratacós-Cubarsí, M., Sárraga, C., \& Castellari, M. (2012). A validated HPLC-DAD method for routine determination of ten phenolic compounds in tomato fruits. Food Analytical Methods, 5(5), 1137-1144.

Sakakibara, H., Honda, Y., Nakagawa, S., Ashida, H., \& Kanazawa, K. (2003). Simultaneous determination of all polyphenols in vegetables, fruits, and teas. Journal of Agricultural and Food Chemistry, 51(3), 571-581.

Sun-Waterhouse, D. (2011). The development of fruit-based functional foods targeting the health and wellness market: a review. International Journal of Food Science \& Technology, 46(5), 899-920.

West, G. E., Gendron, C., Larue, B., \& Lambert, R. (2002). Consumers' Valuation of Functional Properties of Foods: Results from a Canada-wide Survey. Canadian Journal of Agricultural Economics/Revue canadienne d'agroeconomie, 50(4), 541-558. 


\section{CONCLUSIONES}


La presente tesis ha permitido desarrollar herramientas analíticas para la determinación rápida del contenido en polifenoles en tomate y aplicarlas para evaluar el efecto que tiene sobre este tipo de compuestos el uso de genotipos de alto licopeno, el ambiente de cultivo y el uso de estrategias productivas respetuosas con el medioambiente: el manejo ecológico y el riego deficitario controlado. La al ta versatilidad junto con la sencillez y rapidez de las metod ol ogías desarrolladas permiten además su utilización en controles de calidad, en programas de mejora genética o en la evaluación de distintas formas de manejo agrícola, donde es necesario analizar grandes cantidades de muestra. En particular, de los resultados obtenidos se extraen las siguientes conclusiones:

- Se ha desarrollado un método de análisis mediante HPLC de fase reversa para determinar los principales polifenoles presentes en frutas y hortalizas, incluye ndo el tomate. El uso de columnas de núcleo fundido junto con un gradiente segmentado permitió la separación eficaz y simultánea de 17 flavonoides y ácidos fenólicos en menos de 20 minutos. Entre los que se incluyen los principales compuestos fe nólicos presentes en tomate: rutina, quercetina, myricetina, kaempferol, naringenina, ácido clorogénico, ácido caféico, ácido ferúlico y ácido $p$-coumárico, además de otros compuestos fenólicos representativos de las principales familias de polifenoles en otras especies: ácido gálico, catequina, apigenina, luteolina, genisteina, hesperi dina y naringina.

- Previamente a la cuantificación de estos polifenoles en muestras de tomate fue necesario optimizar la extracción de estos compuestos de las muestras. Para ello se emplearon superficies de respuesta multivariantes. Como las condiciones óptimas de extracción para cada analito fueron diferentes, se utilizó la función de deseabilidad ponderada para llegar a un compromiso que optimizase la extracción conjunta de los polifenoles. Las condiciones óptimas incluyeron la extracción asistida por ultrasonidos durante 177 minutos usando una mezcla metanol/agua (48:52 v/v) como disolvente de extracción.

- Los principales polifenoles presentes en tomate fueron rutina, naringenina y los ácidos clorogénico, caféico, $p$-coumárico y ferúlico, presentando una gran variabilidad en función del genotipo. El ácido clorogénico es el que se encontró en mayor concentración en las muestras analizadas seguido de la naringe nina y la rutina. Los contenidos encontrados en las especies silvestres de tomate Solanum neorickii fueron hasta 12 veces mayores que en las especies cultivadas, destacando el interés de este tipo de especies en la mejora del contenido de polifenoles en tomate.

- Como alternativa a la HPLC, se ha desarrollado una metodología basada en cromatografía micelar electrocinética (MEKC) específica para tomate que permite la determinación simultánea de los principales ácidos fenólicos y flavonoides presentes en tomate en 20 minutos, incluyendo los ácidos caféico, $p$-cumárico, trans-ferúlico y clorogénico, kaempferol, quercetina, myricetina, naringenina y rutina. La utilización de la electroforesis capilar permitió reducir el consumo en disolventes a la vez que se consigue una separación rápida y eficaz. 
- Las condiciones de separación se optimizaron también con diseños experimentales basados en superficies de respuesta multivariantes y la función de deseabilidad. Se estudió la influencia del pH y la composición del tampón de carrera probando distintas concentraciones de bórax, acetonitrilo, metanol como modificadores orgánicos, y SDS en la separación. Las condiciones de separación optimizadas consistieron en un tampón de carre ra compuesto por una disolución $11.3 \mathrm{mM}$ de bórax y $11.2 \mathrm{mM} \mathrm{SDS}$ ajustado a pH 8.5 sin ningún modificador orgánico.

- Se comprobó la aplicabilidad del método analizando cuatro muestras de cultivares comerciales de tomate: 'Canario', 'Pera', 'Beef' y 'Cherry', un cultivar de tomate de industria con alto contenido en licopeno 'Kalvert' $y$ dos especi es silvestres relacionadas con el tomate Solanum neorickii y Solanum pimpinellifolium. El flavonol rutina y el ácido hidroxicinámico chlorogénico fueron los dos polifenol es que se encontraron en mayor concentración en las muestras analizadas.

- Por regla general, las muestras de especies silvestres presentaron mayores contenidos en polifenoles que las muestras comerciales. Particularmente destacable es el alto contenido en ácido clorogénico de la muestra de Solanum pimpinellifolium lo que la convierte en una perfecta fuente de variación para su utilización en programas de mejora de este compuesto.

- La evaluación del efecto del manejo ecológico o integrado sobre la acumulación de polifenoles y ácido L-ascórbico en diferentes genotipos de tomate de industria en las dos principales zonas productoras españolas, Navarra y Extremadura, ha permito extraer las siguientes conclusiones.

- El efecto del genotipo sobre la acumulación de polifenoles fue considerablemente mayor que el del modo de cultivo. El genotipo afectó significativamente los contenidos de 7 de los 8 compuestos fenólicos analizados, mientras que el modo de cultivo solo tuvo efecto sobre tres.

- El cultivar de alto licopeno 'Kalvert' fue el que destacó por sus altas acumulaciones de polifenoles entre las que destacan la alta acumulación de ácido clorogénico, ácido caféico, rutina, myricetina, quercetina y naringe nina. Otros cultivares también destacaron por sus elevadas acumulaciones de algunos polifenoles. En ese sentido, los cultivares 'H-9661' y 'H-9997' destacaron por la acumulación de rutina y naringenina respectivamente.

- El modo de cultivo no produjo un efecto claro en la acumulación de polifenoles. El cultivo ecológico aumentó significativamente el contenido de ácido caféico, pero tuvo efectos negativos sobre el contenido de ácido ferúlico y naringenina. Los contenidos del resto de polifenoles no se vieron afe ctados por el modo de cultivo.

- Se detectó una fuerte interacción con el ambiente. En Navarra las dife re ncias fueron limitadas, pero en Extremadura se encontraron menores contenidos de 
ácido ferúlico y mayores de ácido cl orogénico y rutina en el cultivo e cológico para algunos genotipos.

- La evaluación del efecto del riego deficitario controlado sobre la calidad funcional del tomate de industria, reduciendo la dosis de riego después del cuajado de fruto para satisfacer el $75 \%$ y $50 \%$ de la evotranspiración del cultivo condujo a las siguientes conclusiones:

- De nuevo, el genotipo tuvo un gran efecto en la acumulación de los carotenoides y de los polifenoles ácido clorogénico, ácido caféico, rutina y naringenina. El cultivar de alto licopeno 'ISI-24424' destacó por sus altos contenidos en $\beta$-caroteno y licopeno, mientras que el cultivar ' $\mathrm{H}$-9661' volvió a destacar por su elevada acumulación de los flavonoides rutina y naringenina.

- El riego deficitario controlado produjo un aumento en la acumulación de los ácidos hidroxicinámicos clorogénico y ferúlico, el flavonol rutina y de ácido Lascórbico, pero no afectó a la acumulación de carotenoides y el resto de polifenoles.

- Se encontraron interacciones muy importantes que hicieron que el efecto del riego fuera muy dependiente del año y área de cultivo. Las condiciones de cultivo más suaves como las de Navarra son más favorables para producir tomates que satisfagan los mercados de calidad aplicando riego deficitario controlado. Así, en esta zona, la acumulación de polifenoles se maximizó con un déficit de $100-75 \% \mathrm{ET}_{\mathrm{c}}$ mientras que la acumulación de ácido L-ascórbico con $100-50 \% \mathrm{ET}_{\mathrm{c}}$.

- La adecuada selección del genotipo y la zona de cultivo junto con la aplicación de riego deficitario controlado es una herramienta de utilidad para obtener tomates con una elevada calidad funcional a la vez que se ahorra en un recurso tan escaso como el agua. 
X. ANEXO 
Jaime Cebolla Cornejo, Profesor Contratado Doctor de la Universitat Politècnica de

València,

\section{HACE CONSTAR QUE:}

Como coautor de las publicaciones indicadas más abajo, acepto que éstas se presenten como parte de la Tesis Doctoral de Raúl Martí Renau y renuncio expresamente a su utilización como parte de otra tesis doctoral. Por otro lado, estas publicaciones no se han incluido previamente en ninguna otra tesis doctoral.

Marti, R., Roselló, S. and Cebolla-Cornejo, J., 2016. Tomato as a source of carotenoids and polyphenols targeted to cancer prevention. Cancers, $8(6)$, p. 58 .

Marti, R., Valcárcel, M., Herrero-Martínez, J.M., Cebolla-Cornejo, J. and Roselló, S., 2015. Fast simultaneous determination of prominent polyphenols in vegetables and fruits by reversed phase liquid chromatography using a fused-core column. Food chemistry, 169, pp.169-179.

Martí, R., Valcárcel, M., Herrero-Martinez, J.M., Cebolla-Cornejo, J. and Roselló, S., 2017. Simultaneous determination of main phenolic acids and flavonoids in tomato by micellar electrokinetic capillary electrophoresis. Food chemistry, 221, pp.439-446.

Marti, R., Leiva-Brondo, M., Lahoz, I., Campillo, C., Cebolla-Cornejo, J. and Roselló, S., 2018. Polyphenol and L-ascorbic acid content in tomato as influenced by high lycopene genotypes and organic farming at different environments. Food chemistry, 239, pp.148-156.

Marti, R., Valcárcel, M., Leiva-Brondo, M., Lahoz, L., Campillo, C., Roselló, S. and CebollaCornejo, J. 2018. Influence of controlled deficit irrigation on tomato functional value. Food chemistry (ENVIADO).

Y para que conste a los efectos oportunos, así lo firmo.

En València, a 20 de ơctubre de 2017

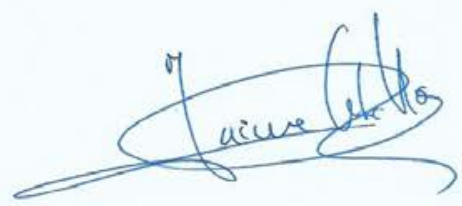

Fdo.: Jaime Cebolla Cornejo 
Salvador Roselló Ripollés, Catedrático de Universidad de la Universitat Jaume I de Castellón,

\section{HACE CONSTAR QUE:}

Como coautor de las publicaciones indicadas más abajo, acepto que éstas se presenten como parte de la Tesis Doctoral de Raúl Martí Renau y renuncio expresamente a su utilización como parte de otra tesis doctoral. Por otro lado, estas publicaciones no se han incluido previamente en ninguna otra tesis doctoral.

Martí, R., Roselló, S. and Cebolla-Cornejo, J., 2016. Tomato as a source of carotenoids and polyphenols targeted to cancer prevention. Cancers, 8(6), p.58.

Martí, R., Valcárcel, M., Herrero-Martínez, J.M., Cebolla-Cornejo, J. and Roselló, S., 2015. Fast simultaneous determination of prominent polyphenols in vegetables and fruits by reversed phase liquid chromatography using a fused-core column. Food chemistry, 169, pp.169-179.

Marti, R., Valcárcel, M., Herrero-Martínez, J.M., Cebolla-Cornejo, J. and Roselló, S., 2017. Simultaneous determination of main phenolic acids and flavonoids in tomato by micellar electrokinetic capillary electrophoresis. Food chemistry, 221, pp.439-446.

Marti, R., Leiva-Brondo, M., Lahoz, I., Campillo, C., Cebolla-Cornejo, J. and Roselló, S., 2018. Polyphenol and L-ascorbic acid content in tomato as influenced by high lycopene genotypes and organic farming at different environments. Food chemistry, 239, pp.148-156.

Martí, R. Valcárcel, M., Leiva-Brondo, M., Lahoz, I., Campillo, C., Roselló, S. and CebollaCornejo, J. 2018. Influence of controlled deficit irrigation on tomato functional value. Food chemistry (ENVIADO).

Y para que conste a los efectos oportunos, así lo firmo.

En Castellón de la Plana, a 20 de octubre de 2017

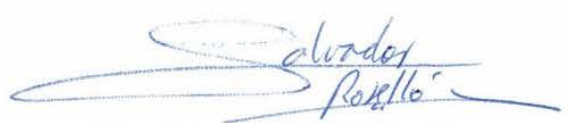

Fdo.: Salvador Roselló Ripollés 
Mercedes Valcárcel Germes, Profesora Asociada de la Universitat Jaume I de Castellón,

\section{HACE CONSTAR QUE:}

Como coautora de las publicaciones indicadas más abajo, acepto que éstas se presenten como parte de la Tesis Doctoral de Raúl Martí Renau y renuncio expresamente a su utilización como parte de otra tesis doctoral. Por otro lado, estas publicaciones no se han incluido previamente en ninguna otra tesis doctoral.

Marti, R., Valcárcel, M., Herrero-Martinez, J.M., Cebolla-Cornejo, J. and Roselló, S., 2015. Fast simultaneous determination of prominent polyphenols in vegetables and fruits by reversed phase liquid chromatography using a fused-core column. Food chemistry, 169, pp.169-179.

Marti, R., Valcárcel, M., Herrero-Martinez, J.M., Cebolla-Cornejo, J. and Roselló, S., 2017. Simultaneous determination of main phenolic acids and flavonoids in tomato by micellar electrokinetic capillary electrophoresis. Food chemistry, 221, pp.439-446.

Marti, R., Valcárcel, M., Leiva-Brondo, M., Lahoz, I., Campillo, C., Roselló, S. and CebollaCornejo, J. 2018. Influence of controlled deficit irrigation on tomato functional value. Food chemistry (ENVIADO).

Y para que conste a los efectos oportunos, así lo firmo.

En Castellón de la Plana, a 20 de octubre de 2017



Fdo.: Mercedes Valcárcel Germes 
José Manuel Herrero Martínez, Profesor Titular de la Universitat de València,

\section{HACE CONSTAR QUE:}

Como coautor de las publicaciones indicadas más abajo, acepto que éstas se presenten como parte de la Tesis Doctoral de Raúl Martí Renau y renuncio expresamente a su utilización como parte de otra tesis doctoral. Por otro lado, estas publicaciones no se han incluido previamente en ninguna otra tesis doctoral.

Martí, R., Valcárcel, M., Herrero-Martínez, J.M., Cebolla-Cornejo, J. and Roselló, S., 2015. Fast simultaneous determination of prominent polyphenols in vegetables and fruits by reversed phase liquid chromatography using a fused-core column. Food chemistry, 169, pp.169-179.

Martí, R., Valcárcel, M., Herrero-Martínez, J.M., Cebolla-Cornejo, J. and Roselló, S., 2017. Simultaneous determination of main phenolic acids and flavonoids in tomato by micellar electrokinetic capillary electrophoresis. Food chemistry, 221, pp.439-446.

Y para que conste a los efectos oportunos, así lo firmo.

En Burjasot, a 20 de octubre de 2017

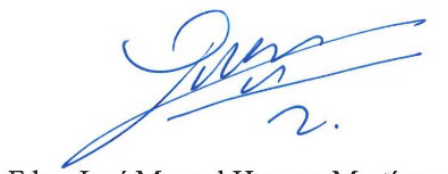

Fdo.: José Manuel Herrero Martínez 
Miguel Leiva Brondo, Profesor Contratado Doctor de la Universitat Politècnica de València,

\section{HACE CONSTAR QUE:}

Como coautor de las publicaciones indicadas más abajo, acepto que éstas se presenten como parte de la Tesis Doctoral de Raúl Martí Renau y renuncio expresamente a su utilización como parte de otra tesis doctoral. Por otro lado, estas publicaciones no se han incluido previamente en ninguna otra tesis doctoral.

Marti, R., Leiva-Brondo, M., Lahoz, I., Campillo, C., Cebolla-Cornejo, J. and Roselló, S., 2018. Polyphenol and L-ascorbic acid content in tomato as influenced by high lycopene genotypes and organic farming at different environments. Food chemistry, 239, pp.148-156.

Martí, R., Valcárcel, M., Leiva-Brondo, M., Lahoz, I., Campillo, C., Roselló, S. and CebollaCornejo, J. 2018. Influence of controlled deficit irrigation on tomato functional value. Food chemistry (ENVIADO).

Y para que conste a los efectos oportunos, así lo firmo.

En València, a 20 de octubre de 2017

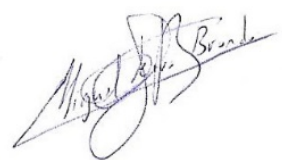

Fdo.: Miguel Leiva Brondo 
Inmaculada Lahoz García, Investigadora de INTIA S.A.,

\section{HACE CONSTAR QUE:}

Como coautora de las publicaciones indicadas más abajo, acepto que éstas se presenten como parte de la Tesis Doctoral de Raúl Martí Renau y renuncio expresamente a su utilización como parte de otra tesis doctoral. Por otro lado, estas publicaciones no se han incluido previamente en ninguna otra tesis doctoral.

Martí, R., Leiva-Brondo, M., Lahoz, I., Campillo, C., Cebolla-Cornejo, J. and Roselló, S., 2018. Polyphenol and L-ascorbic acid content in tomato as influenced by high lycopene genotypes and organic farming at different environments. Food chemistry, 239, pp.148-156.

Martí, R., Valcárcel, M., Leiva-Brondo, M., Lahoz, I., Campillo, C., Roselló, S. and CebollaCornejo, J. 2018. Influence of controlled deficit irrigation on tomato functional value. Food chemistry (ENVIADO).

Y para que conste a los efectos oportunos, así lo firmo.

En Castellón de la Plana, a 20 de octubre de 2017

\section{Inmaculada Lahoz}

Fdo.: Inmaculada Lahoz García 
Carlos Campillo Torres, Investigador del Centro de Investigaciones Científicas y

Tecnológicas de Extremadura (CICYTEX),

\section{HACE CONSTAR QUE:}

Como coautor de las publicaciones indicadas más abajo, acepto que éstas se presenten como parte de la Tesis Doctoral de Raúl Martí Renau y renuncio expresamente a su utilización como parte de otra tesis doctoral. Por otro lado, estas publicaciones no se han incluido previamente en ninguna otra tesis doctoral.

Marti, R., Leiva-Brondo, M., Lahoz, I., Campillo, C., Cebolla-Comejo, J. and Rosello, S. 2018. Polyphenol and L-ascorbic acid content in tomato as influenced by high lycopene genotypes and organic farming at different cnvironments. Food chemistry, 239, pp. 148-156.

Marti, R., Valcárcel, M., Leiva-Brondo, M., Lahoz, I., Campilla, C., Roselló, S. and CebollaComejo, 2. 2018. Influence of controlled deficit imigation on tomato functional value. Food chemistry (ENVIADO).

Y para que conste a los efectos oportunos, así lo firmo.

En Guadajira, a 20 de octubre de 2017

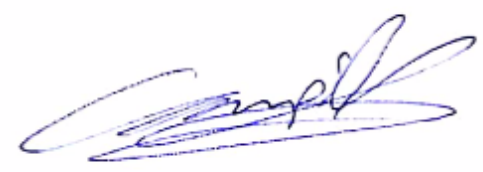

Fdo.:Carlos Campillo Torres 